\title{
Climate, population, and vulnerability in Pakistan: Exploring evidence of linkages for adaptation
}

G.M. Arif

Muhammad Riaz

Nadeem Faisal

Mohammad Jamal Khan Khattak

Zeba Sathar

Population Council

See next page for additional authors

Follow this and additional works at: https://knowledgecommons.popcouncil.org/departments_sbsr-pgy

Part of the Demography, Population, and Ecology Commons, Environmental Public Health Commons, Environmental Studies Commons, Family, Life Course, and Society Commons, International Public Health Commons, and the Medicine and Health Commons

How does access to this work benefit you? Let us know!

\section{Recommended Citation}

Sathar, Zeba and Kiren Khan (eds.). 2019. "Climate, population, and vulnerability in Pakistan: Exploring evidence of linkages for adaptation." Islamabad: Population Council. 


\section{Authors}

G.M. Arif, Muhammad Riaz, Nadeem Faisal, Mohammad Jamal Khan Khattak, Zeba Sathar, Muhammad Khalil, Maqsood Sadiq, Sabahat Hussain, and Kiren Khan 


\section{CLIMATE, POPULATION, AND VULNERABILITY IN PAKISTAN}

\section{EXPLORING EVIDENCE OF LINKAGES FOR ADAPTATION}
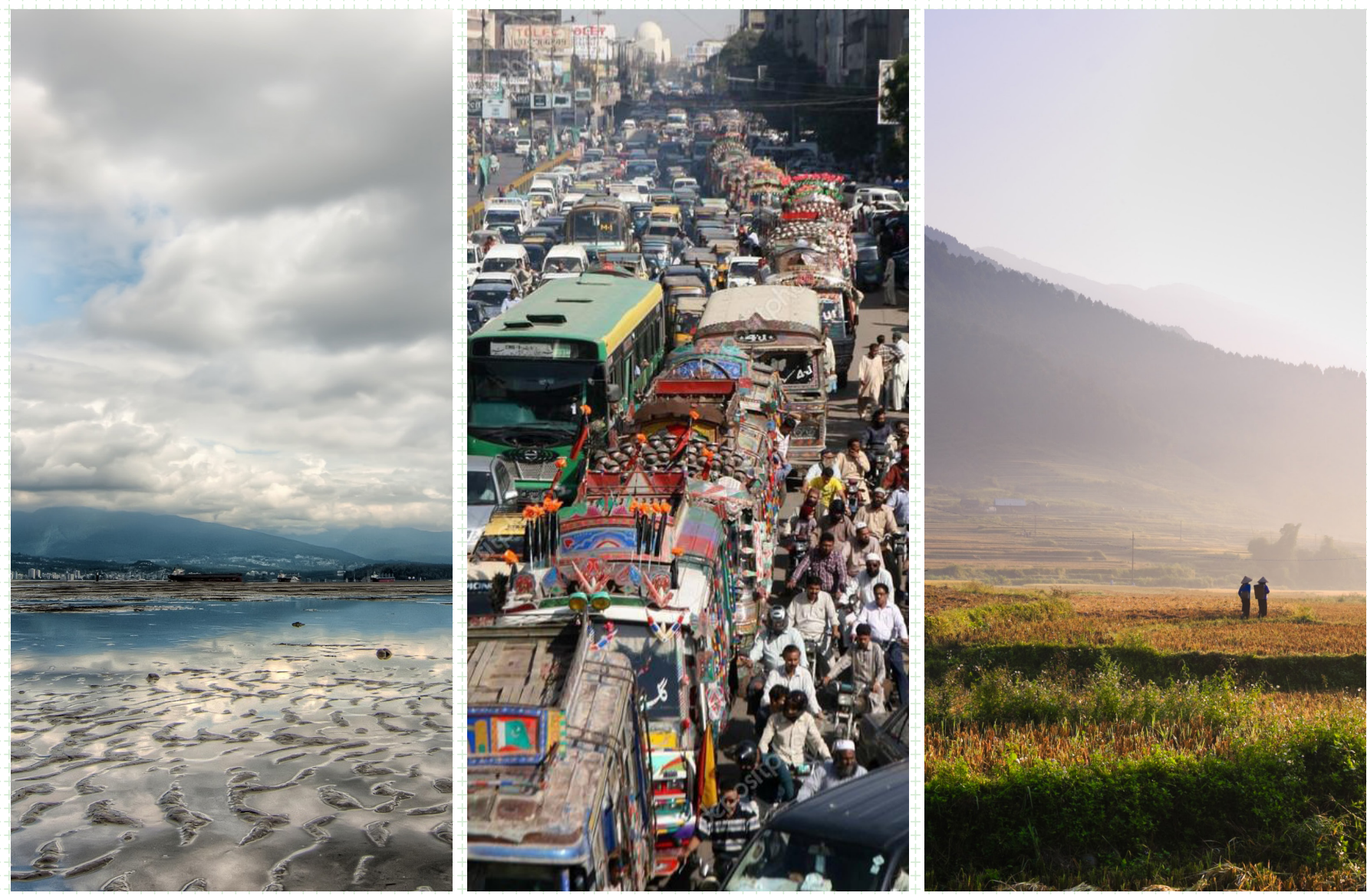



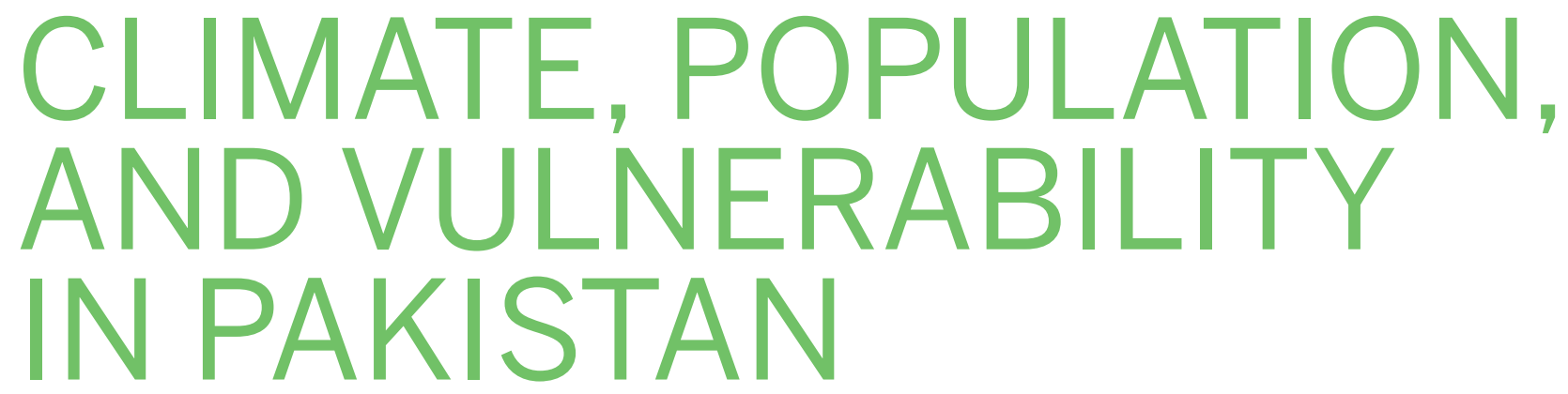

EXPLORING EVIDENCE OF LINKAGES FOR ADAPTATION 
The Population Council's Population, Environmental Risk, and Climate Change (PERCC) initiative is a multidisciplinary effort to understand how environmental changes affect demographic trends and the impact they have on vulnerable populations. The Council is bringing together its experience in social and behavioral science research, diverse perspectives, data, methodologies, and tools to better understand the many facets of adaptation, resilience, and mitigation. This evidence will inform programs, policies and technologies that ensure the grave threat of climate change does not roll-back decades of progress in reducing poverty and improving lives around the world.

\section{ABOUT THIS MONOGRAPH}

Climate, Population, and Vulnerability in Pakistan: Exploring Evidence of Linkages for Adaption uses diverse data sources to initiate an interdisciplinary conversation on the interlinkages of climate change and demography through contributions from national experts in meteorology, migration, and agriculture. The aim is to provide a regionally nuanced perspective of the climatic changes to which the population is exposed; the key demographic and socioeconomic trends that have a bearing on vulnerability, resilience, and adaptation; internal migration; and the expected combined impact of these dynamics on the country's food and economic mainstay-agriculture.

\section{ABOUT THE AUTHORS}

G. M. Arif is Former Joint Director, Pakistan Institute of Development Economics.

Muhammad Riaz is Director-General, Pakistan Meterological Department, Islamabad.

Nadeem Faisal is Director, Climate Data Processing Centre, Pakistan Meterological Department, Karachi.

Mohammad Jamal Khan Khattak is Chairman, Department of Soil and Environmental Sciences, University of Agriculture, Peshawar.

Zeba Sathar is Country Director and Senior Associate; Muhammad Khalil is Program Manager (ICT); Maqsood Sadiq is Deputy Program Manager; Sabahat Hussain is Program Officer; and Kiren Khan is Consulting Editor, Population Council.

Citation: Sathar Z.A. and K. Khan (eds). 2019. Climate, Population, and Vulnerability in Pakistan: Exploring Evidence of Linkages for Adaptation. Islamabad: Population Council.

The Population Council confronts critical health and development issues-from stopping the spread of HIV to improving reproductive health and ensuring that young people lead full and productive lives. Through biomedical, social science, and public health research in 50 countries, we work with our partners to deliver solutions that lead to more effective policies, programs, and technologies that improve lives around the world. Established in 1952 and headquartered in New York, the Council is a nongovernmental, nonprofit organization governed by an international board of trustees. popcouncil.org

(C) 2019 The Population Council, Inc. 


\section{Contents}

Foreword

John Bongaarts

Introduction

Kiren Khan and Sabahat Hussain

Chapter 1: Climate Change in Pakistan

Nadeem Faisal and Mohammad Riaz

Chapter 2: Exploring the Implications of Climate Change and

Population Growth for Agricultural Productivity

Mohammad Jamal Khan Khattak

Chapter 3: Population Exposure and Vulnerability to Climate Change in Pakistan's Agroecological Zones: A Preliminary Data Analysis

Maqsood Sadiq, Zeba Sathar and Muhammad Khalil

Chapter 4: Climate Change and Migration-as-Adaptation in

Pakistan: Preliminary Findings

G.M. Arif and Maqsood Sadiq 


\section{Foreword}

The global discussion of climate change and its impacts and causes has changed completely in the past quarter century. The contentious debate about whether global warming is real and whether humans are to blame has been settled and the consensus of public and scientific opinion now accepts that rapid warming is occurring and that greenhouse gases (GHG) emitted as a result of human activities are largely to blame. The consequences of taking no action will be catastrophic. Unfortunately, the burden of impact will fall disproportionately on the poor and most vulnerable people who rely heavily on agriculture in countries where average temperatures are already high. Climate change is particularly harmful because it increasingly threatens food security in these countries.

Pakistan is one of the most vulnerable countries in the world. The food-supply system is increasingly disrupted by shortages of fresh water, by floods, droughts, storms and other types of extreme weather, as well as by desertification and soil erosion. These changes are occurring as demand for agricultural products continues to rapidly rise due to population growth and improving diets. The population now stands at about 216 million and is expected to increase to 400 million by 2100 . In addition, there is little room for expanding land for productive agriculture since most potential arable land is already serving human needs (e.g., for crops and grazing land, and for infrastructure).

Clearly, action is urgently needed. The latest major effort of the international community to address global warming was the Paris Agreement reached in 2016 within the United Nations Framework Convention on Climate Change. The Agreement aimed to reduce the effects of climate change by limiting the increase in global average temperature to $1.5^{\circ} \mathrm{C}$ above the preindustrial level. Under the Agreement, each country must determine, plan, and regularly report on the contribution that it undertakes to mitigate global warming. According to a recent Intergovernmental Panel on Climate Change (IPCC) report, limiting global warming to $1.5^{\circ} \mathrm{C}$ requires "unprecedented" and extremely steep cuts in global GHG emissions. To meet the Paris goal, emissions must be reduced by half in 2030 and reach "net zero" around 2050. The Paris goal seems unachievable because the commitments made by governments are insufficient to meet the goal and several countries (including the US) have either withdrawn from the agreement or are not meeting even their own limited objectives.

Given this lack of progress in mitigation efforts, it is very likely that the world will exceed the $1.5^{\circ} \mathrm{C}$ limit in the next few decades and much higher temperatures could be reached by 2100 . As a result, the world must get ready for a wide range of adverse effects on natural and manmade systems and on human society. There is an especially urgent need for more effective adaptation measures to protect vulnerable populations. 
This report provides an excellent and timely overview of the challenges faced by Pakistan. Climate change is expected to have wide-ranging effects including an increase in the frequency and intensity of extreme weather events, reduced agricultural productivity, and increased intrusion of saline waters in the Indus delta. All of these changes put additional stresses on agricultural production to increase crop yields, which is already threatened by dwindling per capita availability of land and water due to population growth, land fragmentation, and urbanization.

A key response to these environmental risks has been the migration of people from threatened areas to elsewhere in Pakistan and overseas. This adaptation strategy of households aims to reduce both environmental and economic risks. Unfortunately, many migrants end up in receiving areas where jobs may be scarce and in slums in urban areas where living conditions are often very poor.

This highly accessible report deserves to be widely read by policymakers, researchers, and the general public. It is a wake-up call to take climate change seriously and prepare for the unprecedented challenges ahead.

John Bongaarts

Distinguished Scholar

Population Council 


\section{Introduction}

In its framework for implementation of the Climate Change Policy 2012, the Government of Pakistan (2013) has identified nine major threats to water, food, and energy security arising from these emerging environmental stresses in various parts of the country. These include:

- Considerable increase in the frequency and intensity of extreme weather events, coupled with erratic monsoon rains causing frequent and intense floods and droughts;

- Projected recession of the Hindu Kush-Karakoram-Himalayan (HKH) glaciers due to global warming and carbon soot deposits from trans-boundary pollution sources, threatening water inflows into the Indus River System;

- Increased siltation of major dams caused by more frequent and intense floods;

- Rising temperatures resulting in enhanced heat and water-stressed conditions, particularly in arid and semi-arid regions, leading to reduced agricultural productivity;

- Further decrease in the already scanty forest cover, from too rapid change in climatic conditions to allow natural migration of adversely affected plant species;

- Increased intrusion of saline water in the Indus delta, adversely affecting coastal agriculture, mangroves and the breeding grounds of fish;

- Threat to coastal areas due to projected sea level rise and increased cyclonic activity due to higher sea surface temperatures;

- Increased stress between upper riparian and lower riparian regions in relation to sharing of water resources; and

- Increased health risks and climate change induced migration.

Currently ranking eighth on the Global Environmental Risk Index (Eckstein, Hutfils, and Winges 2019),

Pakistan is already facing considerable negative impacts from climate change. In 2010, heavy rainfall over two months led to floods that affected approximately 20 million people and displaced 11 million. This was one of the most significant human displacement events within 2008-12 (UN News 2011; Yonetani and Morris 2013). Large-scale flooding was also seen in 2011 and 2015. Flooding is not a new environmental stress in the country, but its increased intensity is associated with climate change impacts such as the melting of glaciers and higher incidence of heavy rainfall events. The timing of floods has also become less predictable: for example, in February 2019, unexpected heavy rain resulted in severe flash floods in Balochistan, affecting an estimated 425,000 people and displacing over 9,000 in districts Lasbela, Killa Abdullah, Turbat, Pishin, and Khuzdar (WHO 2019). 
Climate scientists estimate that Pakistan's annual mean temperature has risen by roughly 0.5 degrees Celsius $\left({ }^{\circ} \mathrm{C}\right.$ ) over the last 50 years and will rise by a further $3^{\circ}-6^{\circ} \mathrm{C}$ by the end of the century (Chaudhry 2017). Projections by the Pakistan Meteorological Department (PMD) and Global Change Impact Studies Centre (GCISC) indicate that by 2050, the maximum rise in temperature will occur in the Northern Areas, central and southern Punjab, and southern Khyber Pakhtunkhwa (KP), and precipitation will increase in some regions and decrease in others (Government of Pakistan 2013).

In some parts of the country, especially Balochistan and parts of Sindh, heat stress and drought-like conditions have arisen. Assessing needs in drought-affected areas of Sindh and Balochistan, Food Security Cluster (2016) found that $37 \%$ of pregnant women and $26 \%$ of lactating women were severely malnourished, with numbers varying across different agro-climatic zones. Similarly, in the Thar Desert, which experienced severe drought from 2013 to 2015, high rates of malnutrition have been found (Kunbher et al. 2017). Over 500 children died in Thar in 2018, for reasons such as low birth weight, neonatal sepsis, and birth asphyxia (Dawn 2018). Undernutrition and the associated premature births and low birth weight in Thar are attributed to crop failure resulting from climate change and the subsequent drop in food security (Food Security Cluster 2016).

Acknowledging that "Pakistan's contribution to global greenhouse gas (GHG) emissions is very small" and that climate change is "no longer a distant threat" but already exacting huge human and financial costs (Government of Pakistan 2013, p. 1), the Government's climate change policy and implementation plan focus relatively less on mitigation-that is, efforts to prevent or reduce greenhouse gas emissions-and more on adaptation to actual and expected climate change impacts. The scale and urgency of the task demands efficient and effective approaches, but in identifying and adopting these, the government and other national stakeholders might confront some of the same challenges that have been witnessed globally. Martine and Schensul (2013) observe that, thus far, adaptation approaches have had serious limitations in that they tend to be reflexive and post-hoc, and often lack a basis in solid data. Moreover, there has been "an inordinate focus on technical and economic challenges, without sufficient consideration of people's livelihoods and opportunities" (p. xvi). Guzman, McGranahan, and Giorguli (2013) describe the latter issue in the following terms: "Adaptation is about more than infrastructure and ecosystems. It is about peopletheir characteristics and resources, and how they come together in communities and countries. It is more important than ever that we understand how people, not just places, are vulnerable to climate change, and how they are and can become more resilient" (p. x).

Current discourse on climate change mitigation and adaptation in Pakistan does acknowledge the importance of considering demographic factors, such as population growth and density. As yet, however, little empirical evidence has been generated examining or enabling an exploration of the interplay between climate change-related stresses, population dynamics, and the associated challenges and opportunities for adaptation and development. Again, this problem is not unique to the country. Engelman and colleagues (2016) attribute the global lack of scientific study on the connections between population growth and environmental change to the complexity of the connections; the fact that they are associated with disparate scientific specialties; and the sometimes acute sensitivities that continue to be related to population and contraception. Thus, despite their profound implications for climate change adaptation and development, important demographic dynamics like internal migration and fertility continue to receive scant attention from researchers or policymakers.

The links between population dynamics and adaptation are a new area of work (Guzman, McGranahan, and Giorguli 2013), but the arguments for incorporating demographic analysis in the work of adaptation are too compelling to ignore (Bongaarts and O'Neill 2018). As Schensul and Dodman (2013) recount, population issues are closely linked to economic and social development: economic growth, and access to social safety nets and to services integral to livelihoods are shaped by interactions between fertility, migration, spatial distribution, age structure, household size and composition, race and ethnicity, and gender dynamics, which are the subject of demography. In fact, "some aspects of population dynamics, such as migration, urbanization, and age structure, are directly linked to adaptation" (p. xvii). 
Moreover, population projections generally provide the most reliable scenarios concerning the size, location, and characteristics of the need for adaptation efforts. A demographic lens is also critical to avoid static perceptions of vulnerability; changes that affect the size, distribution, and composition of human populations will also affect the nature of vulnerability and responses to climate change (Martine and Schensul 2013). Therefore, if demographic data are correctly used and exploited, they could "provide a wealth of analyses and insights that can orient more effective approaches, particularly when applied to maps and tied to the geography of current and expected climate-related hazards" (ibid., p. xvi).

The need for effective adaptation efforts is more urgent than ever as climate change is a factor in Pakistan's growing water stress. Aside from the direct effects of drought and shifts in rainfall patterns, warmer temperatures are expected to raise irrigation needs through increased rates of evapotranspiration (Government of Pakistan 2013). The country has the fourth largest groundwater aquifer in the world, covering an area of 1.1 million square kilometers, but the groundwater level is already falling at the rate of one meter per year due to excessive extractions through over 1.2 million tube wells (Imran 2019). Unfortunately, this is only expected to worsen because farmers in many areas are adapting to water shortages through increased use of tube wells (e.g., Ahmad, Iqbal, and Khan 2013; Ahmad, Siftain, and Iqbal 2014). Given that the country meets more than half of its overall irrigation water requirements and $70 \%$ of its drinking water consumption from groundwater abstractions (Watto 2018), this trend does not bode well for future water security.

In the agriculture sector, which is directly affected by climate change, adaptation is particularly important. Agriculture contributes $21 \%$ of the gross domestic product and about $70 \%$ of export earnings, and employs nearly half (45\%) of the labor force (Government of Pakistan 2013). The sector's performance is closely linked to food security. Climatic factors have been estimated to account for $33 \%$ of variability in yields of rice, nearly $30 \%$ of variability in wheat productivity, and about 39\% of variability in maize yields (Ali et al. 2017). Cline (2007) estimates that crop yields in Pakistan will decline by $30 \%$ by 2080 as a result of climate change.

The shortening and warming of winters that is currently underway in Pakistan will particularly affect the production of wheat, a major food staple. It is estimated that an increase of 1 degree Celsius $\left({ }^{\circ} \mathrm{C}\right)$ in mean temperature will reduce yields by 5-7\% (Sivakumar and Stefanski 2011), and an increase of $1^{\circ} \mathrm{C}$ during the wheat-sowing months (November and December) will reduce its yield by $7.4 \%$ (Ahmad et al. 2014). In fact, Iqbal, Goheer, and Khan (2009) predict that growing seasons for major cereal crops will shorten in virtually all agroecological zones of Pakistan. By 2080 , yields of wheat and basmati rice could decline by $6-11 \%$ and $15-18 \%$, respectively (Ali 2011).

Rising temperature is also expected to reduce milk, poultry and meat production by $20-30 \%$, making these food items less affordable (UNISDR, UNDP and IUCN 2009). By the end of the current century, Pakistan's agricultural sector could be losing US\$2-6 billion per year owing to climate change (Mendelsohn, Dinar, and Sanghi 2001).

Literature combining population and climate science perspectives is limited, but the available studies show that demographic analysis not only improves assessments of vulnerability but can also contribute to our understanding of adaptive responses, capacities, and resilience. For example, a study of adaptation to climate change among farmers in Pakistan found that education (measured as literacy) is positively related to soil conservation but negatively related to use of new inputs; age, which the authors viewed as a measure of experience, is positively related with soil and water conservation but negatively associated with crop choice; large farms are more likely than small farms to change crop choices and use new inputs; sharecroppers are more likely to use crop choice and soil conservation, and less likely to use crop timing as adaptive responses; and land ownership increases the likelihood of investments in soil conservation as well as crop choice, but reduces the likelihood of changes in crop timing (Dehlavi et al. 2015). 
Migration is a particularly important demographic dynamic to consider. Among communities in the Northern Areas of Pakistan, studies show that migration to major cities is one of the most frequent adaptive strategies (Gioli et al. 2014, Nizami and Ali 2017, UNDP 2016). These studies also reveal the disparately higher vulnerability of women, who are mostly left behind to take care of the farms and households, facing greater health risks, heavier work burdens, and difficulties in carrying out tasks traditionally performed by men, such as seeking resolution for disputes over irrigation water. Mueller, Gray, and Kosec (2014) observe that while flooding has attracted greater attention and financial compensation for affected people, it is heat stress that has consistently increased long-term migration among men from rural areas of Pakistan.

\section{POPULATION, ENVIRONMENTAL RISKS, AND CLIMATE CHANGE (PERCC)}

To help rectify the neglect of population issues in the existing framework of climate negotiations, the Population Council's Population, Environmental Risk, and Climate Change (PERCC) initiative is evolving a new body of research that brings population data and variables and demographic methodology to climate change science for improved analysis of adaptation, mitigation, and resilience strategies and policies focused on the most vulnerable populations. As part of these efforts, in 2018, the Council's Pakistan office published a case study of demographic changes in Mianwali district after the devastating 2010 floods, which identified a number of trends of great relevance to adaptation efforts, such as a startling increase in contraceptive prevalence in the most affected subdistrict, diversification of livelihoods towards nonagricultural occupations, and markedly higher female participation in the workforce (Sathar et al. 2018). From a research perspective, the findings also confirmed the value of mining and combining data sets that are traditionally used in isolation, such as meteorological data on temperature and rainfall; agricultural data on land use and food and crop production; demographic, economic, and social data from the Pakistan Social and Living Standards Measurement Survey (PSLMS) and Multiple Indicator Cluster Survey (MICS); and geospatial data.

In the current monograph, we have attempted to extend the approach employed in the Mianwali case study and used diverse data sources to develop an integrated picture of climate change and population trends across the country. In this larger effort, we have also initiated an interdisciplinary conversation on the interlinkages of climate change and demography through contributions from national experts in meteorology, migration, and agriculture. The aim is to provide a regionally nuanced perspective of the climatic changes to which the population is exposed; the key demographic and socioeconomic trends that have a bearing on vulnerability, resilience, and adaptation; internal migration; and the expected combined impact of these dynamics on the country's food and economic mainstay-agriculture.

1. The first study presented in this monograph, "Climate Change in Pakistan," was conducted by Muhammad Riaz, Director-General of the Pakistan Meteorological Department (PMD), and Nadeem Faisal, Director of the Climate Data Processing Centre with PMD. The authors have analyzed high-quality climate data for nearly six decades from approximately half the PMD weather stations across the country to identify national and regional trends in temperature and precipitation. The study provides an updated spatial and temporal analysis of some major climate change trends, identifying the areas where environmental stresses are most acute. 
2. In the second study, "Exploring the Implications of Climate Change and Population Growth for Agricultural Productivity," Muhammad Jamal Khan Khattak, Chairman of the Department of Soil and Environmental Sciences at the University of Agriculture, Peshawar, reviews literature and data to identify the key pathways through which climate change is projected to affect agricultural productivity in various parts of the country, such as changes in crop-growing seasons, water availability, and land degradation, and describes how these stresses are being exacerbated simultaneously by demographic changes such as population growth, land fragmentation, ruralurban migration, and urbanization. The study concludes by outlining the disturbing implications of these combined stresses for food security in Pakistan.

3. The third study in this compilation, "Exposure and Vulnerability to Climate Change in Pakistan's Agroecological Zones: A Preliminary Data Analysis," was produced by the Population Council Pakistan team. Adapting an agroecological zone classification by the Pakistan Agricultural Research Council, the study analyzes meteorological data from the PMD to identify the zones that are more severely affected by changing climate as well as those that are less affected. District-level data from the six population censuses conducted by the Government of Pakistan in 1951, 1961, 1972, 1981, 1998, and 2017 are used to identify who and how many are being affected by changes in climate patterns, and also how major demographic changes, such as population growth, urbanization, and migration, are affecting the zones differentially. The analysis then probes differences in householdlevel behaviors that provide indications of vulnerability to changing climate patterns, as well as capacities to cope and adapt, focusing on household conditions, engagement in agriculture, investments in children, fertility and health outcomes, and poverty levels. This examination utilizes the most recent (2014-15) district-level rounds of Pakistan Social and Living Standards Measurement Survey (PSLMS), and data from the last two rounds (2012-13 and 2017-18) of the Pakistan Demographic and Health Survey (PDHS).

4. In the final study, G.M. Arif, former Joint Director of the Pakistan Institute of Development Economics, and Maqsood Sadiq from the Population Council, Pakistan, have analyzed data from the outmigration module of the PDHS 2017-18 to present some preliminary findings about "Climate Change and Migration-as-Adaptation in Pakistan." Based on the agroecological zone classification employed in the second study in the monograph, the authors assess the incidence of economic migration, both internal and international, and review the direction in which people are moving internally for work, including rural-urban, rural-rural, urban-urban, and urban-rural migration. They also investigate selectivity among economic migrants, with a focus on age, educational attainment, and gender, and identify socioeconomic factors associated with the decision to migrate based on a multivariate analysis of household characteristics. The study concludes with a review of the extent of household income diversification in the seven agroecological zones through receipt of remittances.

We hope that the preliminary findings presented in this volume will help highlight the need for incorporating population dynamics into the urgent work of climate change adaptation, and assist in the identification of areas for deeper investigation. 


\title{
CHAPTER 1 \\ Climate Change in Pakistan
}

\author{
NADEEM FAISAL AND MUHAMMAD RIAZ
}

\section{INTRODUCTION}

Climate change refers to decades-long or long-term changes in mean climate or variability in climate. It is a complex phenomenon both affecting and affected by other aspects of our physical environment.

Figure 1.1 shows the major components of the climate system and some of the key climatic changes that interact with and lead to changes in the atmosphere, land, biosphere, hydrosphere, and cryosphere, as identified by the World Meteorological Organization (WMO 2019). As the figure illustrates, climate change can arise from both internal (natural) processes and from external (anthropogenic) factors. Anthropogenic climate change originates from the Earth's response to the long-term "external" radiative imbalance caused by human activities.
Figure 1.1 Key components of climate system and interactions: Energy budget, atmospheric composition, weather, hydrological cycle, ocean, and cryosphere

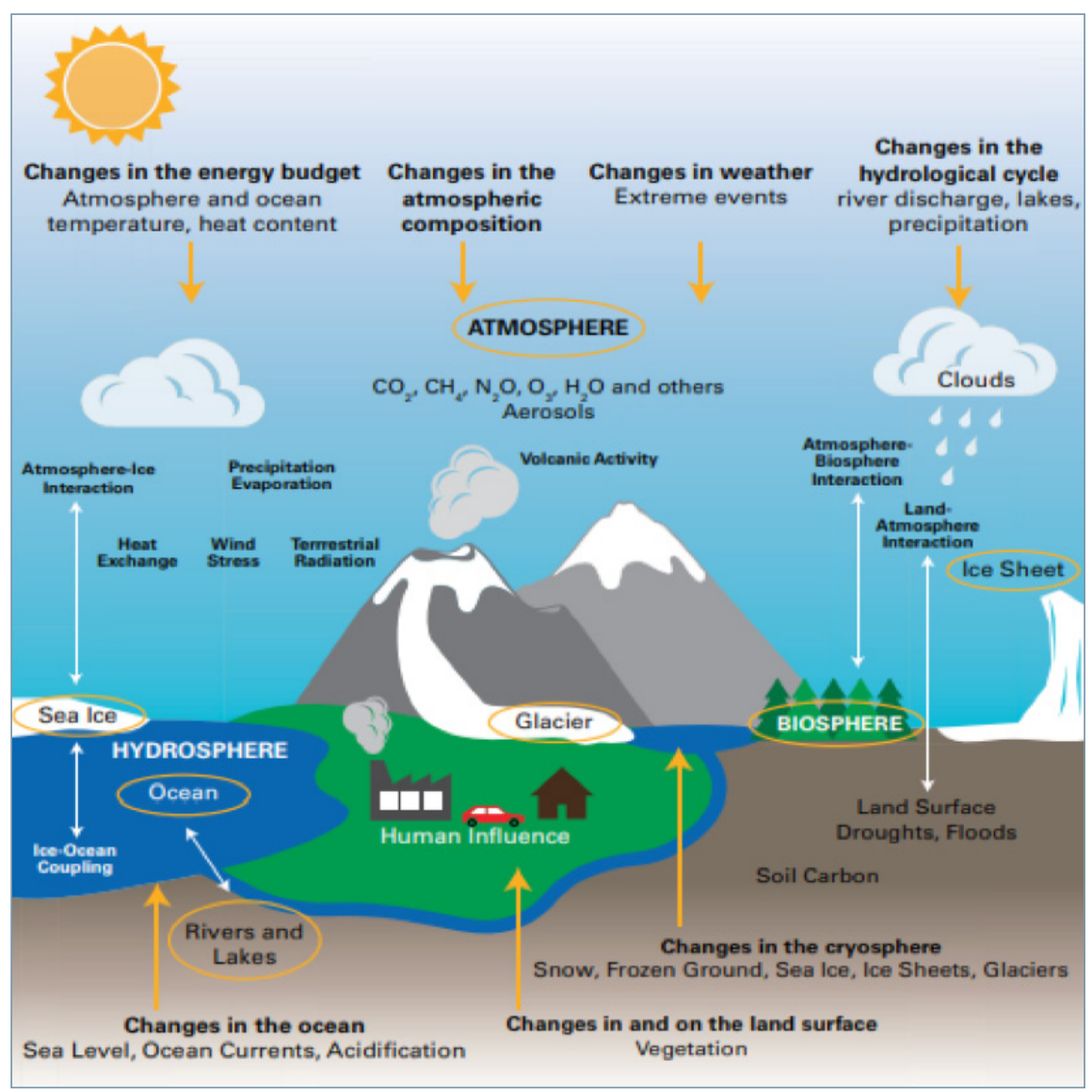

Source: WMO 2019.

A special report of the Inter-governmental Panel on Climate Change (IPCC), Global Warming of $1.5^{\circ} \mathrm{C}$, states that average global temperature for the period $2006-15$ was $0.86^{\circ} \mathrm{C}$ higher than the pre-industrial (1850-1900) baseline. The report estimates that human activities have caused approximately $1.0^{\circ} \mathrm{C}$ of global warming above pre-industrial levels, with a likely range of $0.8^{\circ} \mathrm{C}$ to $1.2^{\circ} \mathrm{C}$. It also projects that global warming is likely to reach $1.5^{\circ} \mathrm{C}$ between 2030 and 2052 if it continues to increase at the current rate (IPCC 2018).

Global warming has been particularly noticeable in recent years. Among its key findings, the WMO Statement on the State of the Global Climate in 2018 highlighted a striking pattern of consecutive record warming from 
2015 through 2018; the year 2018 was the coolest of the four (Figure 1.2) (WMO 2019). The average anomaly above the pre-industrial baseline was $0.93 \pm 0.07^{\circ} \mathrm{C}$ for the most recent decade (2009-18) but $1.04 \pm 0.09^{\circ} \mathrm{C}$ for the past five years (2014-18). These periods include the warming effect of the strong El Niño of 2015-16.

Figure 1.2 Global mean temperature anomalies with respect to the pre-industrial baseline (1850-1900) for the five global temperature datasets

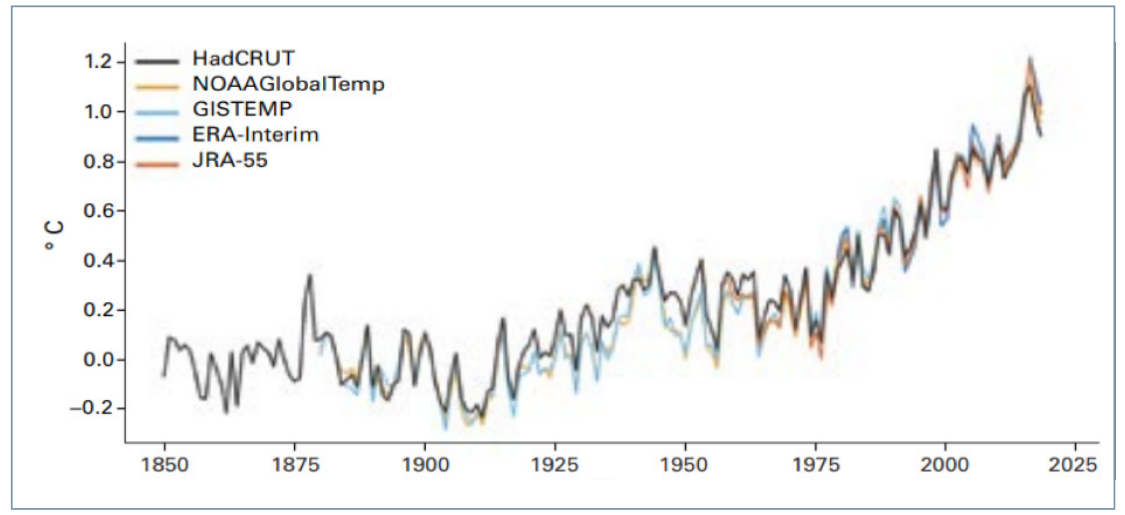

Source: UK Met Office Hadley Centre (in WMO 2019).

Over the years, climate change has affected every region of the globe, but vulnerability to its effects is considerably higher in Africa and Asia. Impacts of extreme weather events, higher temperatures, and variability in rainfall have started to register on the lives and livelihoods of millions of poor people, affecting countries' economic performance. Pakistan is counted among the countries most vulnerable to climate change, as a huge portion of its population depends on the agriculture sector and there is high dependency on precipitation. In the past decade, recurrent spells of extreme weather events such as floods, droughts, glacial lake outbursts, cyclones, and heat waves have taken a heavy toll on both life and property, and adversely affected the country's economic growth (Chaudhry 2017). Germanwatch, in its Global Climate Risk Index 2019, ranked Pakistan eighth among the countries most affected by climate change between 1998 and 2017 (Eckstein, Hutfils, and Winges 2019). On the other hand, Pakistan ranks 140th in total carbon dioxide $\left(\mathrm{CO}_{2}\right)$ per capita emissions (World Bank 2019) and, as of 2017 , accounted for only $0.25 \%$ of total global cumulative $\mathrm{CO}_{2}$ emissions (Ritchie and Roser 2017).

In this study, we have utilized high-quality, long-term data generated at 55 observing stations in Pakistan for multiple climate parameters to assess changes in the country's climate over the period 1961-2018. Key climate change trends are identified at both the national and regional levels, and examined over 58-year as well as shorter time scales for an in-depth examination. We also outline some of the major environmental stresses projected to arise or intensify as a result of these changes.

\section{PAKISTAN'S TOPOGRAPHY AND CLIMATE}

Situated on the western edge of the monsoon region in South Asia, Pakistan extends over a total area of 796,095 square kilometers $\left(\mathrm{km}^{2}\right)$, including $770.875 \mathrm{~km}^{2}$ of land and $25,220 \mathrm{~km}^{2}$ of water. Its major topographical regions include (a) the western offshoots of the Himalayas, which cover its northern and northwestern parts and in which the highest peak, K-2, rises to 8,611 meters above sea level; (b) the Balochistan plateau in the southwest of the country; (c) the Indus Plain, stretching across most of the eastern and central part of the country; and (d) the Potohar Plateau and Salt Range, situated between the Indus and Jhelum rivers in northern Punjab. An elevation map of the country is provided in Figure 1.3. 
Figure 1.3 Elevation map of Pakistan showing weather observing stations

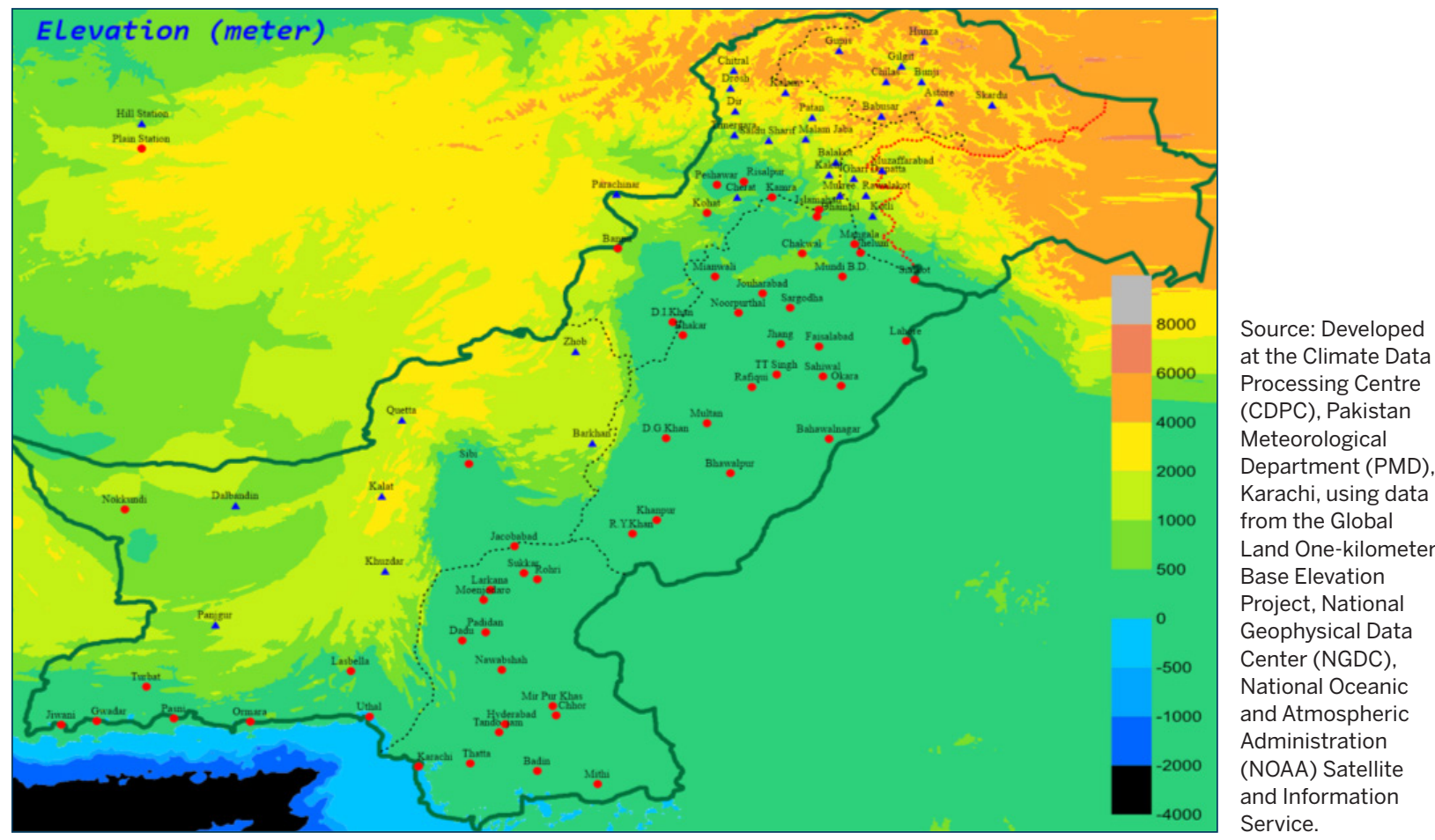

There is great diversity in temperature and precipitation across Pakistan (World Commission on Dams 2000). The climate varies from arid to semiarid. Rainfall, which has great economic value for the country, shows large temporal as well as spatial variability. The annual rainfall pattern exhibits bimodal distribution, with almost half occurring during the monsoon season (July to September). The major amount of monsoon season rainfall occurs in the northern part of the country, in Azad Jammu and Kashmir (AJK), adjoining submountainous areas of Punjab, and in eastern Khyber Pakhtunkhwa (KP). Some effect of the monsoon is also felt in the southeastern parts of the country, but western parts of Balochistan province remain unaffected and dry.

A secondary rainfall peak occurs in winter (January to March) through the western disturbances system (Figure 1.4). The amount of rainfall received during this winter peak is about half of the monsoon rainfall, and it comprises the major proportion of rainfall in the northern and western parts of the southern half of the country. In the intervening periods, i.e., from April to May and October to December, there is almost no rain in the south of the country and relatively less elsewhere.

Figure 1.4 Monthly distribution of rainfall in Pakistan

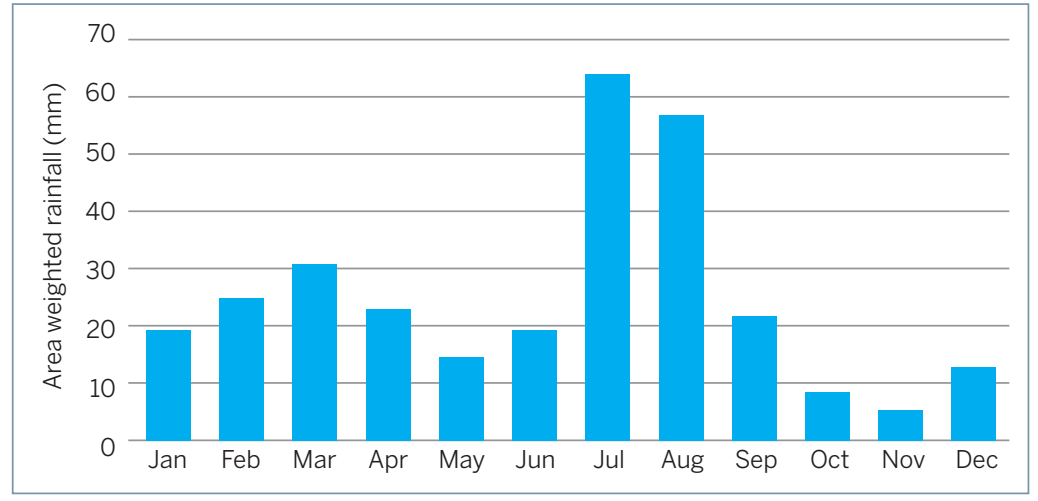

Source: CDPC, PMD, Karachi. 
The northern part of Pakistan experiences rainfall activity throughout the year, although the amounts are relatively small in October and November. In most parts of the country, normal annual rainfall is less than 400 millimeters $(\mathrm{mm})$. However, the southern slopes of the Himalayas, submountainous northern region of AJK, northern Punjab, and parts of northern KP typically receive $800-1,800 \mathrm{~mm}$ of rainfall every year (Figure 1.5). Figure 1.6 shows the share of the six administrative regions of Pakistan in annual rainfall.

Figure 1.5 Spatial distribution of average annual rainfall ( $\mathrm{mm}$ ) in Pakistan, 1961-2010

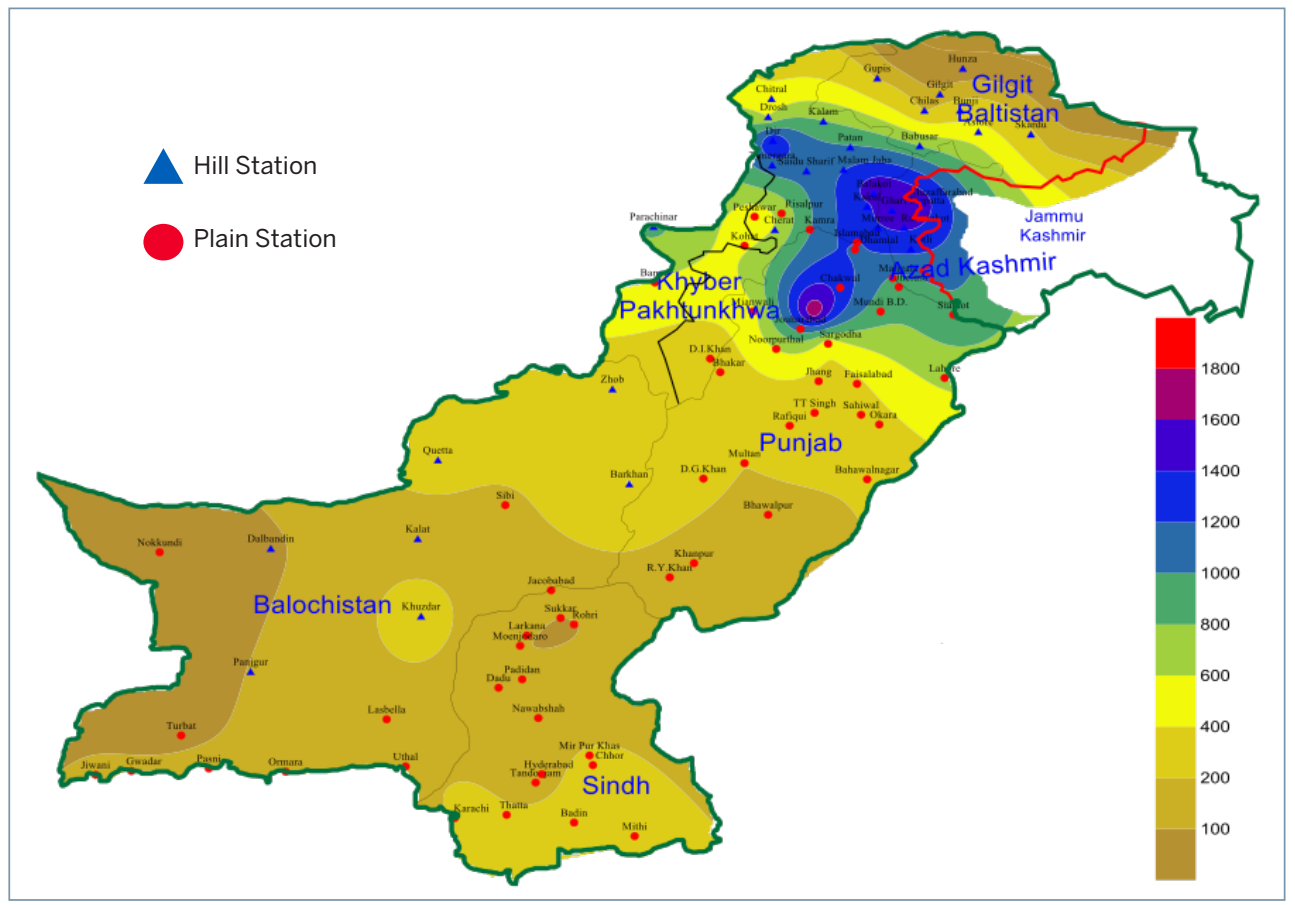

Source: CDPC, PMD, Karachi.

Figure 1.6 Proportion of annual rainfall received by specific administrative regions of Pakistan, 1961-2010

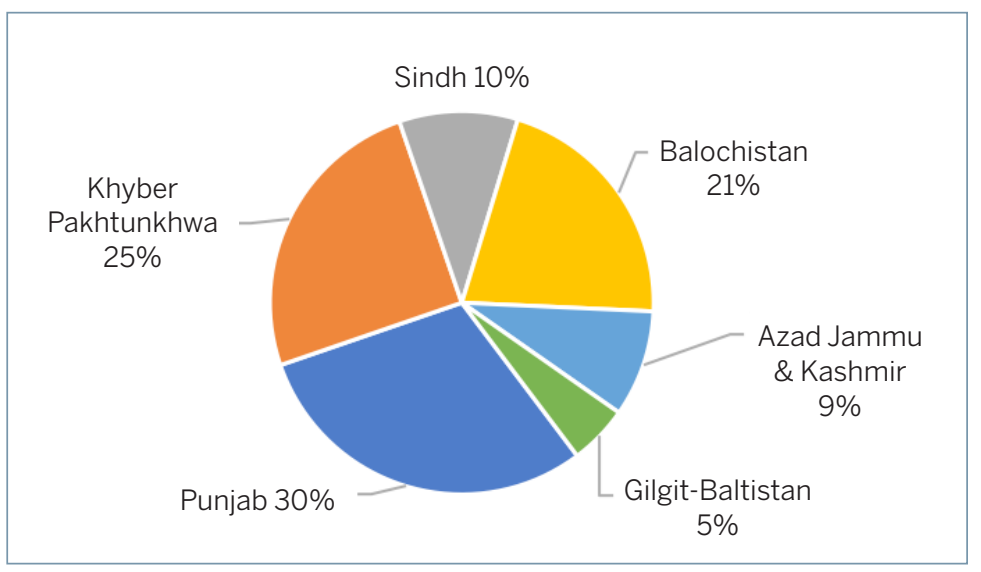

Source: CDPC, PMD, Karachi. 
The temperature varies greatly across Pakistan. The annual normal mean temperature ranges from $8\left({ }^{\circ} \mathrm{C}\right)$ in the north of the country to $28^{\circ} \mathrm{C}$ in the southernmost areas (Figure 1.7). Monthly normal mean temperature ranges from about $0^{\circ} \mathrm{C}$ in winter (December to February) to about $36^{\circ} \mathrm{C}$ in summer (May to July).

Figure 1.7 Annual average mean temperature $\left({ }^{\circ} \mathrm{C}\right)$ in Pakistan, 1961-2010

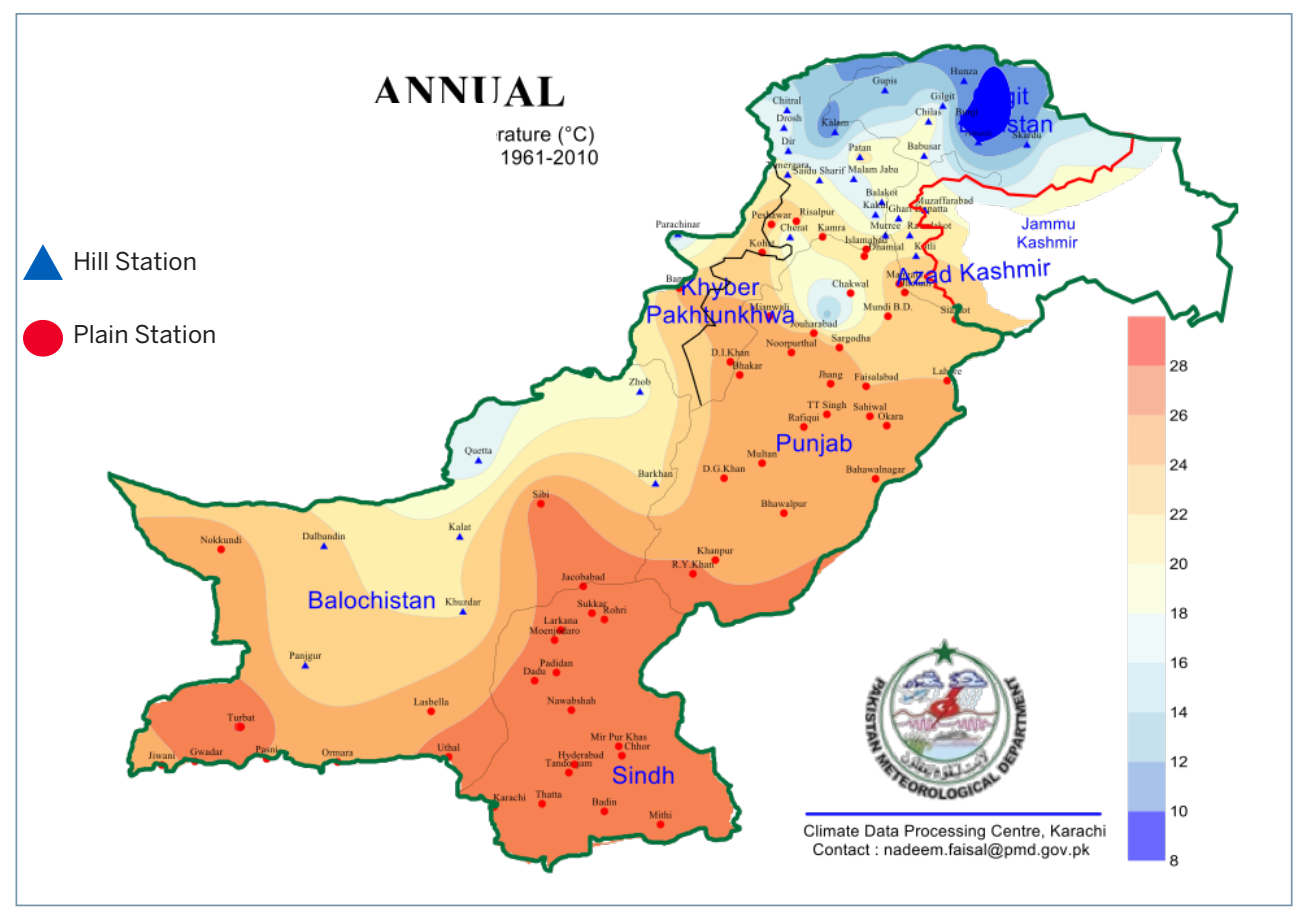

Source: CDPC, PMD, Karachi

\section{DATASET USED}

This study of climate change in Pakistan is based on high-quality climate data generated at 55 observing stations of the Pakistan Meteorological Department (PMD) for the period 1961-2018. These stations represent nearly half of the total PMD stations across the country. Data from the remaining weatherobserving stations were not used because they cover relatively shorter time periods.

The data used in this study cover temperature (daily and monthly averages of mean, ${ }^{1}$ maximum, and minimum temperature), rainfall, and snow (amount and frequencies). We use 30-year averages computed for the period 1961-90, termed "reference normals," as the benchmark for climate change assessment (WMO 2017).

Table 1.1 presents the location and elevation of the observing stations, as well as long-period (LP) averages and decadal trends of temperature and rainfall observed at each station. Analysis of the data was carried out at the Climate Data Processing Centre (CDPC) at PMD, Karachi.

${ }^{1}$ The mean daily temperature is defined as the average of maximum temperature and minimum temperature during a day. On a clear day, the maximum temperature commonly occurs in the daytime, during the afternoon, while the minimum temperature occurs during the night, just before sunrise. 
Table 1.1 Climate dataset used for study

\begin{tabular}{|c|c|c|c|c|c|c|c|c|c|c|}
\hline \multirow[b]{2}{*}{ SNo } & \multirow[b]{2}{*}{ Station } & \multirow[b]{2}{*}{ WMO \# } & \multirow[b]{2}{*}{ Latitude (N) } & \multirow[b]{2}{*}{ Longitude (E) } & \multirow{2}{*}{$\begin{array}{l}\text { Elevation } \\
\text { (meter) }\end{array}$} & \multirow{2}{*}{$\begin{array}{l}\text { Established } \\
\text { year }\end{array}$} & \multicolumn{2}{|c|}{ Annual rainfall (mm) } & \multicolumn{2}{|c|}{ Annual temp $\left({ }^{\circ} \mathrm{C}\right)$} \\
\hline & & & & & & & LP average & $\begin{array}{l}\text { Trend/ } \\
\text { decade }\end{array}$ & $\begin{array}{c}\text { LP } \\
\text { average }\end{array}$ & $\begin{array}{l}\text { Trend/ } \\
\text { decade }\end{array}$ \\
\hline 1 & Astor & 43520 & $35^{\circ} 22^{\prime}$ & $74^{\circ} 54^{\prime}$ & 2167 & 1952 & 482.17 & -7.11 & 9.85 & 0.15 \\
\hline 2 & Badin & 41785 & $24^{\circ} 38^{\prime}$ & $68^{\circ} 54^{\prime}$ & 10 & 1929 & 221.22 & -0.82 & 27.54 & 1.13 \\
\hline 3 & Bahawalnagar & 41678 & $29^{\circ} 57^{\prime}$ & $73^{\circ} 15^{\prime}$ & 161 & 1962 & 225.99 & 21.62 & 26.6 & 0.26 \\
\hline 4 & Bahawalpur & 41700 & $29^{\circ} 24^{\prime}$ & $71^{\circ} 47^{\prime}$ & 116 & 1926 & 174.66 & 3.84 & 26.66 & 0.06 \\
\hline 5 & Balakot & 41536 & $34^{\circ} 23^{\prime}$ & $73^{\circ} 21^{\prime}$ & 980 & 1957 & 1564.44 & -39.38 & 20.03 & 0.1 \\
\hline 6 & Barkhan & 41685 & $29^{\circ} 53^{\prime}$ & $69^{\circ} 43^{\prime}$ & 1097 & 1963 & 372.54 & 32.9 & 22.77 & 0.05 \\
\hline 7 & Bunji & 43518 & $35^{\circ} 40^{\prime}$ & $74^{\circ} 38^{\prime}$ & 1372 & 1952 & 154.11 & 7.72 & 19.14 & -0.04 \\
\hline 8 & Cherat & 41565 & $33^{\circ} 49^{\prime}$ & $71^{\circ} 53^{\prime}$ & 1301 & 1992 & 613.84 & -3.19 & 18.67 & -0.06 \\
\hline 9 & Chhor & 41768 & $25^{\circ} 31^{\prime}$ & $69^{\circ} 47^{\prime}$ & 5 & 1930 & 228.99 & 5.66 & 27.28 & 0.24 \\
\hline 10 & Chilas & 43519 & $35^{\circ} 25^{\prime}$ & $74^{\circ} 6^{\prime}$ & 1250 & 1952 & 187.24 & 6.12 & 21.73 & 0.06 \\
\hline 11 & Chitral & 41506 & $35^{\circ} 51^{\prime}$ & $71^{\circ} 50^{\prime}$ & 1499 & 1964 & 475.44 & -9.59 & 17.53 & 0.11 \\
\hline 12 & Dalbandin & 41712 & $28^{\circ} 53^{\prime}$ & $64^{\circ} 24^{\prime}$ & 848 & 1911 & 84.58 & -2.19 & 23.76 & 0.32 \\
\hline 13 & DI Khan & 41627 & $31^{\circ} 49^{\prime}$ & $70^{\circ} 55^{\prime}$ & 173 & 1866 & 295.44 & 21.54 & 25.37 & 0.05 \\
\hline 14 & Dir & 41508 & $35^{\circ} 12^{\prime}$ & $71^{\circ} 51^{\prime}$ & 1369 & 1966 & 1319.85 & 53.94 & 17.01 & 0.07 \\
\hline 15 & Drosh & 41515 & $35^{\circ} 34^{\prime}$ & $71^{\circ} 47^{\prime}$ & 1464 & 1897 & 583.66 & -32.94 & 19.2 & -0.07 \\
\hline 16 & Faisalabad & 41630 & $31^{\circ} 26^{\prime}$ & $73^{\circ} 6^{\prime}$ & 183 & 1913 & 372.14 & 15.89 & 25.16 & 0.17 \\
\hline 17 & Garhi Dupatta & 43533 & $34^{\circ} 13^{\prime}$ & $73^{\circ} 37^{\prime}$ & 812 & 1954 & 1552.94 & -89.09 & 20.53 & 0.23 \\
\hline 18 & Gilgit & 43516 & $35^{\circ} 55^{\prime}$ & $74^{\circ} 20^{\prime}$ & 1459 & 1952 & 135.54 & 6.88 & 17.38 & 0.1 \\
\hline 19 & Gupis & 43504 & $36^{\circ} 10^{\prime}$ & $73^{\circ} 24^{\prime}$ & 2155 & 1954 & 190.82 & 25.3 & 14.35 & -0.05 \\
\hline 20 & Hyderabad & 41764 & $25^{\circ} 23^{\prime}$ & $68^{\circ} 25^{\prime}$ & 40 & 1877 & 175.99 & -7.73 & 28.48 & -0.04 \\
\hline 21 & Islamabad & 41571 & $33^{\circ} 37^{\prime}$ & $73^{\circ} 6^{\prime}$ & 507 & 1945 & 1178.84 & 36.59 & 22.86 & 0.3 \\
\hline 22 & Jacobabad & 41715 & $28^{\circ} 18^{\prime}$ & $68^{\circ} 28^{\prime}$ & 55 & 1877 & 115.06 & 12.87 & 28.05 & 0.06 \\
\hline 23 & Jhelum & 41598 & $32^{\circ} 56^{\prime}$ & $73^{\circ} 43^{\prime}$ & 232 & 1942 & 868.13 & 7.82 & 24.87 & 0.13 \\
\hline 24 & Jiwani & 41756 & $25^{\circ} 4^{\prime}$ & $61^{\circ} 48^{\prime}$ & 56 & 1938 & 106.63 & -7.64 & 26.37 & 0.13 \\
\hline 25 & Kakul & 41535 & $34^{\circ} 11^{\prime}$ & $73^{\circ} 15^{\prime}$ & 1308 & 1952 & 1332.19 & -21.98 & 18.51 & -0.08 \\
\hline 26 & Kalat & 41696 & $29^{\circ} 2^{\prime}$ & $66^{\circ} 35^{\prime}$ & 2015 & 1896 & 176.99 & 17.45 & 15.22 & 0.1 \\
\hline 27 & Karachi & 41780 & $24^{\circ} 54^{\prime}$ & $67^{\circ} 8^{\prime}$ & 21 & 1928 & 203.37 & -17.4 & 27.16 & 0.32 \\
\hline 28 & Khanpur & 41718 & $28^{\circ} 39^{\prime}$ & $70^{\circ} 41^{\prime}$ & 87 & 1947 & 112.44 & 14.4 & 26.37 & 0.16 \\
\hline 29 & Khuzdar & 41744 & $27 \circ 50^{\prime}$ & $66^{\circ} 38^{\prime}$ & 1231 & 1965 & 236.18 & 14.91 & 22.89 & 0.23 \\
\hline 30 & Kohat & 41564 & $33^{\circ} 34^{\prime}$ & $71^{\circ} 26^{\prime}$ & 510 & 1950 & 570.25 & 10.33 & 24.41 & 0.18 \\
\hline 31 & Kotli & 43563 & $33^{\circ} 1^{\prime}$ & $73^{\circ} 4$ & 613 & 1952 & 1250.09 & -27.93 & 23.24 & -0.04 \\
\hline 32 & Lahore & 41640 & $31^{\circ} 33^{\prime}$ & $74^{\circ} 20^{\prime}$ & 213 & 1866 & 624.91 & 26.03 & 25.7 & 0.17 \\
\hline 33 & Lasbella & 41742 & $26^{\circ} 14^{\prime}$ & $66^{\circ} 19^{\prime}$ & 88 & 1927 & 164.56 & 5.1 & 27.67 & 0.2 \\
\hline 34 & Mianwali & 41592 & $32^{\circ} 33^{\prime}$ & $71^{\circ} 33^{\prime}$ & 210 & 1967 & 524.88 & 53.76 & 25.36 & 0.08 \\
\hline 35 & Moen-Jo-Daro & 41747 & $27^{\circ} 22^{\prime}$ & $68^{\circ} 6^{\prime}$ & 52.1 & 1977 & 109.13 & -4.48 & 27.41 & 0 \\
\hline 36 & Multan & 41675 & $30^{\circ} 12^{\prime}$ & $71^{\circ} 26^{\prime}$ & 122 & 1940 & 201.86 & 9.03 & 26.4 & 0.15 \\
\hline 37 & Muree & 41573 & $33^{\circ} 55^{\prime}$ & $73^{\circ} 23^{\prime}$ & 2167 & 1870 & 1762.16 & -26.94 & 14.53 & 0.22 \\
\hline 38 & Muzaffarabad & 43532 & $34^{\circ} 22^{\prime}$ & $73^{\circ} 29^{\prime}$ & 701 & 1954 & 1520.18 & -19.35 & 21.93 & 0.25 \\
\hline 39 & Nawabshah & 41749 & $26^{\circ} 15^{\prime}$ & $68^{\circ} 22^{\prime}$ & 37 & 1953 & 139.63 & 6.16 & 27.7 & 0.19 \\
\hline 40 & Nokhundi & 41710 & $28^{\circ} 49^{\prime}$ & $62^{\circ} 45^{\prime}$ & 682 & 1932 & 39.8 & 0.15 & 25.66 & 0.27 \\
\hline 41 & Padidan & 41746 & $26^{\circ} 51^{\prime}$ & $68^{\circ} 8^{\prime}$ & 46 & 1941 & 116.53 & -0.9 & 27.32 & 0.16 \\
\hline 42 & Panjgur & 41739 & $26^{\circ} 58^{\prime}$ & $64^{\circ} 6^{\prime}$ & 980 & 1911 & 102.53 & -7.8 & 23.4 & 0.3 \\
\hline 43 & Parachinar & 41560 & $33^{\circ} 52^{\prime}$ & $70^{\circ} 5^{\prime}$ & 1725 & 1897 & 867.82 & 91.57 & 16.29 & -0.2 \\
\hline 44 & Pasni & 41759 & $25^{\circ} 16^{\prime}$ & $63^{\circ} 29^{\prime}$ & 4 & 1911 & 103.41 & -3.87 & 26.61 & 0.1 \\
\hline 45 & Peshawar & 41530 & $34^{\circ} 1^{\prime}$ & $71^{\circ} 35^{\prime}$ & 359 & 1866 & 460.42 & 38.67 & 24.04 & 0.17 \\
\hline 46 & Quetta & 41660 & $30^{\circ} 15^{\prime}$ & $66^{\circ} 53^{\prime}$ & 1600 & 1944 & 245.3 & -6.15 & 17.49 & 0.5 \\
\hline 47 & Shorkot & 41672 & $30^{\circ} 47^{\prime}$ & $72^{\circ} 12^{\prime}$ & 150 & 1967 & 277.15 & 19.1 & 26.01 & 0.18 \\
\hline 48 & Risalpur & 41533 & $34^{\circ} 4^{\prime}$ & $71^{\circ} 59^{\prime}$ & 315 & 1945 & 646.97 & 49.41 & 23.46 & 0.05 \\
\hline 49 & Rohri & 41725 & $27^{\circ} 42^{\prime}$ & $68^{\circ} 54^{\prime}$ & 66 & 1925 & 99.11 & 7.77 & 27.91 & 0.09 \\
\hline 50 & Saidu Sharif & 41523 & $34^{\circ} 44^{\prime}$ & $72^{\circ} 21^{\prime}$ & 961 & 1973 & 1041.87 & 12.91 & 20.54 & 0.01 \\
\hline 51 & Sargodha & 41594 & $32^{\circ} 3^{\prime}$ & $72^{\circ} 40^{\prime}$ & 187 & 1925 & 447.18 & 28.05 & 25.45 & 0.16 \\
\hline 52 & Sialkot & 41600 & $32^{\circ} 30^{\prime}$ & $74^{\circ} 32^{\prime}$ & 251 & 1881 & 974.23 & 19.77 & 24.1 & 0.14 \\
\hline 53 & Sibbi & 41697 & $29^{\circ} 33^{\prime}$ & $67^{\circ} 53^{\prime}$ & 133 & 1925 & 164.15 & 12.66 & 27.63 & 0.2 \\
\hline 54 & Sakardu & 43517 & $35^{\circ} 18^{\prime}$ & $75^{\circ} 41^{\prime}$ & 2209 & 1952 & 224.28 & 10.2 & 13.56 & 0.09 \\
\hline 55 & Zhob & 41620 & $31^{\circ} 21^{\prime}$ & $69^{\circ} 28^{\prime}$ & 1405 & 1938 & 288.39 & -5.44 & 20.55 & 0.13 \\
\hline
\end{tabular}

Note: The annual rainfall average and annual rainfall trend have been calculated for the periods 1961-2010 and 1961-2018, respectively. Source: CDPC, PMD, Karachi. 


\section{CHANGES OBSERVED IN PAKISTAN'S CLIMATE}

\section{CHANGES IN TEMPERATURE}

Increased Warming. Pakistan's temperatures have warmed considerably since the early 1960s, with more warming in daytime maximum temperature than nighttime minimum temperature. Analysis of data for the period 1961-2018 reveals that annual mean temperature for the country as a whole has risen by $0.74^{\circ} \mathrm{C}$ over the last 58 years (Figure 1.8). The rise in the latter half of this period is very prominent $\left(0.67^{\circ} \mathrm{C}\right.$ ). It is pertinent to mention that, compared to the period 1961-90, annual mean temperature has generally been above normal since 1998-in fact, 18 of the last 21 years have seen above-normal annual mean temperatures (Figure 1.9).

Figure 1.8 Annual temperature trends in Pakistan, 1961-2018, 1961-89, and 1990-2018

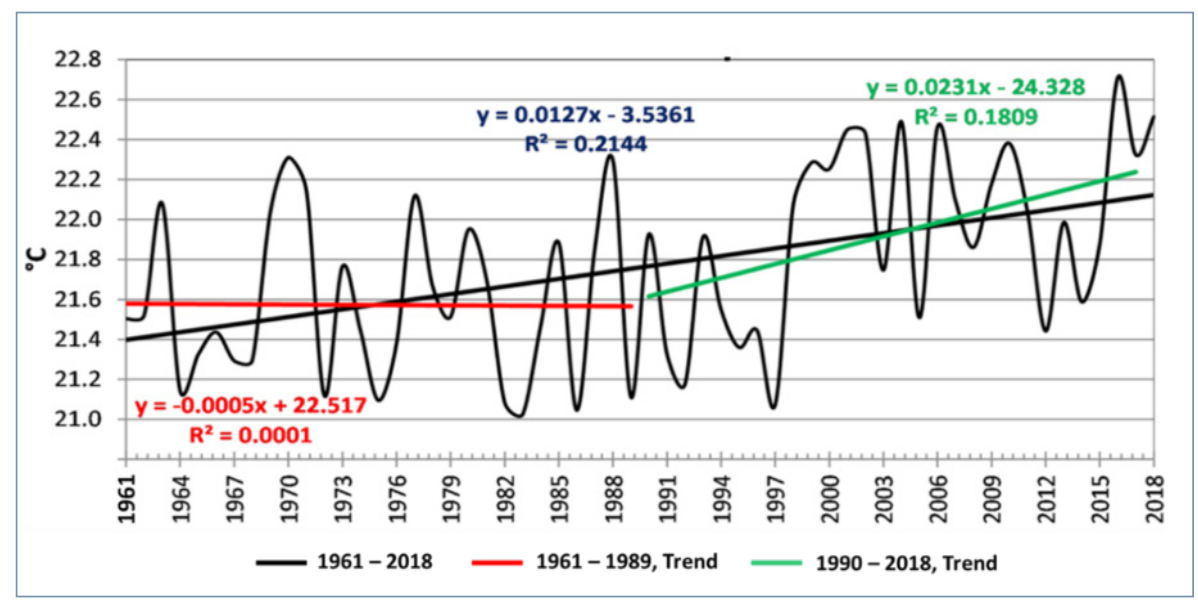

Source: CDPC, PMD, Karachi.

Figure 1.9 Annual mean temperature anomalies in Pakistan, 1961-2018 (Reference period 1961-1990)

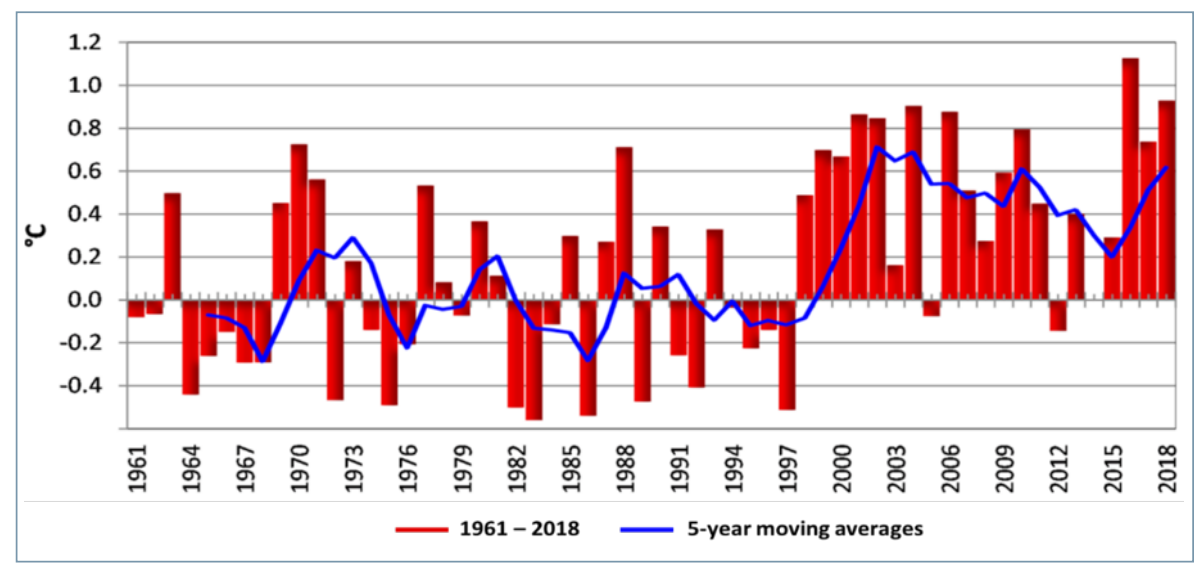

Note: The blue curve shows 5-year moving averages.

Source: CDPC, PMD, Karachi. 
Regional Pockets of Greater Warming. This warming is primarily the result of a rise in maximum temperature across the country, as observed at the majority of observation stations included in our dataset. Figure 1.10 shows the spatial pattern of mean annual temperature changes across Pakistan from 1961 to 2018. Warming is apparent over almost the entire country, and it is greater over major parts of Balochistan, in southeastern and southwestern Sindh, and in eastern parts of Punjab.

Figure 1.10 Spatial distribution of mean annual temperature trends, 1961 to 2018 ( ${ }^{\circ} \mathrm{C} /$ decade)

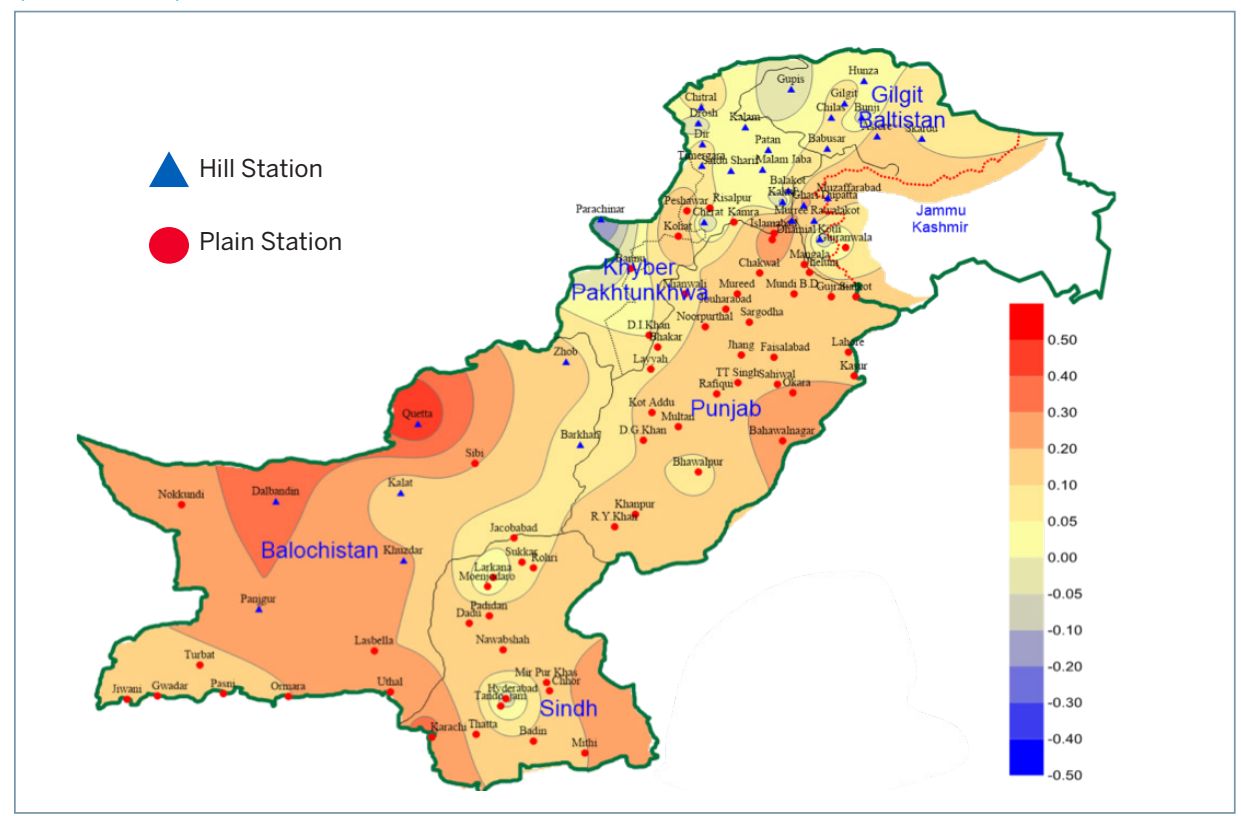

Source: CDPC, PMD, Karachi.

Increase in High-Temperature Extremes. The mean temperature changes have been accompanied by a large increase in extreme temperatures. Since 2011, the number of extreme heat records in Pakistan has significantly increased. The frequency of very warm months (May-August) has increased manifold in the recent decade. While high-temperature extremes have increased significantly, low-temperature extremes are less frequent (Figure 1.11).

Overall, annual hot days have increased by 14 days while annual cold nights have decreased by two days. However, local trends vary greatly. For example, the number of annual hot days increased by 10 days in Karachi and Khuzdar but decreased by 4-5 days in the Badin and Bunji area. Similarly, incidence of cold nights has increased in the Parachinar, Skardu, and Gupis area, but decreased by 14 days in Sibbi, and by 13 days in both Quetta and Kakul. 
Figure 1.11 Trends in the annual number of hot days (maximum temperature $>35^{\circ} \mathrm{C}$ ) (left) and cold nights (minimum temperature $<10^{\circ} \mathrm{C}$ )(right), 1961-2018

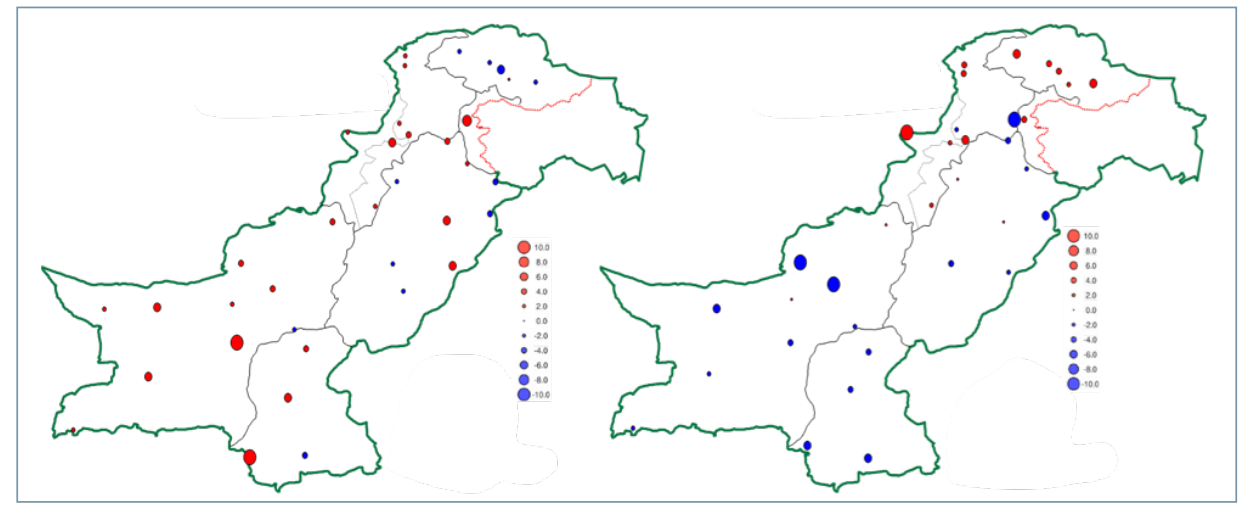

Source: CDPC, PMD, Karachi.

\section{CHANGES IN RAINFALL}

Compared to temperature changes, it is a more difficult task to attribute observed regional rainfall changes to climate change. This is because of the large "normal" variability of rainfall in Pakistan from year to year and decade to decade.

Annual Rainfall. For the country as a whole, average annual rainfall shows an increase of $19 \%$ over the period 1961-2018. However, while there is an overall increase, when the first and second halves of this period (i.e., 1961-1989 and 1990-2018) are compared, there is quite a contrast in annual rainfall behavior. As Figure 1.12 shows, average annual rainfall increased in the earlier period but shows a decreasing trend in the latter half.

Figure 1.12 Changes in annual rainfall trend in Pakistan during 1961-2018, 1961-89, and 1990-2018

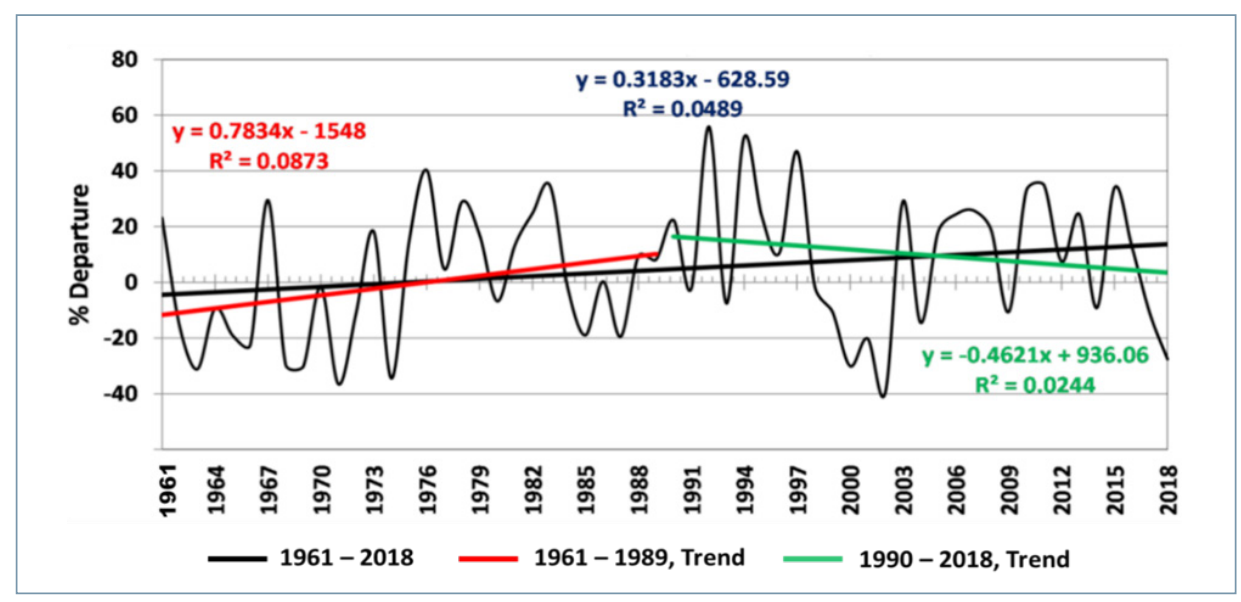

Source: CDPC, PMD, Karachi. 
Figure 1.13 illustrates the spatial distribution of linear annual rainfall trends over the country from 1961 to 2018, while Figure 1.14 depicts the change in annual rainfall between $1961-89$ and 1990-2018. The figures show that in most parts of the country, there is either no change in average annual rainfall or a slight increase. However, a decline in annual rainfall is evident in the southernmost parts of the country and also in the northeastern region of AJK and adjoining areas in the second half of the study period (1990-2018).

Figure 1.13 Spatial distribution of total annual rainfall trends, 1961 to 2018 ( $\mathrm{mm} /$ decade)

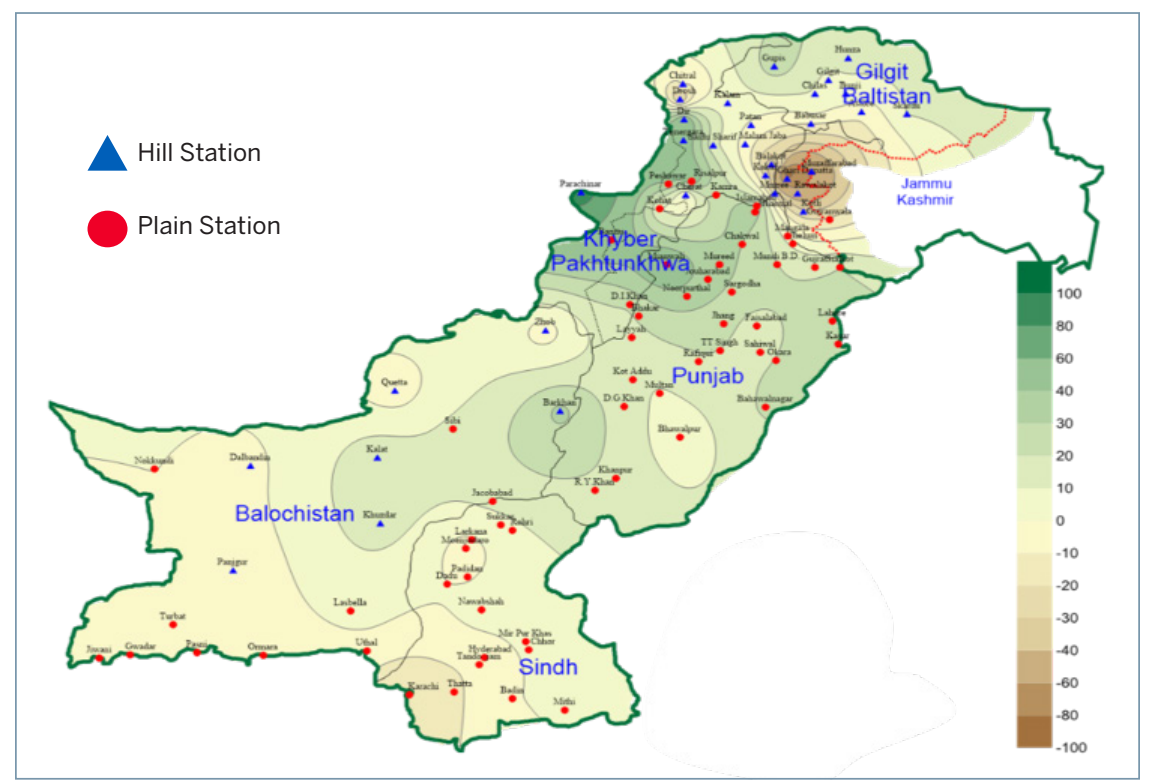

Source: CDPC, PMD, Karachi.

Figure 1.14 Difference in average annual rainfall between 1961-1989 and 1990-2018 (mm)

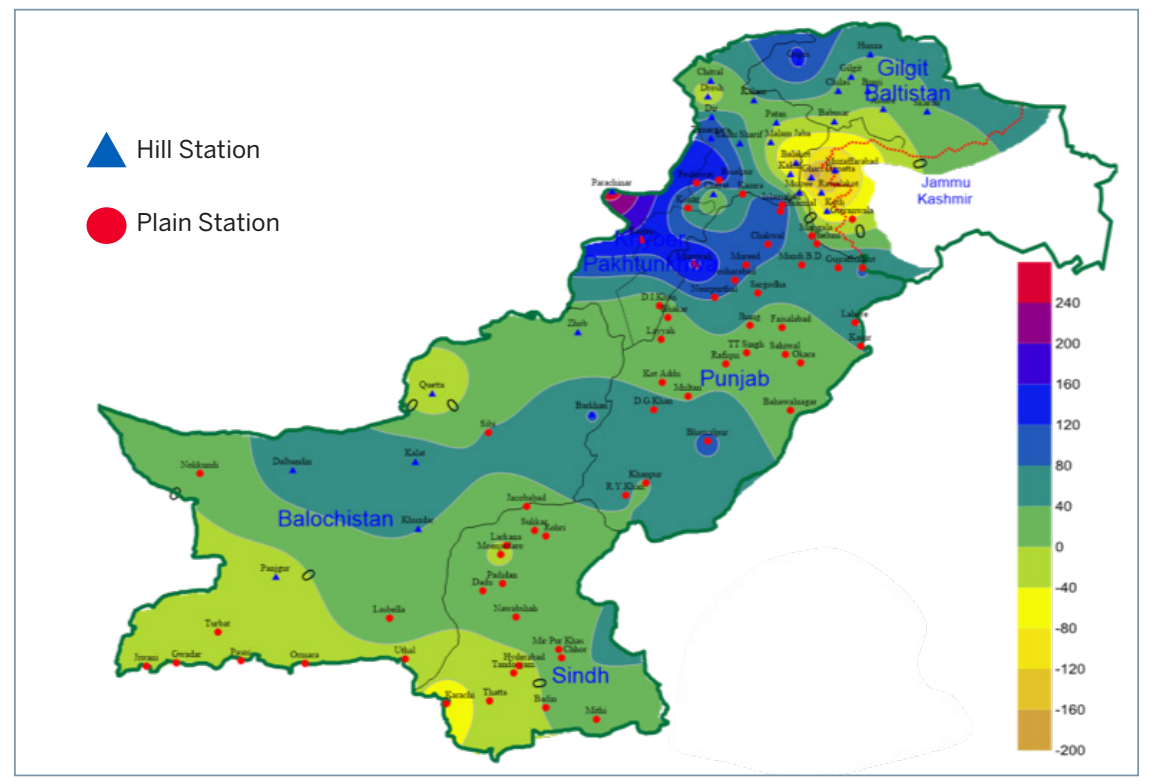

Source: CDPC, PMD, Karachi. 
Figure 1.15 provides a closer look at trends in annual rainfall in the four provinces (Punjab, Sindh, KP, and Balochistan) and two administrative regions (AJK and Gilgit-Baltistan [GB]) of the country. In AJK, a decreasing trend is prominent, especially in the latter half of the study period. In Balochistan, there is an increase in annual rainfall over 1961-2018, but while there is an increasing trend in the first half of the study period the second period shows a decreasing trend. Significant increases are observed in annual rainfall in both KP and Punjab over the study period, but they are far sharper in the first half of the study period. In Sindh, there is no significant change in annual rainfall over the study period, although a slight decreasing trend is evident in the latter half. Annual rainfall has also increased in GB.

Figure 1.15 Annual rainfall trends in the six administrative regions of Pakistan during 1961-2018, 1961-89, and 1990-2018

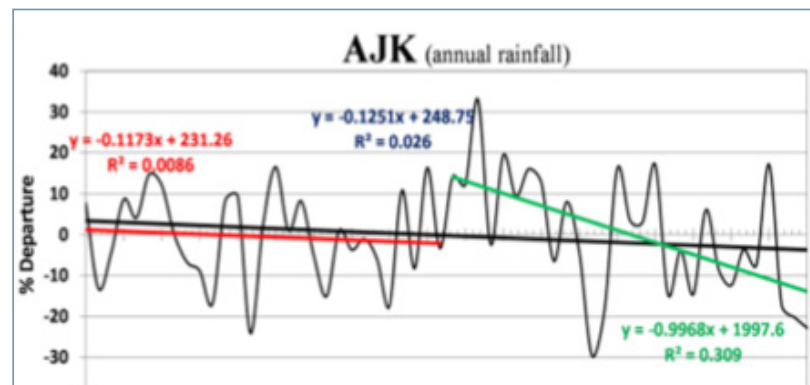

豆

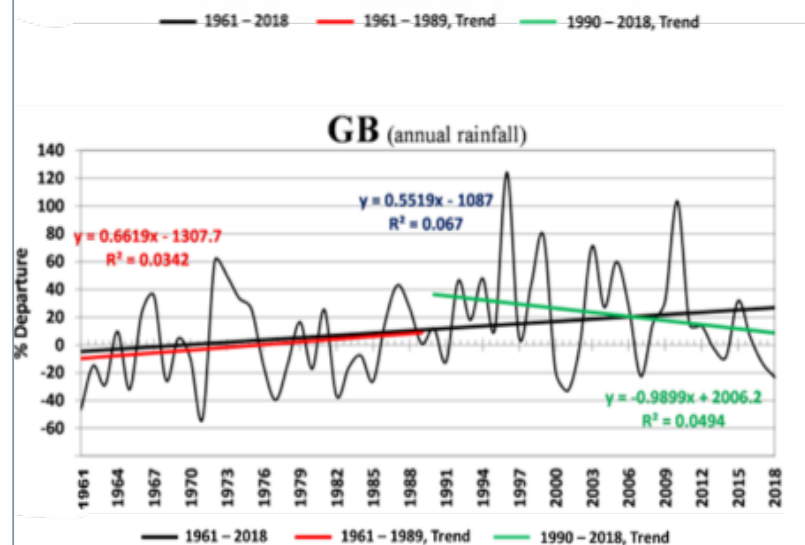

— 1961-2018 — 1961-1989, Trend — 1990-2018, Trend

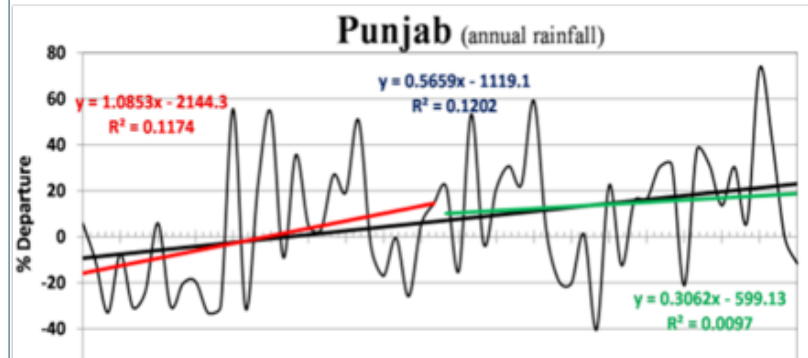

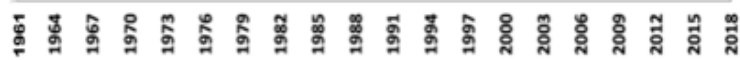
— 1961-2018 — 1961-1989, Trend - 1990-2018, Trend
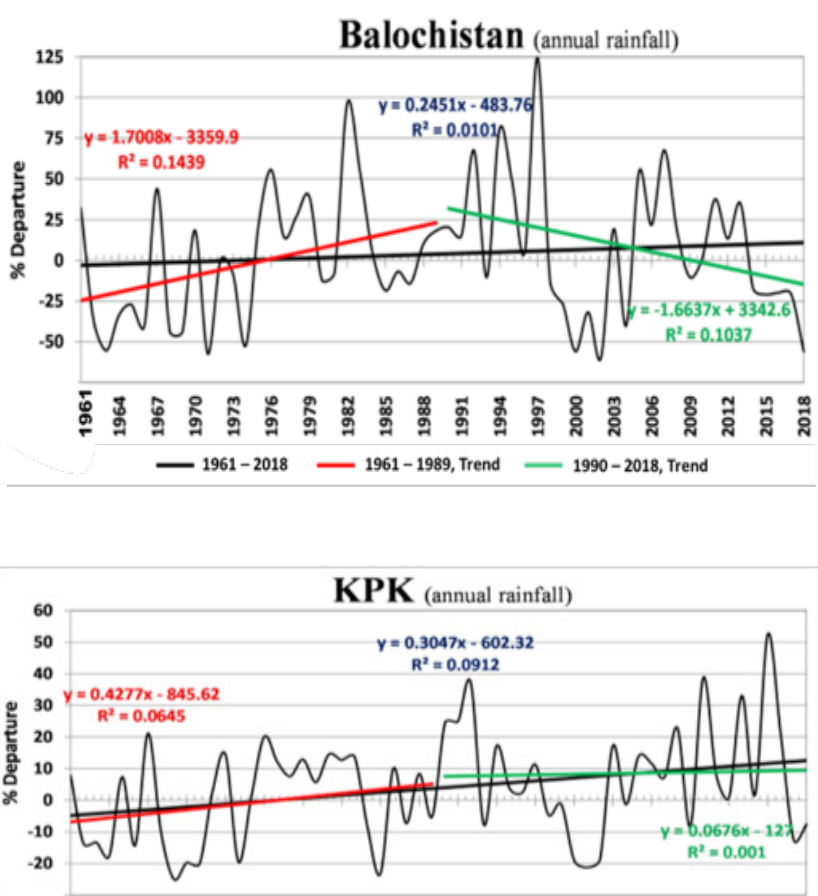

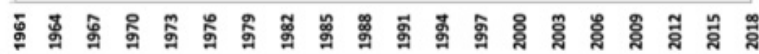
— $1961-2018-1961-1989$, Trend -1990 - 2018, Trend

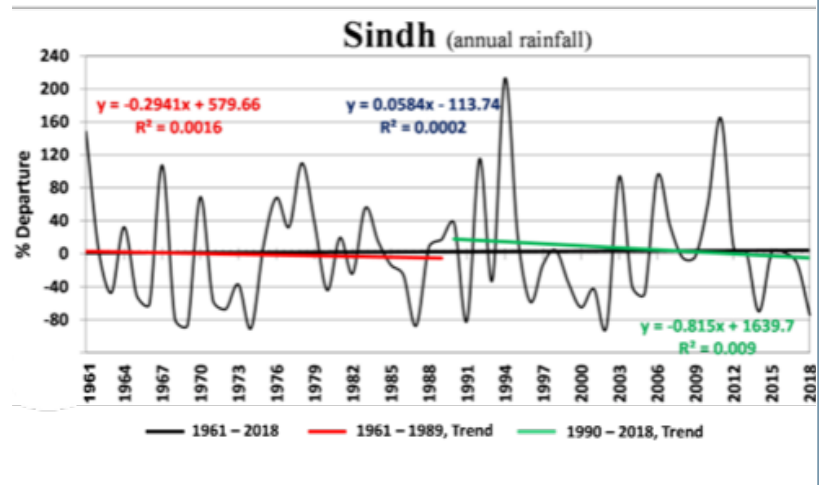

Source: CDPC, PMD, Karachi. 
Seasonal Rainfall. Seasonal rainfall in Pakistan has large spatial as well as temporal variability. Long-term winter (Jan-Mar) rainfall in the country depicts no changing trend for the overall study period. However, it does show an increasing trend in the first half and a decreasing trend in the second half of this period (Figure 1.16). On the other hand, long-term monsoon (Jul-Sep) rainfall exhibits a slight increasing trend over the study period, mainly in the first half (Figure 1.17). Overall, between 1961 and 2018, annual winter rainfall in Pakistan has increased by $11 \%$ and monsoon rain by $18 \%$.

Figure 1.16 Winter rainfall trend in Pakistan during 1961-2018, 1961-89, and 1990-2018

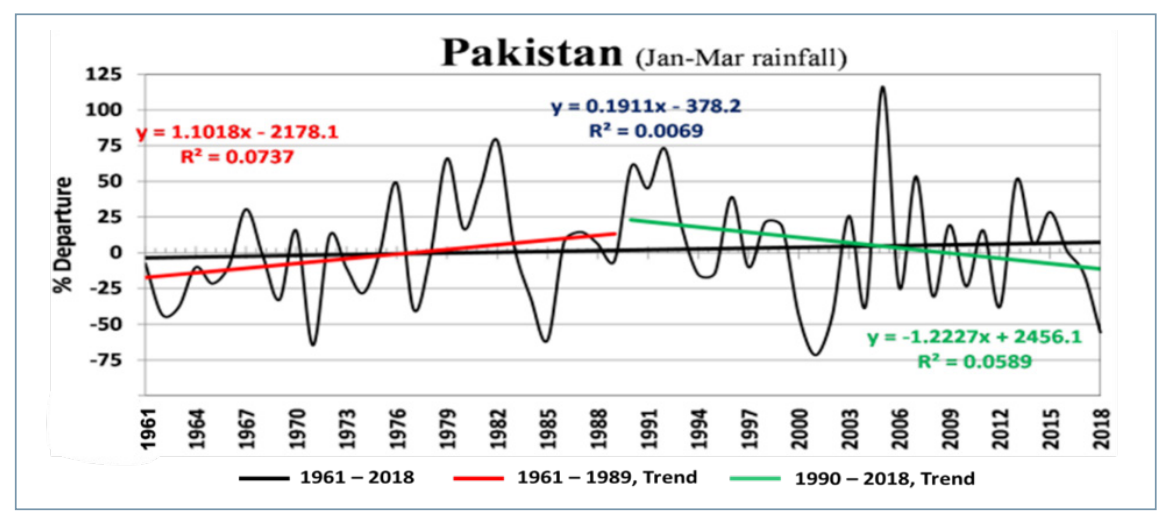

Source: CDPC, PMD, Karachi.

Figure 1.17 Monsoon rainfall trend in Pakistan during 1961-2018, 1961-89, and 1990-2018

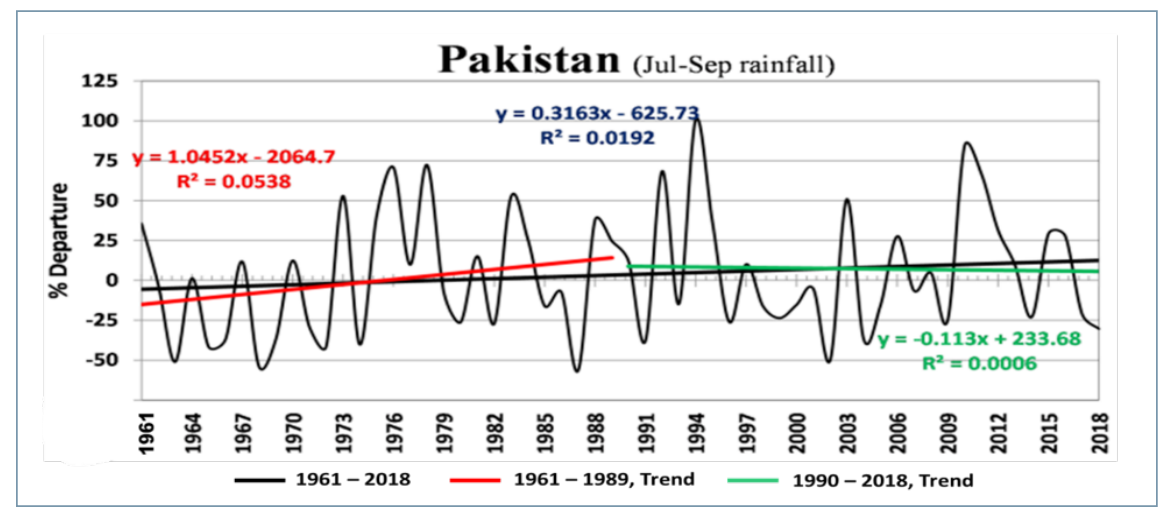

Source: CDPC, PMD, Karachi. 
In terms of regions, the amount of both winter and monsoon rainfall has increased significantly in GB, KP, and Punjab during the period 1961-2018 (Figure 1.18). However, changes in the amount of rainfall in Balochistan and AJK have been insignificant. It is pertinent to note the major decrease in the amount of winter rainfall in Sindh.

Figure 1.18 Major seasonal rainfall trends in Pakistan, by region

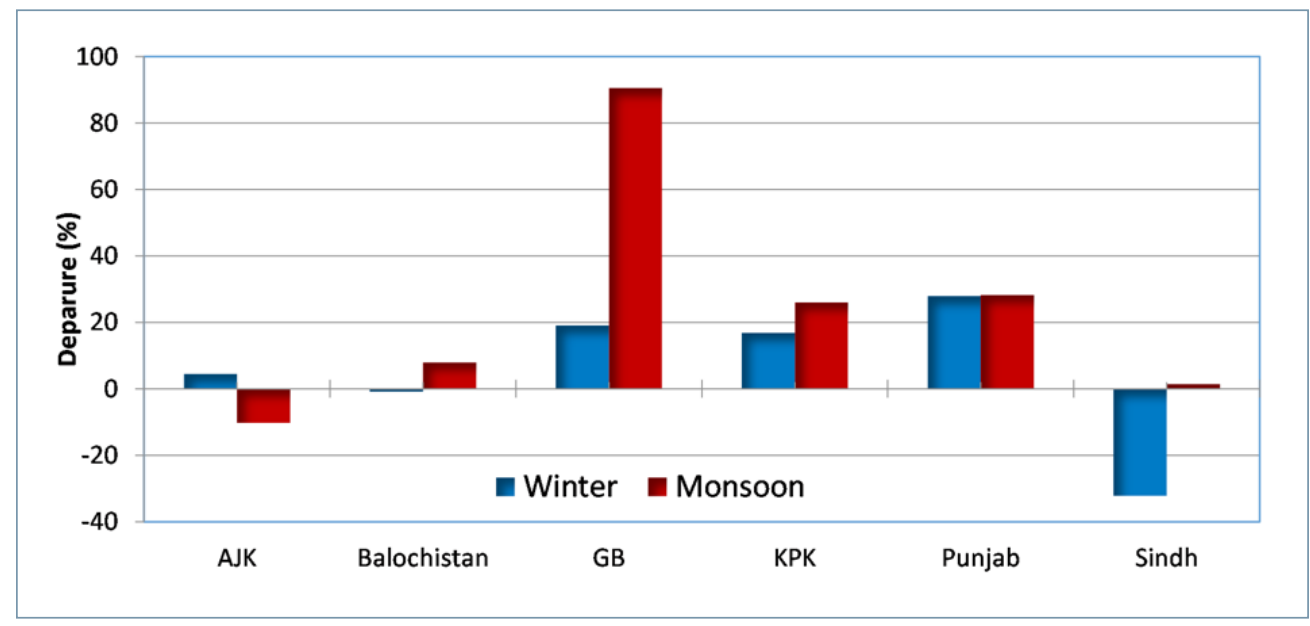

Source: CDPC, PMD, Karachi.

Increase in Heavy Rainfall. Globally, incidence of extremes of heavy precipitation is on the rise. An increase in the proportion of heavy rainfall is also evident in Pakistan. As Figure 1.19 shows, the number of "extreme rain" or "wet" days (defined as a 24-hour period in which rainfall exceeds $30 \mathrm{~mm}$ ) has increased considerably in the second half of the study period. For the country as a whole, wet days increased by two over the period 1961-2018 and by three in the period 1990-2018. Figure 1.20 shows the spatial distribution of trends in the frequency of wet days across the country.

Figure 1.19 Frequency of wet days (24-hour rain > $30 \mathrm{~mm}$ ) per year in Pakistan during 1961-2018, 1961-89, and 1990-2018

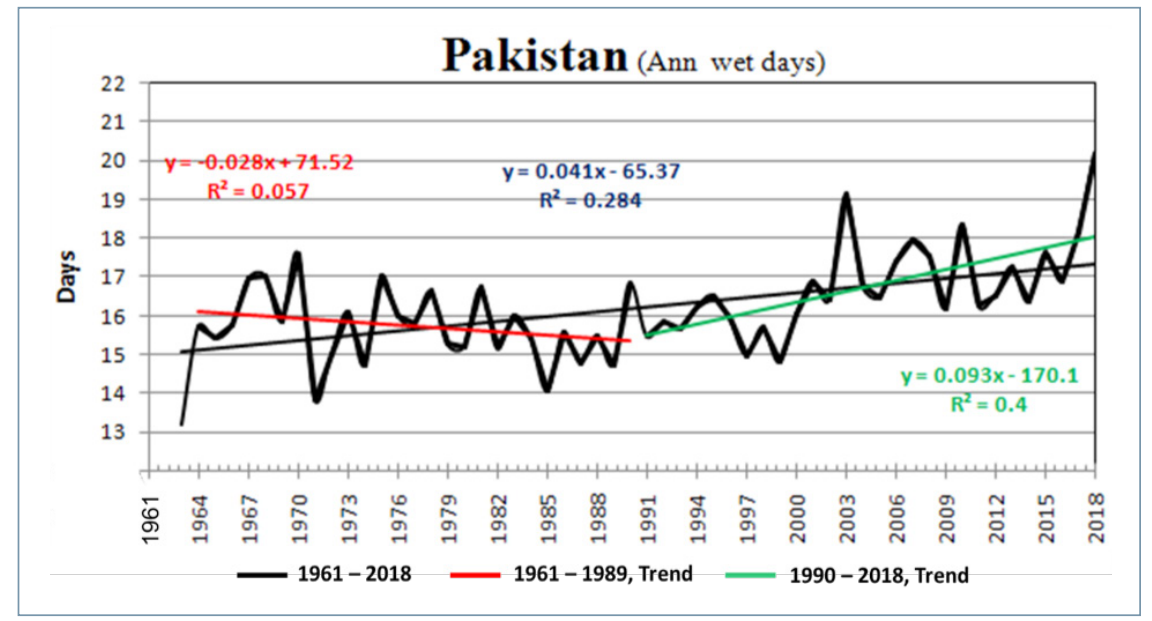

Source: CDPC, PMD, Karachi. 
Figure 1.20 Spatial distribution of heavy precipitation event (24-hour rain > 30) trends, 1961-2018

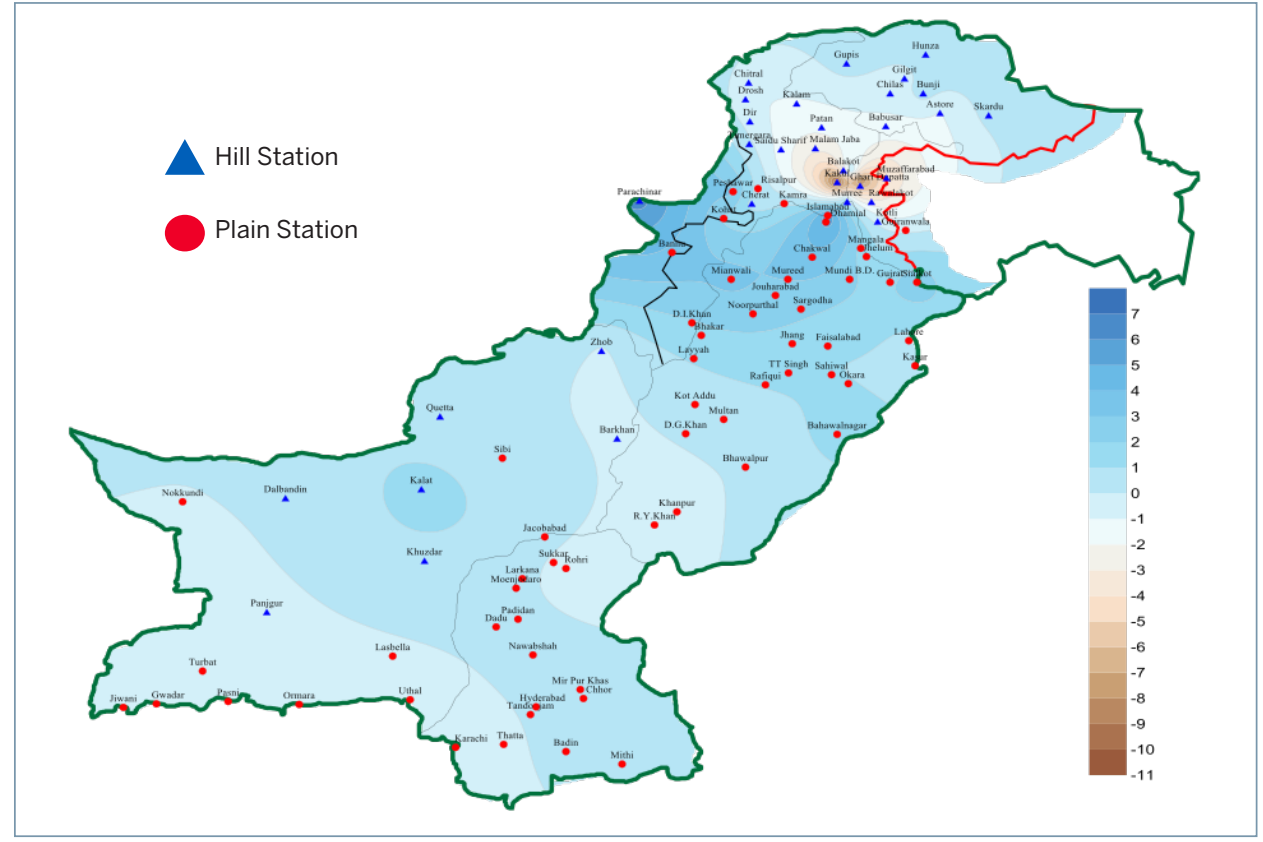

Source: CDPC, PMD, Karachi.

\section{CHANGES IN SNOWFALL}

Accumulation of seasonal snow is a critical weather element as changes in it directly impact the availability of fresh water in mountains, riverbeds, and plain areas of the country for drinking, irrigation, and hydropower generation. Of the 55 observation stations included in this study, 13 are hill stations in areas that receive snow. Analysis of snow depth data, available for the period 2007-18, indicates a significant declining trend (Figure 1.21).

Figure 1.21 Trend in average annual snow depth in Pakistan, 2007-2018

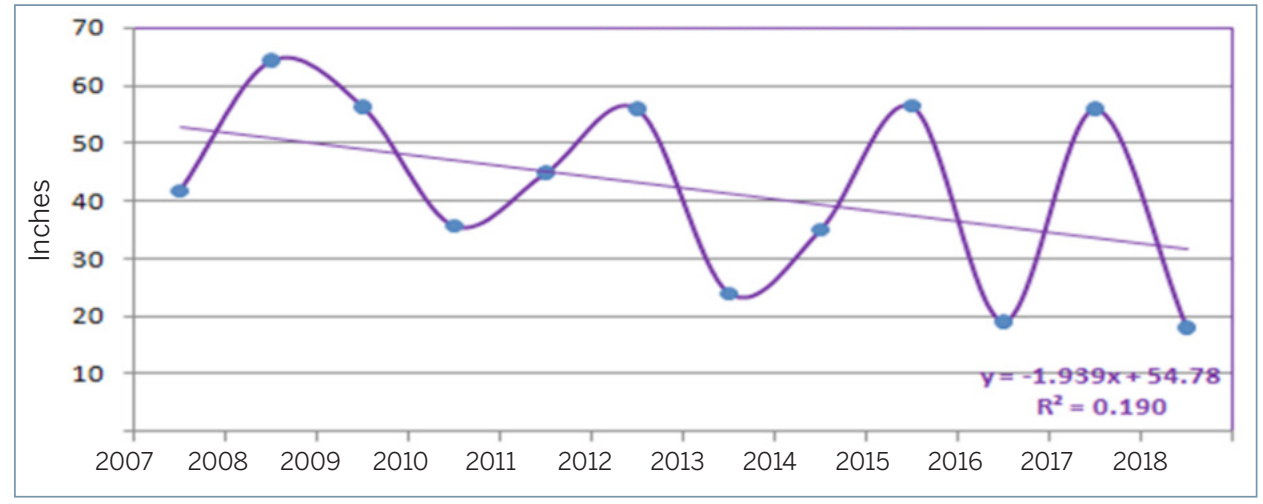

Source: CDPC, PMD, Karachi. 
Between 1960 and 2018, the annual number of snow days has been decreasing considerably in Parachinar, Astore, Murree, Skardu, Chitral, and Drosh (Figure 1.22). The analysis reveals that snowfall has decreased in most snow-receiving areas of the country. Because of the rise in temperature, more winter precipitation is occurring in the form of rain rather than snow.

Figure 1.22 Trends in annual average snow days in Pakistan, 1961-2018 (days/decade)

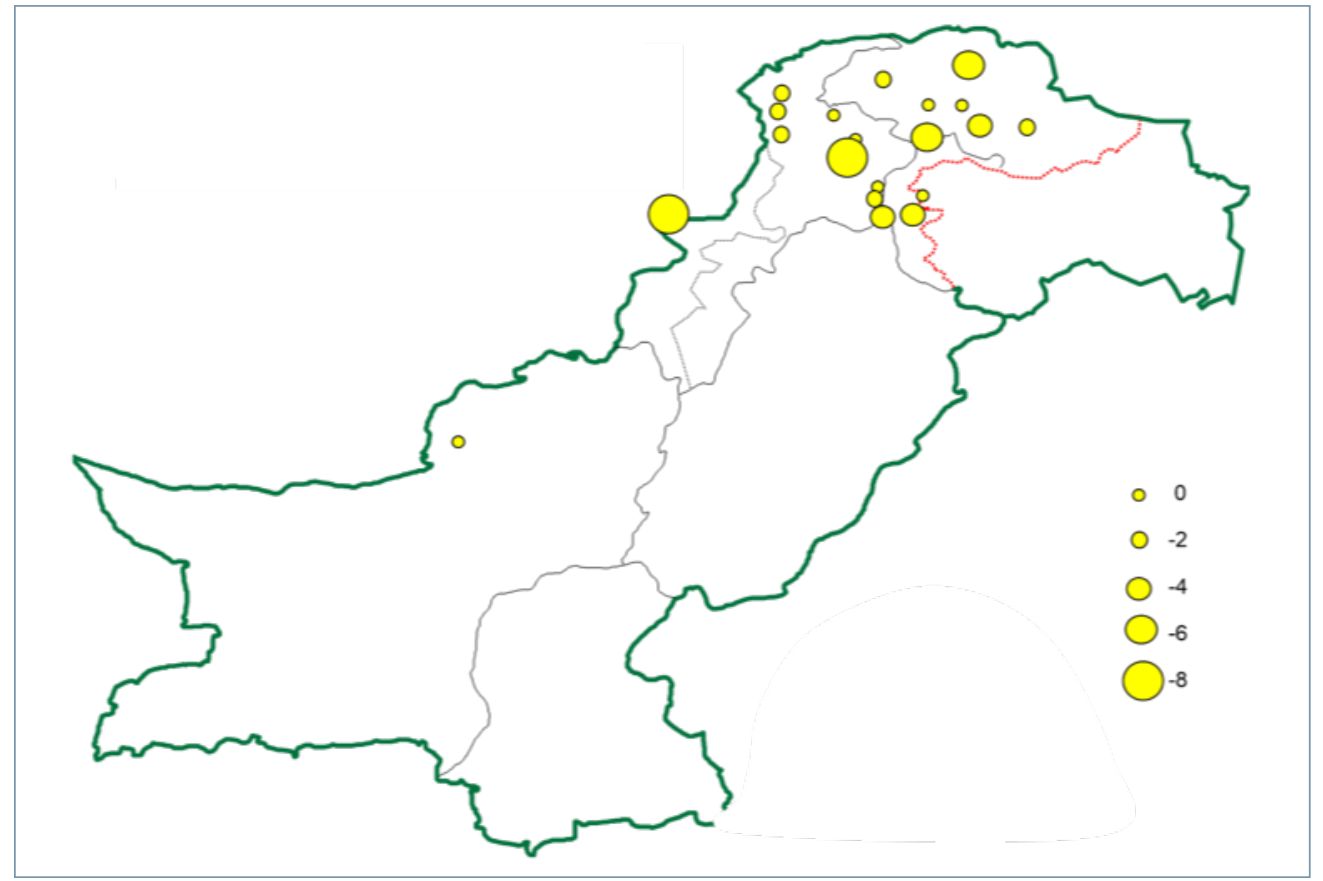

Source: CDPC, PMD, Karachi

\section{CHANGES IN THE CLIMATE OF MAJOR CITIES}

Analysis of climate data for major cities reveals a significant increasing tendency of annual mean temperature between 1961 and 2018. The highest increase is seen in the southern cities of Quetta (in Balochistan), at $+0.50^{\circ} \mathrm{C}$ per decade, followed by Karachi (in Sindh), where the annual mean temperature has risen by $+0.32^{\circ} \mathrm{C}$ per decade. The northernmost cities, Muzaffarabad (in AJK) and Gilgit (in GB), have experienced the least increase at $+0.02^{\circ} \mathrm{C}$ per decade and $+0.10^{\circ} \mathrm{C}$ per decade, respectively (Figure 1.23).

On the other hand, the tendency of rainfall is somewhat mixed. Annual total rainfall has increased the most in Peshawar (+39 mm/decade), followed by Islamabad (+37 mm/decade) and Lahore (+26 mm/decade), while it has declined in Muzaffarabad ( $-19 \mathrm{~mm} /$ decade) and Karachi ( $-17 \mathrm{~mm} /$ decade). 
Figure 1.23 Trends in annual mean temperature $\left({ }^{\circ} \mathrm{C} / \mathrm{decade}\right)$ and average annual rainfall (mm/decade) in major cities of Pakistan, 1961-2018
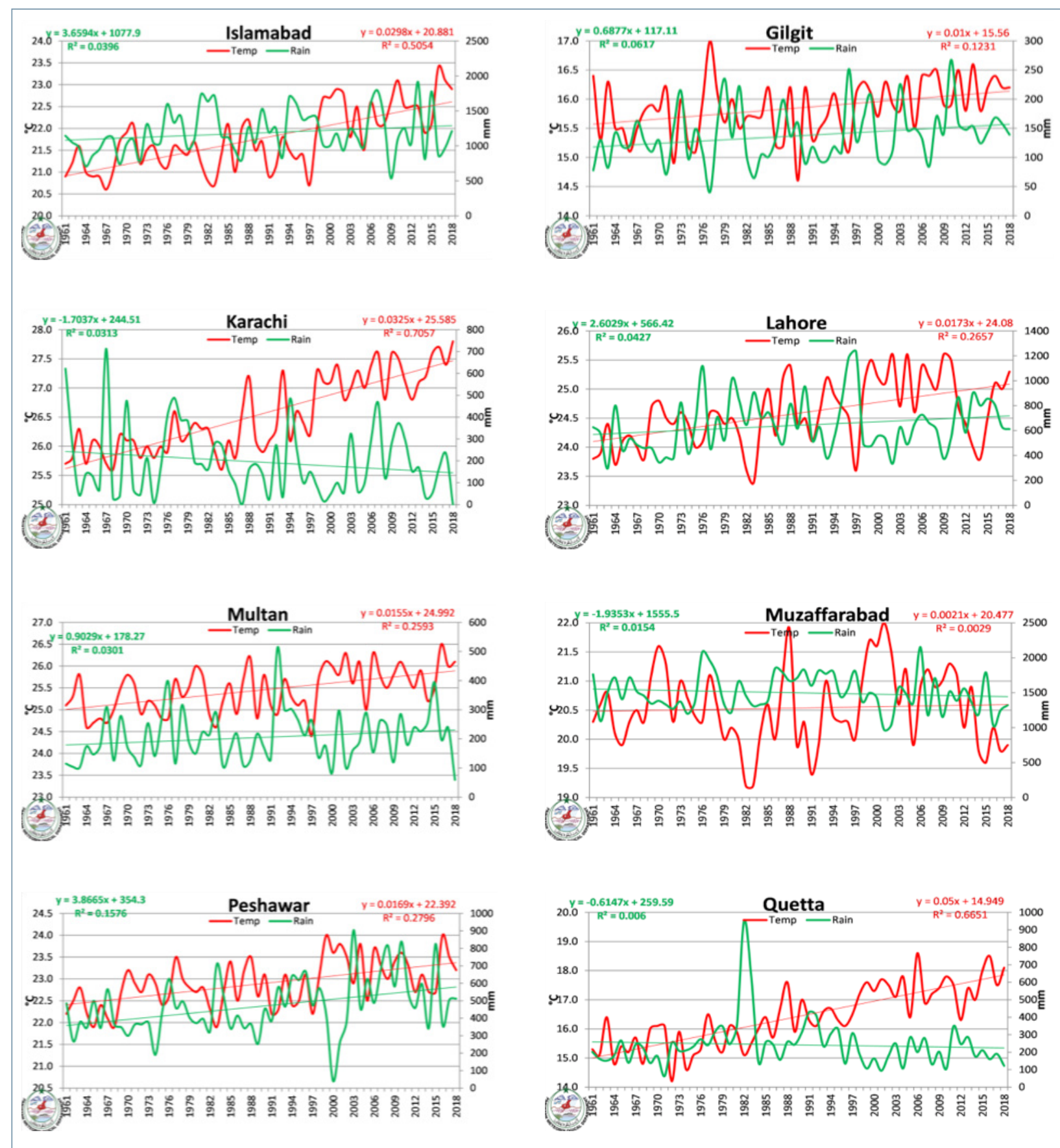

Source: CDPC, PMD, Karachi 


\section{ENVIRONMENTAL STRESSES}

The changes in temperature and precipitation discussed above are linked to a number of environmental stresses in Pakistan. The most prominent of these include heat waves, heavy rains, intense floods, droughts, rising sea level, and cyclones.

\section{HEAT WAVES}

Pakistan experienced its hottest recorded daytime temperature of $54.0^{\circ} \mathrm{C}$ on May 28,2017 in Turbat. The previous record of $53.5^{\circ} \mathrm{C}$ had been set not too long ago, on May 27, 2010, in Mohenjo-daro. With increased intensity and frequency of high-temperature extremes, the risk of heat waves has risen in Pakistan. Like the rest of the world, the country saw its most severe heat wave within the current decade, specifically in June 2015, which caused a high number of casualties, especially in Karachi.

In 2018, exceptionally hot conditions affected the southern half of Pakistan, starting in late March, when the record for previous highest temperature in the month was broken at 34 sites (Figure 1.24). Most PMD observing stations in the southern part of the country recorded temperatures between $40^{\circ} \mathrm{C}$ and $45^{\circ} \mathrm{C}$, making it the fourth hottest month on record since 1961.

Figure 1.24 Location of weather stations where record-breaking maximum temperatures for March were recorded on 30-31 March 2018

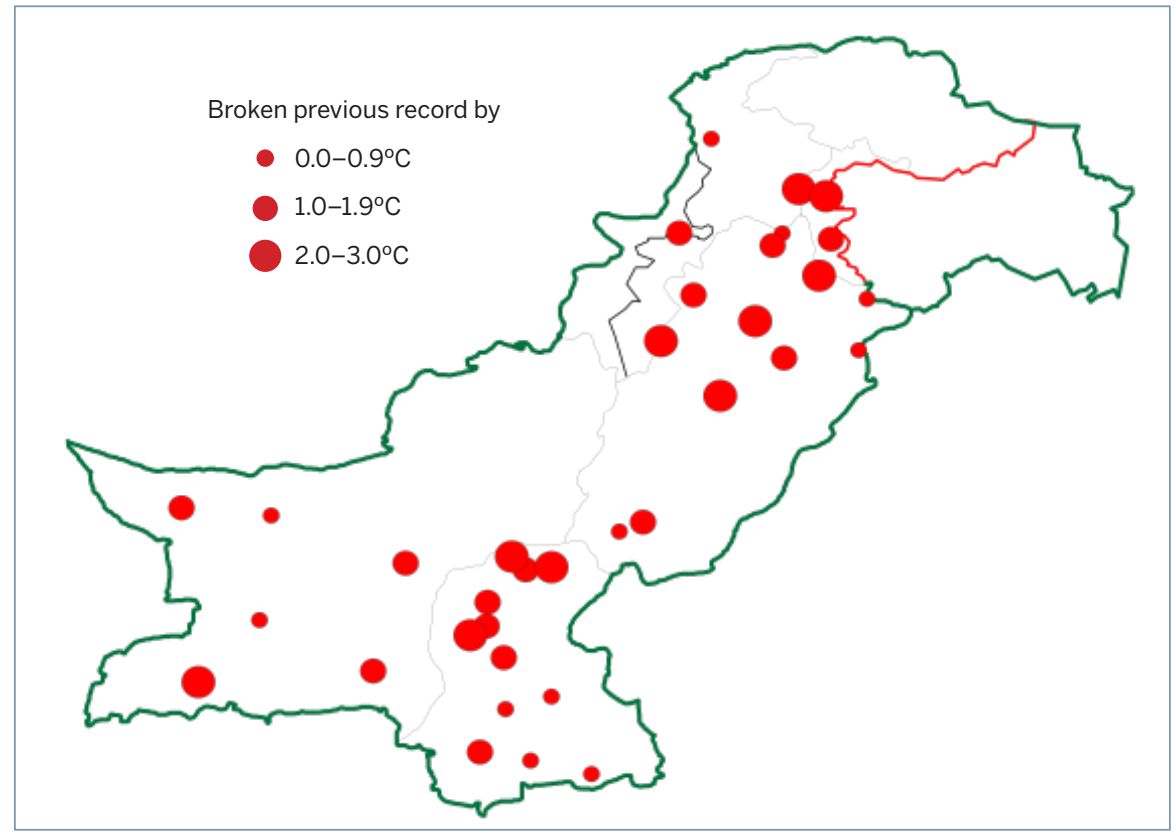

Note: In the map, the size of the circular marker indicates the margin by which the previous record was broken.

Source: CDPC, PMD, Karachi. 


\section{EXTREME PRECIPITATION, FLOODS, AND DROUGHTS}

In all parts of the world, precipitation, floods, and droughts vary naturally from year to year and from decade to decade. Droughts and floods are hydrological extremes which occur due to lack of rainfall and surplus rain, respectively. Floods result from persistent and prolonged rainfall or a heavy amount of rainfall in a short span of time. Additional flood risks have arisen in Pakistan due to the acceleration in the melting of glaciers in the northern areas as a result of rising temperatures. Once generated, floods can cause large-scale havoc regardless of the rainfall history of the area they inundate (Rasul 2012). In addition, because warm air can hold more moisture, it is likely that climate change has influenced the occurrence and intensity of extreme precipitation events. Greater warmth also speeds up the hydrological cycle, which should contribute to both heavier rainfall and increased evaporation.

Global average land-surface precipitation in 2001-10 was above the 1961-90 average. In fact this period was the second-wettest decade since 1901, after the 1950s. According to a WMO survey, floods were the most frequently experienced extreme event over the course of the decade. Eastern Europe was particularly affected in 2001 and 2005, India in 2005, Africa in 2008, and Asia (notably Pakistan) in 2010 (WMO 2013).

Figure 1.25 shows the extent to which annual rainfall varied from its normal level in Pakistan between 1961 and 2018. The variation is linked to the incidence of floods and droughts.

Figure 1.25 Percentage departure of annual rainfall in Pakistan, 1961-2018

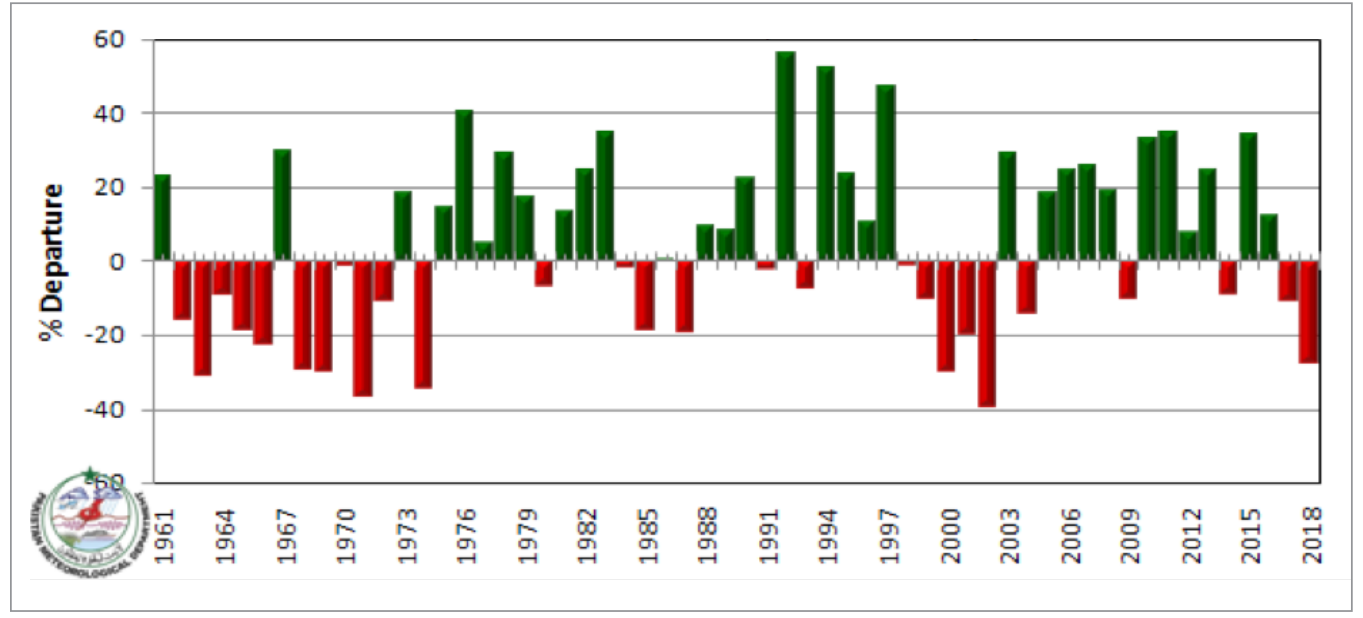

Source: CDPC, PMD, Karachi.

Pakistan received above-normal (1961-90) rainfall in the decade 2000-10. In 2010, the country experienced one of the worst cases of flooding in its history as a result of exceptionally heavy monsoon rains. The event caused some 2,000 casualties and affected more than 20 million people. Other years in which the country faced severe flooding include (in decreasing order of severity) 2015, 1983, 2011, 1976, 1997, 1994, and 1992.

Droughts develop slowly and extend over regions of low rainfall. Pakistan has experienced three major dry periods over the last 58 years, including in 1962-66, 1968-72, and 1999-2002. At the national level, 2018 was the eighth driest year in Pakistan since 1961; annual average rainfall was $207.2 \mathrm{~mm}, 34 \%$ below the normal (1981-2010) annual average value of $312.2 \mathrm{~mm}$. This was also the fifth consecutive year in which dry conditions prevailed in the southwest of the country (Balochistan province), with rainfall less than $62 \%$ of the normal amount. 


\section{TROPICAL CYCLONES}

Tropical cyclones affecting Bangladesh, India, and Pakistan have all developed in the Bay of Bengal. Occasionally, a few of these reached Pakistan's coastal area while moving westward. These cyclones occurred primarily in the pre-monsoon (May-June) and post-monsoon (October-December) period.

In recent years, however, cyclogenesis has become more frequent in the North Arabian Sea as a result of its favorable thermal regime (Baig and Rasul 2008). Although analysis for the period 1961 to 2018 depicts no statistically significant trend in the total number of cyclones in the Arabian Sea region (Figure 1.26), the number of cyclones approaching Pakistan in the near past has increased significantly. During 1999-2018, four tropical cyclones crossed or nearly landed on the country's coast (JTWC 2019), including Cyclone 02-A (May 15-21, 1999), Cyclone 01-A (May 21-22, 2001), Cyclone Yemyin (June 20-27, 2007), and Cyclone Phet (May 30-June 7, 2010), highlighting the vulnerability of Pakistan's coastal areas to cyclones and storm surges. Cyclone 02-A was one of the most intense to develop over the Arabian Sea; according to press reports, 700 people were reported missing during this event and presumed dead, including 11 paramilitary soldiers who were lost during a rescue attempt at sea. Similarly, Cyclone Yemyin resulted in torrential rains in at least 10 districts of Balochistan and four districts of Sindh, killing over 600 people and affecting the lives of 1.5 million.

Figure 1.26 Location of weather stations where record-breaking maximum temperatures for March were recorded on 30-31 March 2018
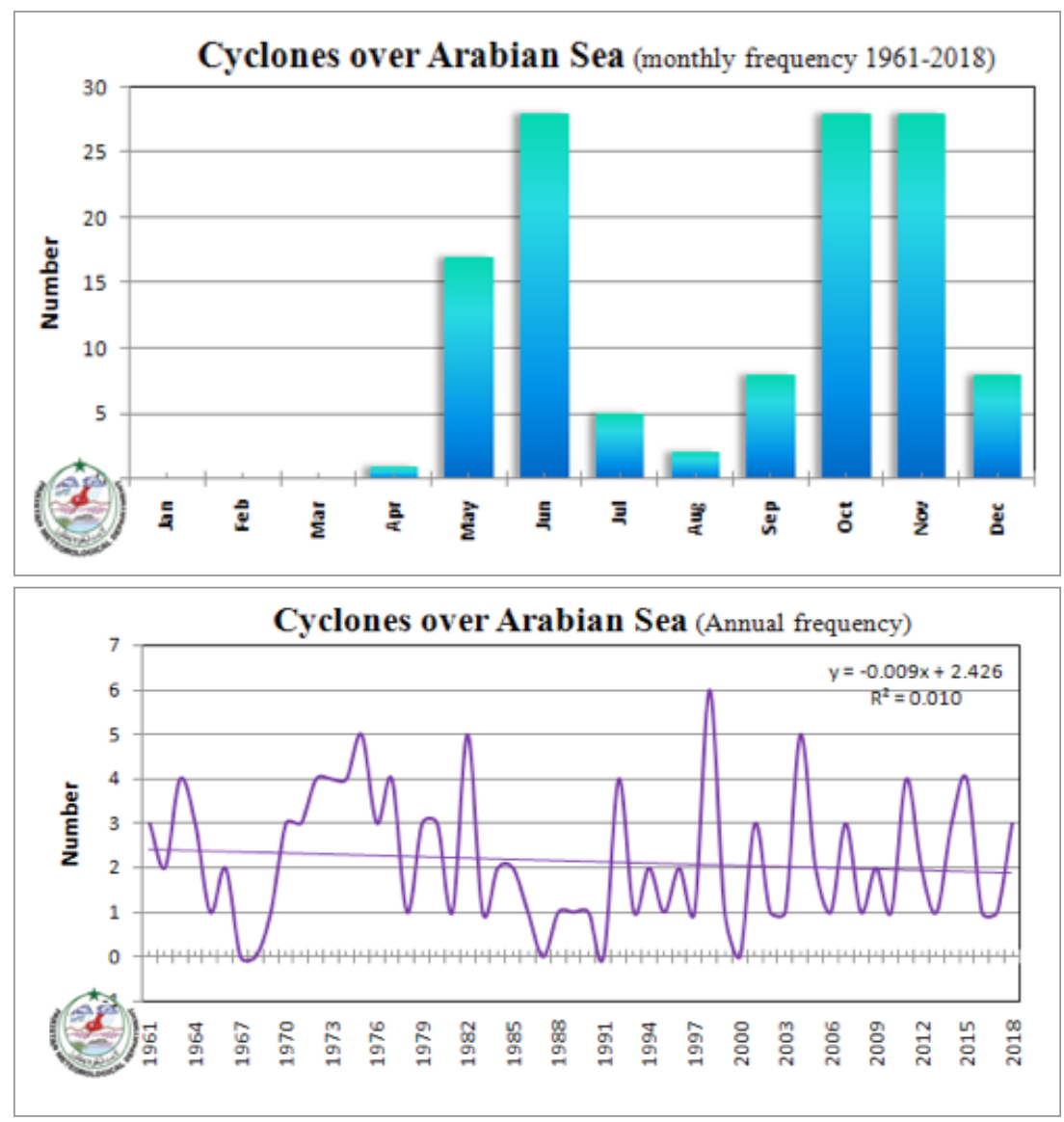

Source: JTWC 2019. 


\section{SEA LEVEL RISE}

The average global sea level has been rising over the past century, and the rate at which it is doing so has increased in recent decades to about one-eighth of an inch per year. The two major causes of global sea level rise are thermal expansion, caused by warming of the ocean (since water expands as it warms), and increased melting of land-based ice, such as glaciers and ice sheets. The oceans are absorbing more than $90 \%$ of the increased atmospheric heat associated with emissions from human activity (NOAA 2019). As in other parts of the world, there is evidence of sea level rise along the coastal areas of Pakistan. Analysis of sea level data recorded at Karachi for the period 1906-2016 reveals that the sea level has risen at the rate of 2.02 millimeters per year, for a total of 220.24 centimeters ( 7.97 inches) in 110 years (Figure 1.27).

Figure 1.27 Monthly mean sea level at Karachi, Pakistan from 1906 to 2017

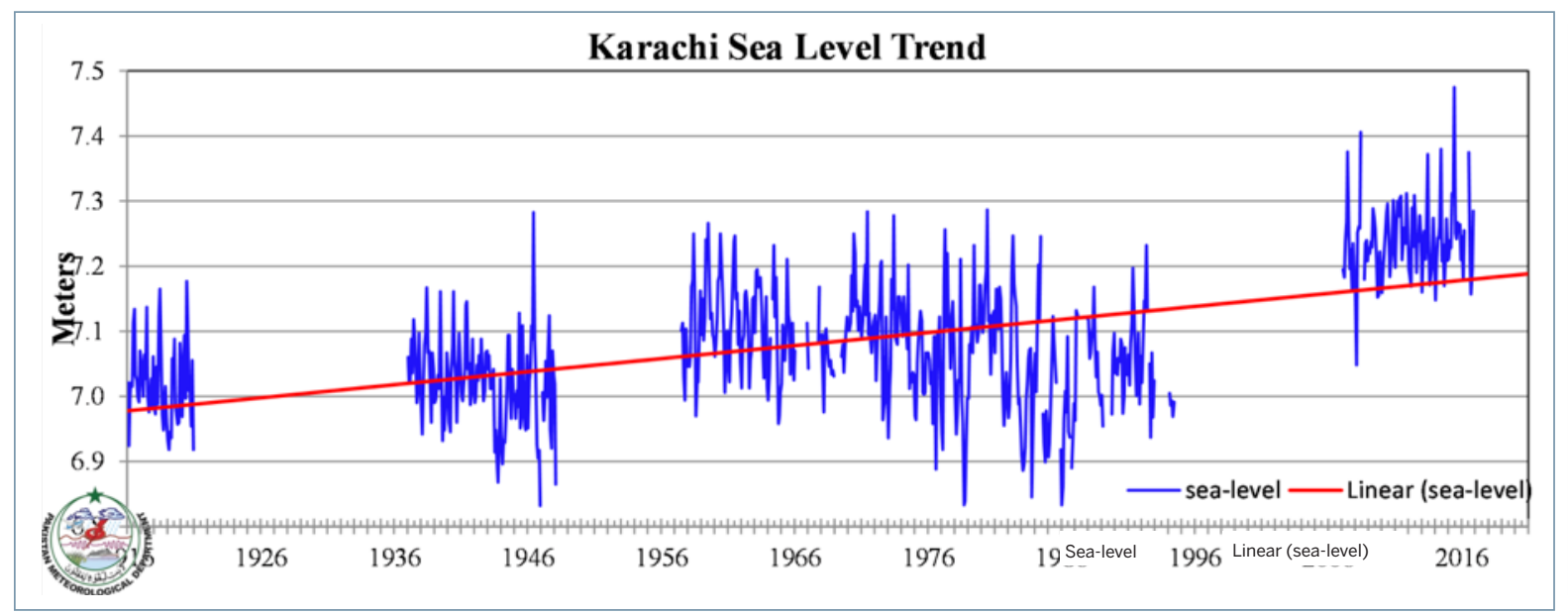

Source: Permanent Service for Mean Sea Level (PSMSL), UK Natural Environment Research Council (NERC).

\section{CONCLUSIONS}

The analysis of meteorological data presented in this study indicates clearly that the climate of Pakistan is getting warmer, with some regions facing a faster increase in average annual temperature. Overall, incidence of hot days is increasing while cold nights are getting less frequent, but local trends can be quite different across regions. Since 1961, average annual rainfall has increased; but for the most part, that increase occurred in 1961-89, while the years after 1990 generally show a decline in rainfall. Again, regional variations are important: while other parts of the country have seen an increase in rainfall, AJK is experiencing a decline, and there is no significant change in Sindh. The increasing number of wet days is a concern because it heightens the risk of floods, especially when combined with faster melting of glaciers caused by temperature increase. While this analysis has identified some of the broad changes underway in Pakistan's climate, its findings also point to the critical need to take into account regional and local trends-which may diverge greatly from country-level trends-in efforts to prepare populations for resulting environmental stresses. Also important is a perspective that takes into account multiple timescales, including long period averages but also more recent trends, so that strategies may be as responsive as possible to likely emerging conditions. 


\section{CHAPTER 2}

\section{Exploring the Implications of Climate Change and Population Growth for Agricultural Productivity}

MOHAMMAD JAMAL KHAN KHATTAK

\section{INTRODUCTION}

Global warming is likely to reach $1.5^{\circ} \mathrm{C}$ between 2030 and 2052 if it continues to increase at the current rate (IPCC 2018). Threats to food supplies and the sustainability of agriculture are at the forefront of the predicted impacts of climate change, and the outlook for Asia is particularly troubling. Collectively, Asian countries are projected to lose about 50\% of their wheat production by 2100 (MOE 2009). Fischer, Shah, and van Velthuizen (2002) expect substantial losses in wheat production in rainfed areas in South and Southeast Asia. Kumar and Parekh (1998) also predict that a decline in yields of wheat and rice in non-irrigated areas in South Asia will be significant for a temperature increase greater than $2.5^{\circ} \mathrm{C}$, reducing farm-level net revenue by up to $25 \%$. Net cereal production in South Asian countries is projected to decline by $4-10 \%$ by the end of this century under the most conservative climate change scenarios (Alam et al. 2007). However, regional differences in the response of wheat, maize, and rice yields to projected climate change are likely to be significant.

Three factors make Pakistan particularly vulnerable to climate change and its likely impacts on agriculture and food security. The first is its geographical location. Temperature increases in the country are expected to be higher than the global average (Janjua et al. 2010). Based on its exposure to climate risks, Pakistan was ranked the seventh most vulnerable country in the Global Climate Risk Index 2017 (Kreft, Eckstein, and Melchior 2016). Second, demographic dynamics in Pakistan threaten to compound climate risks. At over 208 billion, the country not only has the sixth largest population in the world, but this population is still growing fast-at a rate of $2.4 \%$ between the 1998 and 2017 censuses-and also urbanizing rapidly. These processes are exerting great stress on the natural resources needed to sustain agriculture and food security. Third, the country is economically vulnerable to climate change because of its heavy reliance on agriculture. The second largest sector of the economy, agriculture (including crops, livestock, fisheries and forestry) contributes about $25 \%$ of the gross domestic product (GDP) (World Bank 2017); according to the Economic Survey of Pakistan (Government of Pakistan 2016), major crops (wheat, rice, maize, sugarcane and cotton) account for about $25.6 \%$ of agricultural output and $5.4 \%$ of GDP. Moreover, agriculture employs more than $42 \%$ of the labor force (Government of Pakistan 2016), and generates over $75 \%$ of export revenue through agri-based textiles (cotton) and agri-food products (TDAP 2016). 
Rising temperature is already leading to a number of environmental stresses in Pakistan, including changes in the pattern and intensity of rainfall, melting of glaciers, shifting of seasons, and increasing frequency of extreme events (especially floods and droughts). All of these changes require adaptations in agricultural practices to maintain crop yields and livelihoods. At the same time, farmers' ability to adapt is threatened by population pressures, including dwindling per capita availability of land and water due to population growth, land fragmentation and rural-to-urban migration, urbanization, and the rapid conversion of agricultural lands at the peripheries of fast-growing cities.

This paper examines how climate and population changes are affecting agricultural productivity in Pakistan, with a focus on food crops and implications for food security.

\section{IMPLICATIONS OF CLIMATE CHANGE}

Saif Ullah (2017) has identified a number of major climatic stresses that will influence agriculture production in the future. These include increasing temperatures in arable areas, which will raise demand for irrigation; changes in rainfall patterns and distribution, with greater irregularity and severity; increased variability of monsoon rains; shifting of seasons (prolonged summer and shrinking winter); changes in availability of irrigation water; severe water-stressed conditions in arid and semi-arid areas; and greater frequency and intensity of extreme events, such as floods, droughts, heat waves, cold waves, and cyclones.

The negative and positive impacts of climate change on crop cultivation in Pakistan have been documented extensively in literature. Iqbal et al. (2009) list a number of ways in which climate change will negatively impact crops, including shortening of the growing period, loss in crop yield, changes in river flow, increased evapotranspiration, land degradation (such as salinity and waterlogging), and extreme events.

According to several studies, Pakistan's average surface air temperature has increased by $0.7^{\circ} \mathrm{C}$ since 1910 (Hanif 2015). Temperature increase at annual and seasonal time scales is consistent over most of the country. Higher temperatures alter the sowing window as well as the span of the growing period for crops. For crops cultivated in cooler seasons, such as wheat, the growing season, i.e., the time taken from sowing to maturity, can be shortened, forcing crops to mature earlier. Full crop production cannot be realized in these conditions. A study of climate scenarios up to 2040 in 10 districts of Khyber Pakhtunkhwa (Hanif 2015) projects that the temperature will continue to increase, hot days will become more frequent, and cold days less frequent, which will affect the growth of many crops in the province, as well as most other parts of the country.

Rising atmospheric temperatures are also changing river flows in Pakistan by increasing the pace at which glaciers are melting in the northern mountainous region. Pakistani rivers derive up to $80 \%$ or more of their water from the Himalaya-Karakorum-Hindukush (HKH) glaciers (Young and Hewitt 1990). According to the IPCC (2007), glacier melting in the Himalayas is projected to increase flooding in the downstream region over the next two to three decades. This will be followed by decreased river flows, as the glaciers recede.

At the same time, a rise in average temperature will cause more water to evaporate from the soil surface and to transpire from plant leaves, increasing the need for irrigation or rainwater.

Projected changes in rainfall at annual and seasonal time scales are much less spatially uniform than projected temperatures. Rainfall is generally projected to increase during the summer and spring seasons. As Figure 2.1 shows, $65 \%$ of rainfall in Pakistan is received in the summer months, when soils are barren in rainfed areas. High-intensity, low-duration rains during the monsoon can lead to flash floods and soil erosion, a major cause of land degradation and desertification.

Hanif (2015) points out that a spatial change, specifically a westward shift, has occurred in the monsoon rainfall pattern during the last three decades (Figure 2.2). This is a major climatic change that needs more attention from planners, researchers, and policymakers so that strategies may be prepared for adaptation 
Figure 2.1 Seasonal distribution of rainfall $(\mathrm{mm})$ in Pakistan

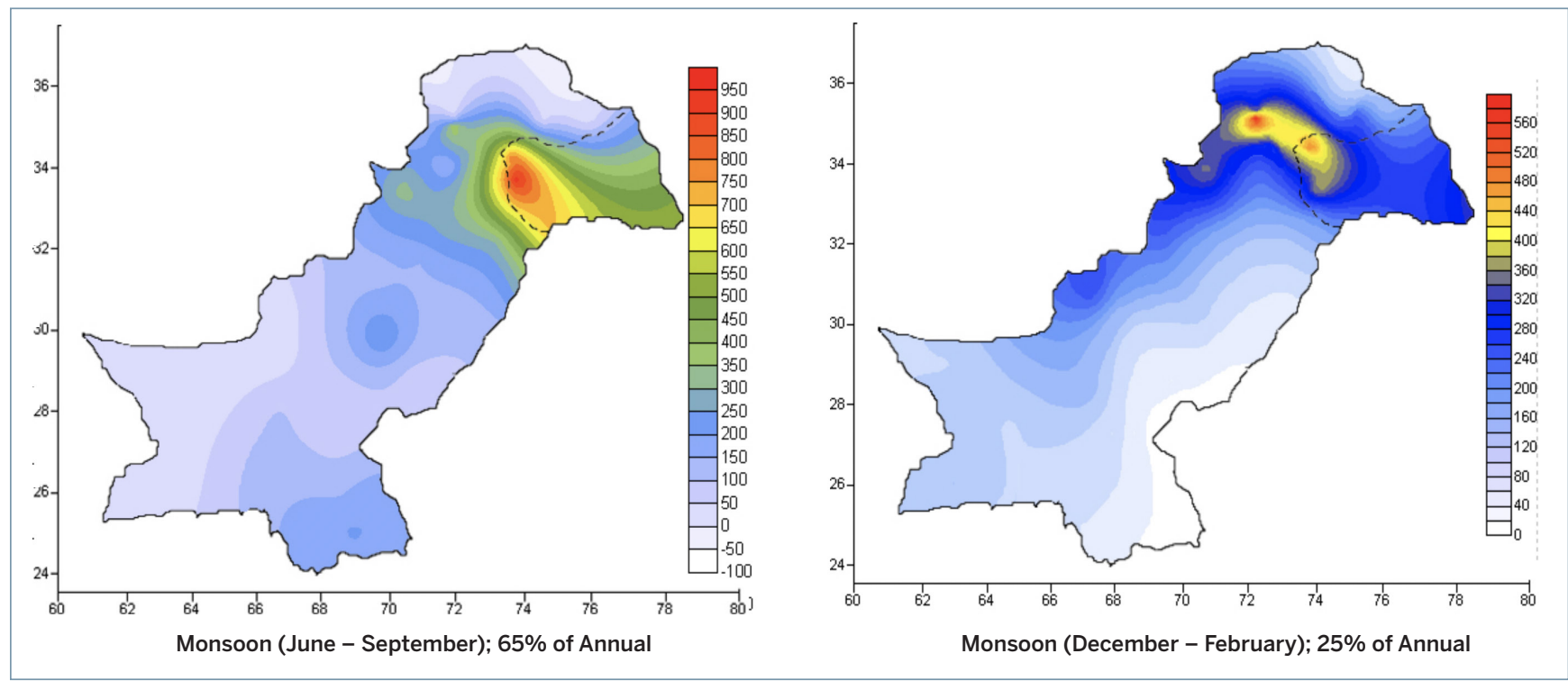

Source: Hanif 2015.

as well as flood impact mitigation, especially for the western areas that will be receiving more rain in the future. The shifting of the monsoon pathway from east to west will bring a lot of changes in agriculture and potential problems in soil degradation. Areas receiving monsoon rain at present are generally prepared to cope with heavy rains. Farmers prepare the land in such a way that it absorbs most of the rain and runoff is reduced, either through soil roughening/deep plowing or cultivation of crops that reduce flow over land during this period, thus minimizing soil erosion. As the monsoon path changes, farmers in the new western fringes receiving monsoon rain will need to adopt similar practices to cope with excess water and avoid the resulting soil erosion. At the same time, in the eastern areas from which the monsoon system is moving out, soil management practices and cropping patterns will need to be changed to cope with reduced moisture availability, including possible dry spells, during this period, and to avoid soil erosion, waterlogging and salinity issues, and desertification.

Figure 2.2: Shifting of Monsoon from East to West

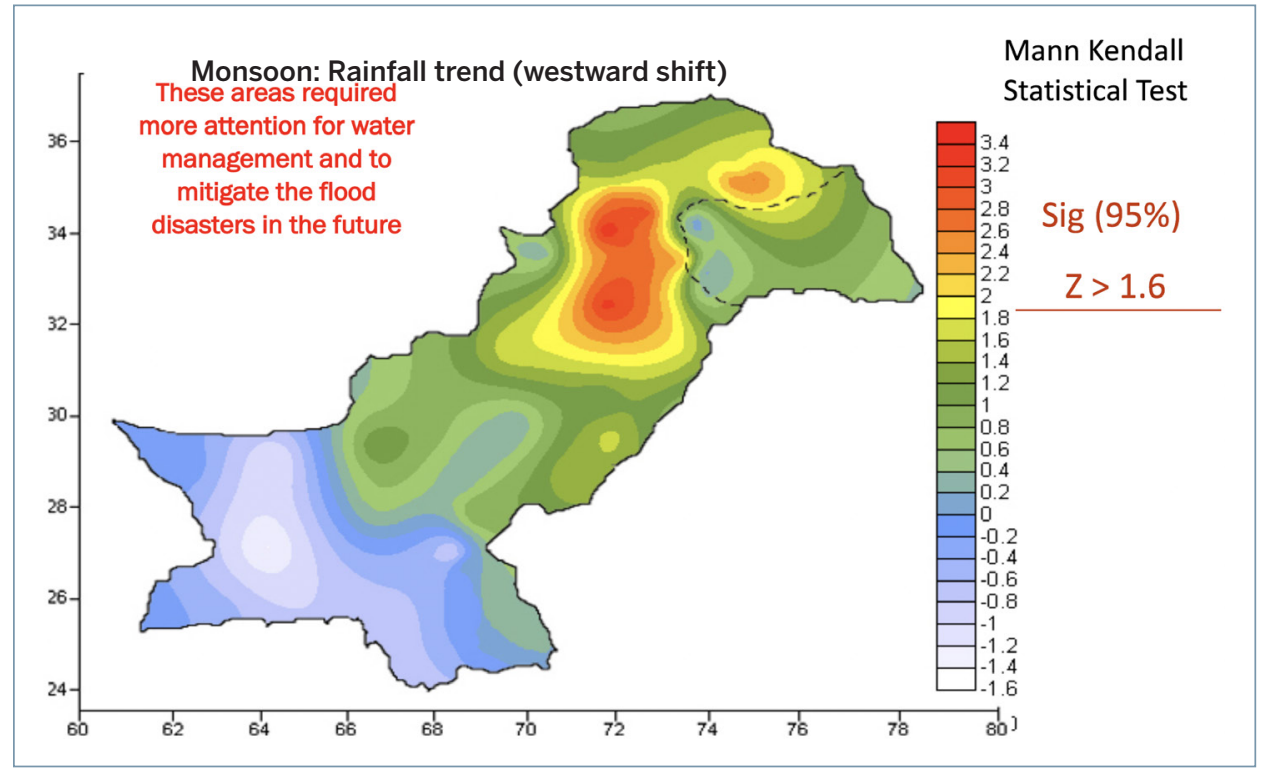

Source: Hanif 2015. 
Seasonal shifts in rainfall are also prominent in Pakistan (Figure 2.3a). April and May, relatively dry months in the past, will be wetter while October, November, and December, which were also dry in the past, will become drier in the future as a result of climate change. This seasonal shift is critical for rabi crops, especially wheat (Janjua et al. 2010) in both irrigated and nonirrigated areas, which is sown from late October to midDecember and harvested in April and May. Changes in temperature and rainfall during the reproductive and vegetative stages are important factors in wheat production (Mitra and Bhatia 2008, Semenov 2009). In future years, as the sowing period for wheat becomes the driest season, there will not be enough moisture available for germination, especially in arid and semiarid regions where irrigation water is not available (Figure 2.3b). Farmers may have to delay sowing or not sow wheat altogether. On the other hand, excessive rains in April and May will affect the harvest of wheat due to lodging (bending of stems near ground level) or incomplete grain filling, leading to lower yield as well as lower quality.

Figure 2.3a Seasonal shifts in rainfall (1961-2020)

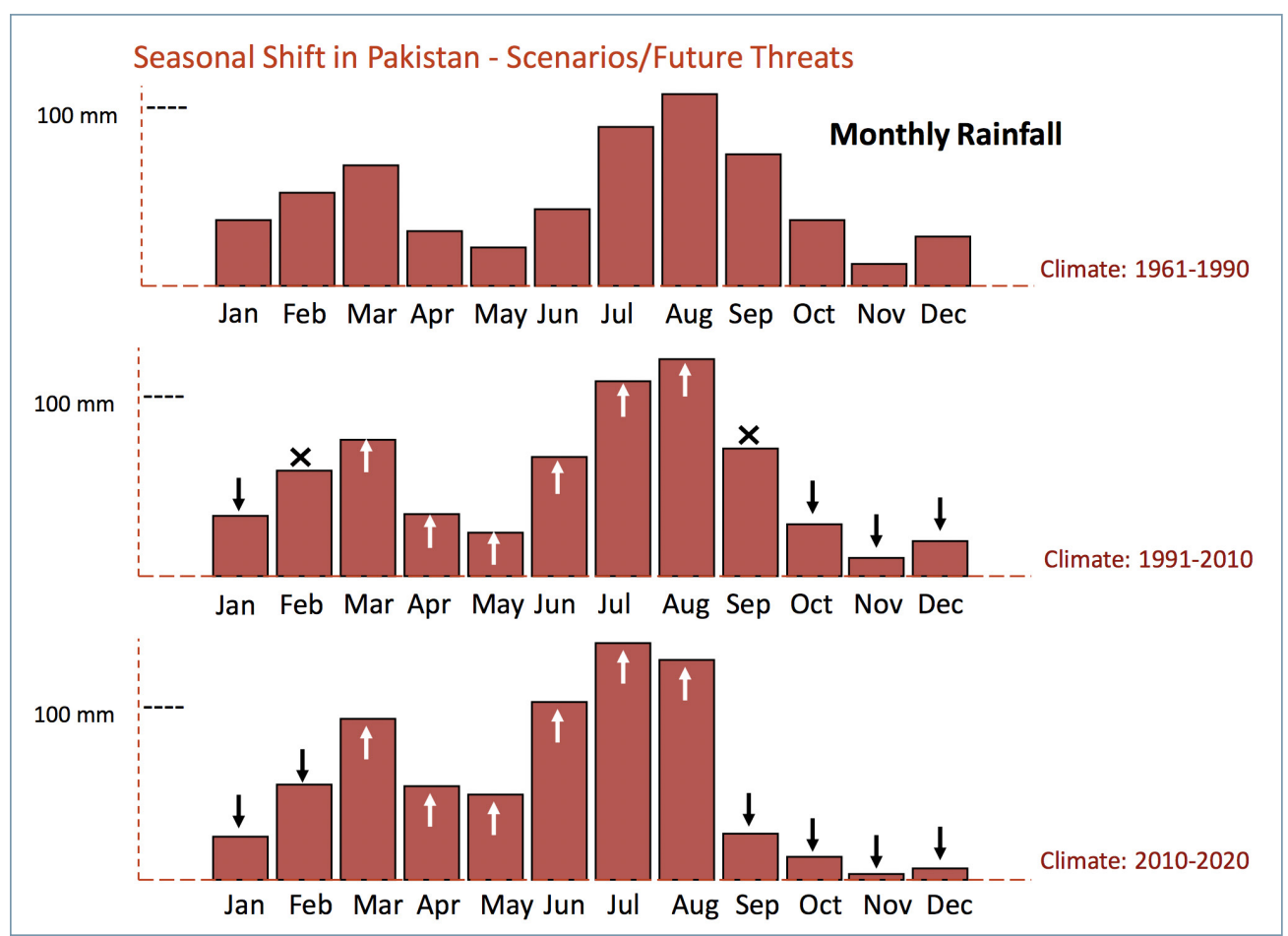

Source: Hanif 2015. 
Figure 2.3b Seasonal shifts in rainfall and future threats (1961-2030)

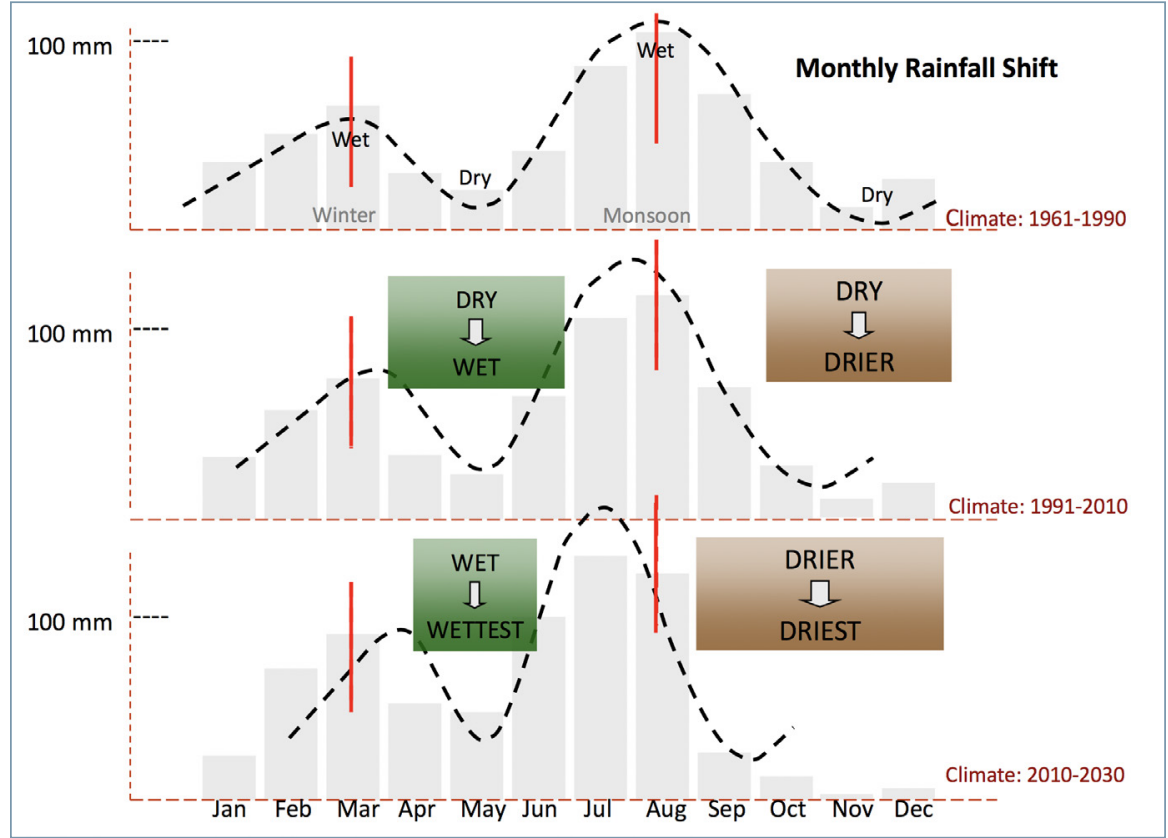

Source: Hanif 2015.

Rapid climate changes in Pakistan and elsewhere are also manifesting as extreme weather events like drought, heat waves, and floods, with adverse effects on agriculture. While the incidence of extreme events is hard to predict, their frequency and intensity is likely to increase in the future (IPCC 2007). Such events can be particularly devastating when they destroy healthy standing crops and damage grains stored in godowns because of roof leakage, fungus development, or diseases arising from damp, spoiling the quality of grains.

It is important to mention that, apart from crops, livestock, a very important sector within agriculture, is also at risk from climate change. The major ways in which this sector is adversely affected include widespread outbreaks of diseases associated with abrupt changes in climate, and decreased production due to unavailability of fodder or a balanced diet for livestock. At the same time, because of excessive pumping of groundwater for irrigation and other uses, the water table has been lowered significantly, leading to water shortages for livestock. This issue may worsen in the future.

In terms of vulnerability to climate change impacts, some parts of the country face greater risk. Of Pakistan's total land area, $80 \%$ is arid or semiarid, $12 \%$ is subhumid, and $8 \%$ is underhumid (Khan, Ahmad, and Hashmi 2012). Soils of the arid and semiarid regions (including the central and southern districts of Khyber Pakhtunkhwa, southern Punjab, and most of Sindh and Balochistan) are more vulnerable to a wide range of degradation processes that are exacerbated by rises in temperature or shifting of seasons, especially the merging of spring with either summer in dry years or winter in wet years, as seen in 2018-19. Crops like wheat are at greater risk from this kind of climatic change because of the possibility of low or even no yield as a result of drought at the time of sowing or heavy rains during grain formation (Khan and Khan 2018). Saif Ullah (2017) estimates that climate change impacts-specifically, shortening of the length of the growing season (particularly for wheat), heat stress at critical reproductive stages of both kharif and rabi crops, and increased water requirements of crops-decrease crop yields in arid and semiarid regions by about 6-18\%.

Changes in the rainfall pattern, especially seasonal shifts and greater irregularity, have also made farmers more vulnerable in rainfed areas (i.e., the southern districts) of Khyber Pakhtunkhwa, southern Punjab, and most of Balochistan. In 2015-2017, wheat could not be cultivated in rainfed areas because of a delay in winter 
rains. Similarly, high temperatures in tje summer increase the demand for water which cannot be met in these areas because of a shortage of both surface and groundwater. Rainfed agriculture and the livelihoods of farmers in these areas are therefore at great risk from climate change.

Similarly, farmers living in the mountainous and coastal areas are more exposed to climate change and extreme events. Heavy snow or rains during the winter delay sowing of Rabi crops in the northern mountainous region, while in the coastal areas, summer monsoon or upstream floods damage standing crops and there can be prolonged drought in winter.

Finally, it is important to point out that across all types of agricultural areas, small landholders, who make up more than $80 \%$ of the total farming community, are most vulnerable to climate change in Pakistan. The issues confronting this segment of the agriculture sector are discussed later in this paper.

Farmers in Pakistan are aware that the climate is changing. Studies undertaken by the Climate Change Center of the University of Agriculture reveal that they have perceived changes in rainfall distribution and pattern as well as temperature. (Unfortunately, these changes are not yet fully appreciated by planners and researchers, despite the imminent threat to rural livelihoods, especially small farmers.)

\section{IMPLICATIONS OF DEMOGRAPHIC CHANGES}

In addition to climate change, Pakistan's agriculture sector also faces pressure from demographic dynamics. The country's high population growth rate is particularly concerning-at the current rate of fertility decline, the population is projected to reach 350 million by 2050, making Pakistan the fifth most populous country in the world. On the other hand, in terms of land area, the country ranks 34th in the world. The rapidly growing size of the population is exerting immense stress on critical natural resources such as land, water, and soil, leading to a decline in the quality as well as quantity of these natural resources.

Agricultural land area in Pakistan has been constant since 1960 at about 30 million hectares (Mha) for arable land and 5 Mha for permanent pastures and meadows (Table 2.1). Land area under irrigation has increased by a significant $187 \%$, from 10.8 Mha in 1961 to 20.2 Mha in 2015. However, further increase is unlikely to be easily achieved in view of constraints such as limited reservoir capacity and lack of planning for water storage, as well as environmental stresses like rising temperature. There has been a linear decline in the area under forest, which has decreased by $40 \%$ since 1990 at an average annual rate of $2.8 \%$ per year (Lal 2018). Deforestation driven by urbanization, rural reliance on fuelwood, and poor land planning are linked with socioeconomic vulnerability, soil erosion, and sedimentation of water reservoirs. According to a study on deforestation in Swat, "expansion of agriculture has mainly been achieved at the expense of forested areas, with only negligible accounts of afforestation from 1968 to 2007. The valuable coniferous forest has significantly decreased, frequently leading to land degradation" (Qasim et al. 2011).

Table 2.1 Agricultural land use in Pakistan, Mha

\begin{tabular}{|l|r|r|r|r|r|r|r|r|}
\hline Land Use & 1961 & 1970 & 1980 & 1990 & 2000 & 2010 & 2015 & $\%$ Change \\
\hline Agricultural land $^{\mathrm{a}}$ & 35.7 & 35.9 & 37.4 & 35.2 & 36.7 & 35.2 & 36.3 & 1.02 \\
\hline Arable land $^{\mathrm{b}}$ & 30.6 & 30.7 & 32.1 & 29.8 & 31.0 & 29.4 & 30.4 & -0.01 \\
\hline Irrigated land & 10.8 & 13.0 & 14.7 & 15.7 & 18.1 & 20.2 & 20.2 & 187 \\
\hline Pastures & 5.0 & 5.0 & 5.0 & 5.0 & 5.0 & 5.0 & 5.0 & 0 \\
\hline Forest & & & & 2.5 & 2.1 & 1.7 & 1.5 & -40 \\
\hline
\end{tabular}

Source: FAO 2018, World Bank 2018.

${ }^{a}$ Agricultural land is defined as land area that is either arable, under permanent crops, or under permanent pastures.

${ }^{\mathrm{b}}$ Arable land includes land under temporary crops such as cereals, temporary meadows for mowing or for pasture, land under market or kitchen gardens, and land temporarily fallow. 
It is estimated that approximately 0.5 hectares of cropland must be available per capita to ensure an adequate diet for a population (Lal 1989). Unfortunately, at the global level, per capita availability is already lower than 0.23 hectares (Table 2.2). However, the situation in Pakistan is even worse and, according to Lal (2018), by 2050 the basic necessities of life will have to be met and the well-being of people realized from a meager 0.10 hectares of cropland, 0.07 hectares of irrigated land, and 0.015 hectares of pasture land per capita. This is a huge challenge for farmers, land managers, policymakers, researchers, and the general public.

Notably, while per capita land has been used as an indicator of sustainability, food security, or carrying capacity, this can result in erroneous or misleading conclusions. The indicator should reflect the ability of a unit of land to support a number of persons (Eswaran, Bienroth, and Reich 1999), and on this basis, per capita arable land may be considered a better indicator; the reciprocal of this number would be an estimate of the carrying capacity. Smil (1987) argues that a country with arable land of less than 0.07 hectares per person cannot feed its population even with very intensive agriculture. Even this limit is equivalent to a supporting capacity of about 14 persons per hectare of land, which is perhaps an unrealistically high number. The energy inputs required to produce at this level would be too high for any meaningful output. There are countries where per capita land availability is numerically close to 0.07 ha; however, this does not mean that their agriculture systems are designed to support 14 or more persons per hectare. United Nations organizations use a threshold of 0.07 hectares per capita to evaluate a land's carrying capacity (Eswaran, Bienroth, and Reich 1999) rather than the above-mentioned value of 0.5 hectares of cropland per capita which seems unrealistic in view of the required technological development and input availability and prices in developing countries.

Table 2.2 Per capita land in the world and in Pakistan, hectares

\begin{tabular}{|l|c|c|}
\hline & \multicolumn{2}{|c|}{ Per capita land } \\
\hline Year & World & Pakistan \\
\hline 1986 & 0.3 & 0.20 \\
\hline 2005 & 0.23 & 0.14 \\
\hline 2050 & 0.15 & 0.06 \\
\hline
\end{tabular}

Source: Lal 2018

Values are calculated from the projected estimate of population growth over time and arable land resources of Pakistan.

Table 2.3 shows where per capita land resources stood in Pakistan in 1950 and 2015, and how they are projected to decline in light of a future population increase. By 2050, basic necessities of life will have to be met from very small per capita shares of cropland, irrigated land, and pastureland.

Table 2.3 Past and projected per capita land resources in Pakistan, hectares

\begin{tabular}{|l|c|c|c|c|c|}
\hline Land use & 1950 & 2015 & 2030 & 2050 & 2100 \\
\hline Agricultural land & 0.95 & 0.18 & 0.15 & 0.12 & 0.10 \\
\hline Arable land & 0.82 & 0.15 & 0.12 & 0.10 & 0.09 \\
\hline Irrigated land & 0.29 & 0.10 & 0.08 & 0.067 & 0.057 \\
\hline Pastureland & 0.13 & 0.025 & 0.02 & 0.015 & 0.014 \\
\hline
\end{tabular}

Source: Lal 2018, FAO 2018, World Bank 2018. 
Notably, the above projections of per capita land availability reflect only population increase and not to possible conversion of agricultural land to other uses, such as urban, infrastructure, or recreational development. Exact data are not available about soil under roads, buildings, and housing, but the 2017 census did record a doubling of housing units in Khyber Pakhtunkhwa from 0.369 million in 1998 to 0.738 million in 2017 , and the same may be true in other provinces. Also worth considering is the decline in land productivity through soil degradation-for example, erosion, salinization, depletion of organic matter, and decline in soil structure and nutrient contents-including the increased degradation likely to accrue from climate change, especially drought stress.

Water is another major natural resource that is running out for the agricultural sector in Pakistan. Falkenmark, Rockström, and Karlberg (2009) present a very bleak picture of the potential to increase food production through area expansion by 2050 , pointing out that most arable land is already in use, while freshwater is likely to be the most fundamental constraints in food production in coming decades. The study concludes that Pakistan is among those countries that are "approaching the end of the road unless income growth in the meantime allows them to import the food required" (Ahmad \& Farooq 2010).

About $95 \%$ of Pakistan's water is used for agricultural purposes. The country has the largest irrigation system in the world but also a poor drainage system that leads to waterlogging and salinity problems. Land area equipped for irrigation has followed an increasing trend from 10.8 Mha in 1961 to 15.7 Mha in 1990, and 20.2 Mha in 2015. However, any future increase in irrigation may be a challenging task because of the limited water resources (Lal 2018). The water demand for agriculture was 109 million acre-feet (MAF) in 2017. Based on population growth projections, it is estimated that this demand will increase to $124 \mathrm{MAF}$ by 2030 . At the planning level, there are presently no concrete strategies for meeting the current water deficit or future demand.

In 2017, water availability in Pakistan was 900 cubic meters (m3) per capita per year-well below the 1,700 m3 per capita per year threshold for water-stressed conditions. In fact, Pakistan crossed the limit of water scarcity (1000 m3) in 2013 (Pakistan Engineering Congress 2018). The huge impact of population growth on water availability in Pakistan is shown in Figure 2.4. Per capita water availability in the country has shrunk from 5,260 m3 in 1951 (population: 34 million) to less than $1000 \mathrm{~m} 3$ in 2018 (population: 207.77 million), and if the situation remains the same, it will dwindle to only $550 \mathrm{~m} 3$ by 2025.

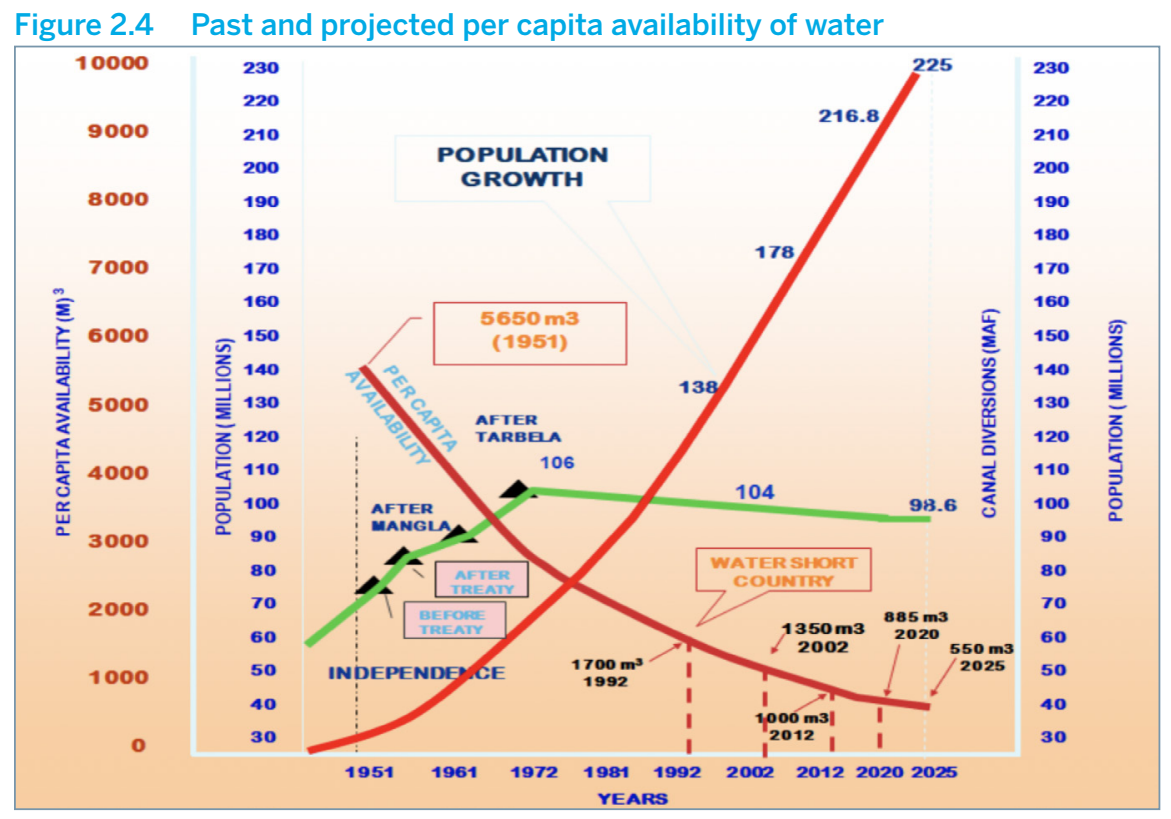

Source: “WAPDA Vision 2025” cited in Pakistan Engineering Congress 2018. 
Water storage capacity in Pakistan is alarmingly low at only $132 \mathrm{~m} 3$ per person compared to $6,150 \mathrm{~m} 3$ per person in the United States and 5,000 m3 per person in Australia. Stored water in Pakistan is only sufficient for 30 days whereas neighboring India has the capacity for water to last 120-220 days and Egypt has the highest carryover capacity of 1,000 days (Saeed, Sheikh, and Shoaib 2018). The lack of reservoir capacity in Pakistan makes it even more vulnerable to climate change, especially irregular rainfall and glacier melting.

Since the construction of Tarbela Dam in 1972, the country has failed to construct any other major reservoir and the water issue has been politicized, especially since the proposal of Kalabagh Dam, which evoked both strong support and staunch opposition. Meanwhile, existing storage capacity is declining due to sedimentation. About $30 \mathrm{MAF}$ of water flow into the sea without being used for agriculture, industries, or power generation (currently, a third of the country's energy supply is generated from hydropower). In 2018, Pakistan was facing a shortfall of about $31 \mathrm{MAF}$ in surface water supplies, which was compensated through massive mining of groundwater, estimated at 50 MAF (Pakistan Engineering Congress 2018).

While the former Chief Justice of Pakistan did take suo motu notice of the issue and a number of steps to galvanize support for increasing reservoir capacity in the country, concerted effort at the government level remains to be seen. For now, Pakistan continues to move toward worsening water scarcity, and agriculture is likely to be the worst-hit sector in the future. This will be the result not only of rapid population growth and rising temperature due to climatic changes, but also inefficient use of existing water resources and low storage capacity.

Apart from declining land and water availability, soil degradation is a third route through which population growth is adversely impacting agriculture. FAO and ITPS (2015) list 10 major physical degradation threats to soil arising from specific physiographic or climatic conditions that lead to desertification, including erosion, organic carbon loss, nutrient imbalance, acidification, contamination, waterlogging, compaction, sealing, salinization, and loss of soil biodiversity. With the exception of soil acidification, all of these degradation threats exist to some extent in Pakistan, and they are exacerbated by certain population dynamics. Pakistan's demographics have changed dramatically with its rapid rise in population. The Population Division of the United Nations Department of Economic and Social Affairs (2018) estimates the rate of urbanization in Pakistan at 0.62\% for the period $2015-2020$ and predicts that by 2025 , nearly $39 \%$ of the country's population will live in urban areas. More than $20 \%$ of Pakistanis now live in just 10 major cities, whose population has virtually doubled during the last two decades, greatly straining urban infrastructure. In addition, there is a strong trend of rural-to-urban migration for diversification of income sources, which is discussed by Arif and Sadiq in this volume.

Rapid population growth increases the demand for housing, sanitation, health, and education facilities, and of course food. Meeting these requirements often entails degradation of soil-a nonrenewable natural resource that takes several thousand to millions of years to form but can be washed away permanently in only a couple of hours of heavy rain. The soil resources of a country are fixed to some extent and provide a variety of fundamental services for human well-being. Population growth and rapid industrialization exert direct pressure on soil resources to grow more food from smaller units of land using less water. Critical limits of production are reached beyond which soil health can be compromised. Overexploitation of soils for food production to meet the demand of a growing population makes soil vulnerable to problems like erosion, lower fertility, salinity, and waterlogging.

Moreover, productive land may be converted to nonproductive uses like housing, urban expansion, schools, hospitals, industries, and roads. Conversion of prime agriculture land to nonagricultural uses, such as housing developments, ring roads around major cities, and unplanned city waste dumping sites, is a major concern in Pakistan that shows a lack or even absence of planning on the part of the government. While there are agricultural policies for zonation of soil for agriculture, these are rendered ineffective by lack of implementation. For example, the government of Khyber Pakhtunkhwa framed an Agriculture Policy in 2016 specifically addressing the zonation of soil and restricting the conversion of agricultural land for any other purposes, but its implementation is yet to be seen. Thus, fertile land is brought irretrievably under buildings and roads. 
In addition, land fragmentation is a key issue that is hampering the rehabilitation of degraded land and forcing low-income families to switch from agriculture to new sources of livelihood. The Agricultural Census 2010 reported that the average farm size in Pakistan is 2.6 ha, with approximately $43 \%$ of farmers categorized as small farmers with landholdings of less than one hectare and $22 \%$ owning more than 3 hectares of land. Most smallholders are resource-poor and operate in a low-input, low-output scenario. They use less-effective farming techniques, and may be unable to afford fertilizers and labor-saving equipment, which limits food production. Often, they cannot grow enough produce to be able to sell to others, or even to subsist. They may be edged into moving to less productive land which is more prone to environmental deterioration.

The problems of low income, lack of credit facilities, and untenable levels of land fragmentation in intergenerational transfer are being further compounded for these farmers and laborers by unpredictable and changing climatic conditions, forcing them to migrate to cities in search of alternative sources of income and better facilities. The smallholdings abandoned by these migrating families are usually left barren and are therefore most vulnerable to desertification and soil erosion. The phenomenon has led to the emergence of a new debate in Pakistan as to whether migration for adaptation leads to desertification or is being caused by it.

\section{THE OUTLOOK FOR FOOD SECURITY}

The World Food Summit in 1996 defined food security as "a situation that exists when all people, at all times, have physical, social and economic access to sufficient, safe and nutritious food that meets their dietary needs and food preferences for an active and healthy life" (FAO 1996). This definition emphasizes access of people to food and not its availability. The latter has occasionally been an issue in Pakistan, especially after the 1965 war with India and later in 1997, when the country experienced a severe shortage of wheat flour. For the most part, however, hunger, malnutrition, and food insecurity in Pakistan are driven by lack of access to food qas a result of poverty.

The recent State Bank Quarterly report notes that 37\% of households are labelled as "food insecure." Further while Pakistan is currently sufficient in terms of major staples, the recent UNICEF National Nutritional Survey 2018, incorporating the FAO Food Insecurity experience scale, found that severe food insecurity prevails in $18.3 \%$ of households. Across the provinces, KP, Gilgit Baltistan, and Punjab are relatively more food secure than Sind and Balochistan (State Bank of Pakistan 2019).

A Sustainable Development Policy Institute report (2009) noted that the state of food security in Pakistan has been compromised further by major crises that have confronted the country since 2003. Crises include: the Kashmir earthquake of 2005; floods in 2010; militancy in KP, FATA, and Balochistan and displacement of over three million people due to military operations in various areas; security issues in major urban areas; an energy crisis; and removal of general subsidies under the International Monetary Fund (IMF) standby facility.

Major factors that determine the food security of a country include its natural endowments (including soil and water resources as well as suitability of climate), population dynamics, economic stability, and political well-being. Unfortunately, Pakistan is facing major challenges on all of these fronts. The challenges to land, water, and soil resources and their adverse effect on physical availability of food in the country have been discussed above. In addition, political instability remains an issue and economic conditions remain far short of any level that could ensure food security. Production and distribution systems in agriculture are currently inequitable: a small number of large farmers in the country have a much higher share in land and production than smallholders, over whom they wield great power. Small farmers dominate the agricultural labor force in numbers, but their share in land and production is limited and they are among the most 
vulnerable groups in society. Low income, coupled with a high rate of unemployment, also restricts access of people to food. Ahmad and Farooq (2010) identify high cost and lack of purchasing power of the majority of poor people, insufficient agricultural production, political instability, and corruption as key reasons for low food security in the country.

\section{CLIMATE CHANGE AND FUTURE FOOD SECURITY}

In the future, the major components of food security, including production, distribution, and accessibility, will be substantially affected by changes in both temperature and rainfall (Mahmood et al. 2012 and Janjua et al. 2010). The production component of food security is most vulnerable to climate change impacts, through direct effects on crops and livestock, as well as indirectly through impacts on productive resources, mainly soil and water.

Changing climatic conditions have already affected the production of some staple crops like wheat and rice and future climate change poses more threats to food availability. A further rise in temperatures will reduce crop yields by increasing demand for water-the availability of which is shrinking - while changes in rainfall will affect both quality and quantity of the crops produced. Already, reduced water availability is altering crop rotation and cropping patterns. Seasonal shifts in rainfall have started to affect the yield and quality of wheat, a staple food crop in Pakistan and therefore a major focus of policymakers with respect to food security. Janjua et al. (2010) projected that higher temperatures in the future may negatively affect the growth process of wheat and further decrease its production. Using an empirical vector autoregression (VAR) model with annual data from 1960 to 2009 to project the impact of global climate change on wheat production in Pakistan, the authors concluded that climate change had not had a significant impact thus far but that future wheat production in the country (2010-16) would depend significantly on climate change variables.

Apart from wheat, climate change will drastically reduce production of rice as well as cotton and sugarcane in the next two decades. In southern Pakistan, yields of major cereals are predicted to decline by $15-20 \%$ according to regional climate models. In parts of the Northern Areas (including Upper Dir, Chitral, Shangla, and Upper Swat), minor improvements are predicted in yield due to increased duration of the growing period. However, since soil resources are limited in this mountainous region, the improved yields are unlikely to offset the loss of crops in other parts of the country.

Rangelands will be overstressed from prolonged droughts and shifting human and livestock populations around riverine areas and in mountainous regions. This will reduce tree and shrub cover. Pakistan is already among the most forest resource-poor countries in the world with forest areas comprising a meager $2 \%$ of total land area, compared to the world average of over 30\% (World Bank 2017), and even that is sparsely stocked. Livestock production is predicted to decline due to a shortage of fodders, especially in arid and semiarid regions, creating crises in milk, meat, and poultry supplies and pushing prices beyond the reach of the average Pakistani. Prices of major crops are also expected to increase in some regions, further restricting access to food.

Moreover, inland fisheries will be reduced because of decreased water availability. Production of fruits, vegetables, and horticultural products, which are high-value exports for Pakistan, will also be hindered under the changing scenarios.

Given that $67 \%$ of the rural population is engaged in agriculture, and that the sector accounts for $42 \%$ of total employment in the country, climate change could have a huge impact on rural livelihoods in Pakistan. Under these conditions, the poorest people, who already use most of their income on food, will have to sacrifice additional income and other assets to meet their nutritional requirements. Marginalized groups like women, children, and the elderly will be negatively impacted through widespread malnutrition (World Bank 2017). The hardest hit community are likely to be smallholding farmers, who will suffer both lower agricultural output and lower incomes. 


\section{MALTHUSIAN GROUNDS FOR CONCERN}

The famous theory of Reverend Thomas Malthus that population growth would eventually outstrip food shortage, causing "positive checks" to set in, is still debated today. The pessimistic view of its proponents is that food production and yield increases have plateaued or will eventually do so, and this will be followed by scarcity, starvation, disease, war, and devastation until the population is reduced to a sustainable level (Hartemink 2007). Ehrlich (1968), a follower of Malthus, was of a similar opinion that unchecked population growth would outstrip food production and destroy the earth's environment. On the other hand, optimists against the theory argue that sufficient food can be produced for many billions to come using the advances in biotechnology, genetic engineering, and other innovations in agriculture. Boserup (1965) advocated that the growth rate of food production will accelerate when the population grows because it will intensify land use and increase use of inputs. However, this assumption can hold true only if sufficient land is available and the economic condition of the land user allows adoption of developed technology and investment in inputs. Therefore, comparing the developed and developing countries of the world, it is clear that the former have more reason to be optimistic, while the situation in the latter favors a Malthusian view.

In Pakistan, certainly, the outlook for natural resources and food production, coupled with the current rate of population growth, provide grounds for pessimism. The country's limited soil and water resources are being degraded by inappropriate management as well as increasing environmental harshness as a result of climate change. Per capita land availability is also dangerously below the level needed to sustain the human population at an acceptable level. Critics of Malthusian theory may argue that intensification of agriculture and technological development will surpass food production, but this may be a precarious assumption for Pakistan because the carrying capacity of its soil is already less than 0.07 hectares per person (Eswaran, Beinroth, and Reich 1999), which means even intensive farming will be insufficient for feeding its population (Smil 1987).

Intensification of agriculture in Pakistan is largely related to farm size and income, which are low, and farmers with small holdings cannot afford to adopt innovative new technologies for crop production. Moreover, in some irrigated areas of the country, cropping intensity is already in the vicinity of $200 \%$; there is no chance of exceeding this level. In other areas, the high cost of inputs makes unit production of output uneconomical or productivity simply cannot be increased beyond certain limits because of environmental concerns.

Among soil problems, some, like poor health, salinization, and erosion, are reversible to an extent, but the soil being lost to buildings or roads will be gone forever, impossible to reclaim. While existing prime agricultural land is being converted to nonagricultural uses, scope for bringing new land under cultivation is limited. There has been negligible a increase in cultivated area in the last 60 years, but the population has increased fivefold, and urban expansion over sevenfold. New or marginal lands that could be brought under cultivation are either limited in acreage or of such poor quality that the level of investment required to make them productive would be uneconomical and unsustainable (Fullbrook 2010).

Timely availability of water, a key input, is also a major issue that will become a limiting factor for agriculture intensification-and food security -in the future. Food production requires massive amounts of water: for example, it takes $1 \mathrm{~m} 3$ (1,000 liters) to produce a kilogram of wheat, and about $5 \mathrm{~m} 3$ to produce a kilogram of rice (Brown 2013). It is predicted that global warming will increase irrigation needs by $26 \%$ to maintain yields (Pimentel et al. 1997). Declining water availability and changes in the rainfall pattern are already affecting crop yields in Pakistan. Water scarcity, coupled with declining soil resources and rapid urbanization, is likely to be the major limiting factor in crop husbandry and food security in Pakistan in the future.

Tremendous efforts are needed in terms of both advances in agricultural technology and efforts to reduce population growth to narrow the food supply-demand gap. Pakistan has made significant progress over the past decades in increasing yields of major crops and achieving self-sufficiency in the main staple food crops (USAID 2018). This was possible by using modern inputs, including fertilizers, pesticides, better quality seeds, and mechanized farming. However, area under cultivation has stagnated at just around $25 \%$ of the 
total land area of the country (FAO 2019) and food output cannot keep pace with rapid population increases. Agricultural crop production must be enhanced and made sustainable by responding to the major issues of soil degradation (e.g., through salinity, soil erosion, and imbalanced fertilizer use); erratic rainfall distribution, especially in rainfed areas; water scarcity; and migration that is leading to soil desertification.

\section{CONCLUSIONS AND RECOMMENDATIONS}

Pakistan's agriculture sector will be negatively affected on the whole by climate change unless appropriate and timely adaptation measures are undertaken. Adapting to climate change can reduce its negative impact on agricultural productivity (Di Falco and Chavas 2009). The survival of communities confronting climate change will eventually depend on how wisely they adapt to climatic vagaries. For their part, farmers in Pakistan are cognizant of climatic changes and adopting the measures they can; however, the government must become a much more aware and active player to facilitate adaptation, especially for resource-poor small farmers. New germplasms of crops/fruit and vegetables to tolerate the extremes of climate need to be developed. Crop sowing time, sowing methods, and seed treatment techniques need to be addressed in future research. Soil moisture conservation, rainwater harvesting, and water-use efficiency must be ensured for wider adaptability. A climate-smart agriculture approach must be adopted and land redefined as agroclimatic zones rather than agroecological zones. Moreover, district-level climate adaptation plans are needed rather than uniform province-level plans, especially for the Soil and Water Conservation and Water Management departments.

It is also crucial to tackle the growing problem of the country's "population explosion." If the population continues to grow at its current rate, already limited land, soil, and water resources will soon be exhausted. Aside from the strain of sheer numbers, certain demographic trends-such as desertification associated with land fragmentation and rural-to-urban migration, and agricultural land conversion associated with urbanization-are accelerating land degradation. Among other measures, policies must be effectively framed and implemented to provide universal access to family planning services, and prevent further conversion of agricultural lands to other uses.

Addressing poverty is also important. The World Food Programme Country Director Lola Castro noted in September 2018 that Pakistan does not have an issue with food production but the quality and quantity of food available to most poor and illiterate Pakistanis is insufficient to meet their basic nutritional needs. There is a famine-like situation in Thar almost every year, and many children die of different diseases caused by malnutrition, but the Ministry of National Food Security does nothing to find a permanent solution.

Poverty, starvation, and famine generally arise from inadequate natural resource endowments and the lack of capital to mitigate these constraints. At the same time, according to Eswaran, Beinroth, and Reich (1999), famine and starvation have occurred in some countries not because global land resources were unable to produce the necessary food but because of an absence of political will. In the context of Pakistan, lack of political will, lack of capital, rapid population growth, inadequate natural resources, especially soil and water, and changes in climate are all contributing to food insecurity. The issues of poverty, hunger, agricultural production technologies, desertification, migration from rural areas, and climate changes are all interlinked and must be addressed collectively. 


\title{
CHAPTER 3
}

\section{Population Exposure and Vulnerability to Climate Change in Pakistan's Agroecological Zones: A Preliminary Data Analysis}

\author{
MAQSOOD SADIQ, ZEBA SATHAR, AND MUHAMMAD KHALIL
}

\section{INTRODUCTION}

The Intergovernmental Panel on Climate Change (IPCC) describes vulnerability as the susceptibility of a system to climate change and its inability to cope with the consequences (Guzman, Schensul, and Zhang 2013). By this definition, vulnerability has three components: hazard exposure, sensitivity, and adaptation capacity. Environmental data, such as climate change projections, precipitation, and surface temperature can help us identify the hazard exposure. However, assessment of the other two components of vulnerability, i.e., sensitivity and adaptation capacity, is more complex and demands that we examine what we know about human conditions, behaviors, and capacities. Yet, research on climate change vulnerability has tended to focus on hazard exposure, a bias that may have some part to play in the greater focus on technical and economic challenges, and the relative neglect of people's livelihoods and opportunities (Martine and Schensul 2013) in the response to climate change.

Data on population distribution and dynamics have largely been omitted from the dialogue on climate adaptation, although they are vitally important for understanding the contribution of population processes to both mitigation of and adaptation to climate change (Balk, Guzman, and Schensul 2013). Given their breadth, coverage, and flexibility, census data can help us map many dimensions of vulnerability and adaptive capacity (Guzman, Schensul, and Zhang 2013), such as the size and density of populations, their housing conditions, and access to services. Household surveys, such as the Demographic and Health Survey, can also be harnessed to identify vulnerability traits over time, and examine behaviors relevant for environmental outcomes. These tools can help us better understand the dynamics underlying vulnerability to climate change, as well as variations in a population's adaptive capacity (Peña and Fuchs 2013).

In the context of adaptation and disaster management efforts, demographic analysis at the subnational level is particularly crucial because the impacts of climate change play out in unique ways in regional and local settings; disaggregated demographic data must be available and used to evaluate and address climate-related vulnerability (Balk, Guzman, and Schensul 2013).

In the current study, we demonstrate how population data can be processed and linked to climate data to enable a better understanding of adaptation needs. 
The specific aims of this study are:

- To identify which among the agroecological zones are the populations most at risk from climate change (based on the nature and extent of change in climate patterns);

- To assess population characteristics and trends in the zones where climate patterns are changing, including population size, location, growth, levels of urbanization, and densities; and

- To explore social, housing, and economic behaviors across the zones, especially in those more severely affected and less affected by changes in the climate patterns.

\section{DATA AND APPROACH}

Our analysis is based on population census data for Pakistan for the period 1951-2017 and climate data from the Pakistan Meteorological Department (PMD) and the World Bank for the period 1901-2016. (The World Bank data portal provides rainfall and temperature data from the weather stations established across the country by the PMD.)

To assess the current situation and historical trends in environmental variables and demographic features, these data are analyzed by agroecological zone, adapting the work of the Pakistan Agricultural Research Council (PARC). In 1980, PARC classified the country's territory into 10 agroecological zones (Figure 3.1), mainly based on physiography, climate, land use, and water availability. In many respects, this classification is still relevant and useful in capturing agricultural and ecological characteristics-and, we would like to propose, development patterns as well-in different parts of the country. Our adaptation of PARC's classification collapses and combines some of the smaller zones, and is also shown in Figure 3.1. Because of data limitations, Gilgit-Baltistan (GB) and Azad Jammu \& Kashmir (AJK) are regarded as separate zones, and not included in most of the analysis. The districts comprising each zone in our adapted classification are listed in Table 3.1.

Figure 3.1 Re-classification of PARC agroecological zones

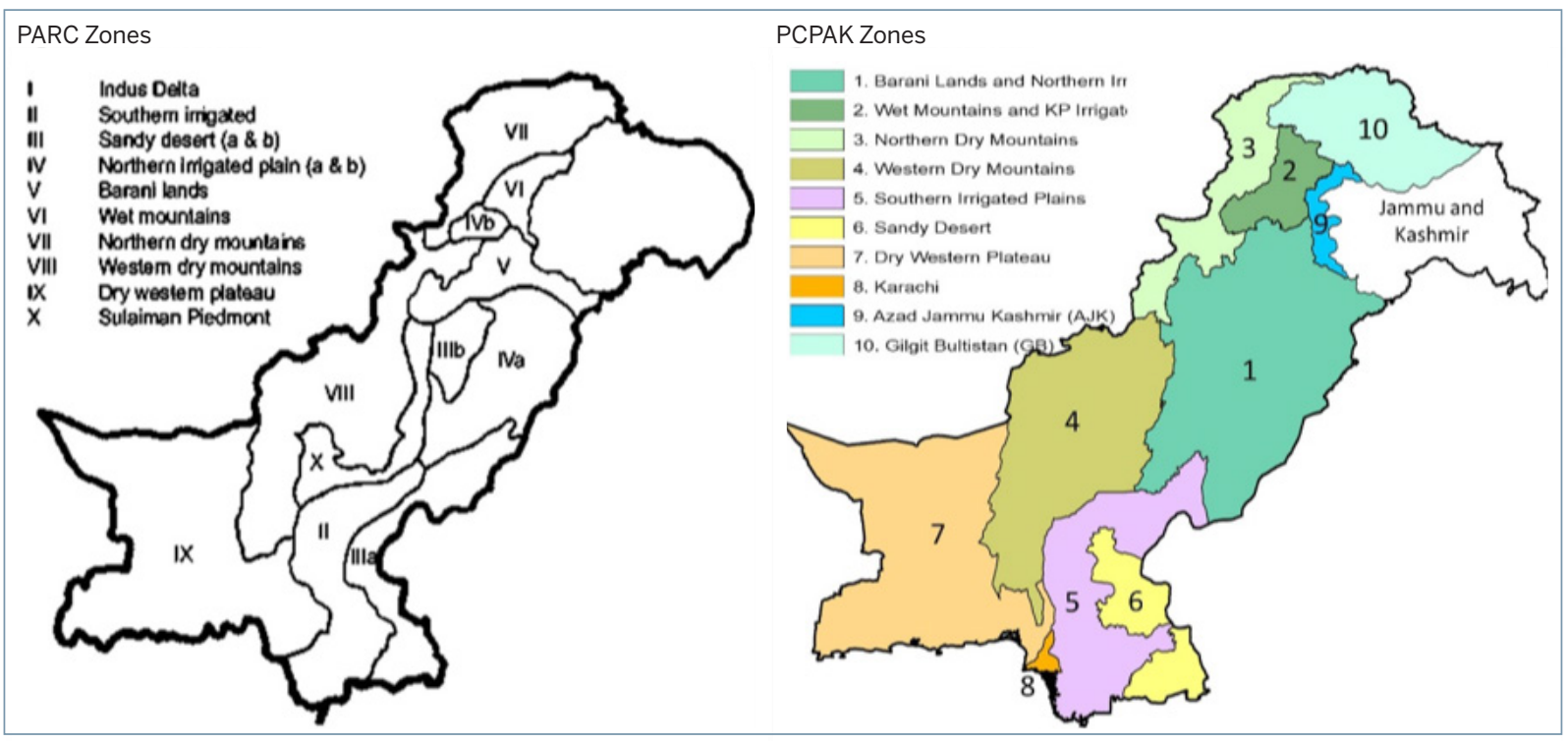

Source: PARC, 1980, available on FAO website.

Source: PCPAK Zones based on PARC Zones. 
Table 3.1 Districts and characteristics of the agroecological zones defined for this study

\begin{tabular}{|c|c|c|c|c|}
\hline SNo & Zone & Province & Districts & Characteristics \\
\hline \multirow[t]{2}{*}{1} & \multirow[t]{2}{*}{$\begin{array}{l}\text { Barani Lands } \\
\text { and Northern } \\
\text { Irrigated Plains }\end{array}$} & Punjab & $\begin{array}{l}\text { Attock, Chakwal, Islamabad, Jhelum } \\
\text { Mianwali Rawalpindi Bahawalnagar } \\
\text { Bahawalpur, Chiniot, Dera Ghazi } \\
\text { Khan Faisalabad GujranwalaGujrat, } \\
\text { Hafizabad, Jhang, Kasur, Khanewal, } \\
\text { Lahore City, Layyah, Lodhran, Mandi } \\
\text { Bahauddin, Multan, Muzaffargarh, } \\
\text { Nankana Sahib, Narowal, Okara, } \\
\text { Pakpattan, Rajanpur, Sahiwal, } \\
\text { Sargodha, Sheikhupura, Sialkot, } \\
\text { Toba Tek Singh, Vehari, Bhakkar, } \\
\text { Khushab }\end{array}$ & \multirow[t]{2}{*}{$\begin{array}{l}\text { These include Barani (rainfed) Lands, } \\
\text { Flood Plains and Bar Uplands. Also include } \\
\text { the Salt Range and Potowar Plateau. The } \\
\text { climate is semi-arid. Canal-irrigated crops } \\
\text { are wheat, rice, sugarcane, oilseed, and } \\
\text { millet in the north and wheat, cotton, } \\
\text { sugarcane, maize, citrus, and mangoes in } \\
\text { the center and south. }\end{array}$} \\
\hline & & KP & $\begin{array}{l}\text { Bannu, Lakki Marwat, Tank, Dera } \\
\text { Ismail Khan }\end{array}$ & \\
\hline 2 & $\begin{array}{l}\text { Wet Mountains } \\
\text { and KP } \\
\text { Irrigated Plains }\end{array}$ & KP & $\begin{array}{l}\text { Abbottabad, Kohistan, Mansehra, } \\
\text { Torghar, Batagram, Buner, Shangla } \\
\text { Charsadda, Haripur, Mardan, } \\
\text { Nowshera, Peshawar, Swabi }\end{array}$ & $\begin{array}{l}\text { Wet Mountains - High Mountains. The soils } \\
\text { consist of silt loams to silty clays. A small } \\
\text { area is under rainfed agriculture but most of } \\
\text { it is under forest. }\end{array}$ \\
\hline 3 & $\begin{array}{l}\text { Northern Dry } \\
\text { Mountains }\end{array}$ & $\mathrm{KP}$ & $\begin{array}{l}\text { Bajaur Agency, Chitral, Khyber } \\
\text { Agency, Kurram Agency, Lower Dir, } \\
\text { Malakand, Mohmand Agency, North } \\
\text { Waziristan, Orakzai Agency, South } \\
\text { Waziristan, Swat, Upper Dir, Hangu, } \\
\text { Karak, Kohat }\end{array}$ & $\begin{array}{l}\text { The valley soils are deep and clayey. Most of } \\
\text { the area is used for grazing. }\end{array}$ \\
\hline 4 & $\begin{array}{l}\text { Western Dry } \\
\text { Mountains }\end{array}$ & Balochistan & $\begin{array}{l}\text { Jafarabad, Jhal Magsi, Lehri, } \\
\text { Nasirabad, Sohbatpur, Barkhan, } \\
\text { Bolan, Dera Bugti, Kalat, Khuzdar, } \\
\text { Killa Abdullah, Killa Saifullah, Kohlu, } \\
\text { Loralai, Mastung, Musakhel, Pishin, } \\
\text { Quetta, Sherani,Sibi, Zhob, Ziarat }\end{array}$ & $\begin{array}{l}\text { Barren hills with steep slopes. Soils in the } \\
\text { valleys are deep and loamy. Most of the land } \\
\text { is used for grazing. On part of the loamy } \\
\text { soil, wheat and fruit crops are grown. }\end{array}$ \\
\hline \multirow[t]{2}{*}{5} & \multirow[t]{2}{*}{$\begin{array}{l}\text { Southern } \\
\text { Irrigated Plains }\end{array}$} & Sindh & $\begin{array}{l}\text { Mirpur Khas, Badin, Dadu, Ghotki, } \\
\text { Hyderabad, Jacobabad, Kambar } \\
\text { Shahdad Kot, Kashmore, Larkana, } \\
\text { Matiari, Naushahro Feroze, Nawab } \\
\text { Shah, } \\
\text { Shikarpur, Sujawal, Sukkur, Tando } \\
\text { Allah Yar, Tando Muhammad Khan, } \\
\text { Thatta, Umer Kot }\end{array}$ & \multirow[t]{2}{*}{$\begin{array}{l}\text { These include the Southern Irrigated Plain } \\
\text { and the Lower Indus Plain. The climate is } \\
\text { arid and subtropical. The soils are silty and } \\
\text { sandy loam, but the upper areas of the flood } \\
\text { plain are calcareous, loamy, and clayey. } \\
\text { Cotton, wheat, and sugarcane are grown on } \\
\text { the left bank of the Indus and rice, wheat, } \\
\text { and gram on the right bank. }\end{array}$} \\
\hline & & Punjab & Rahim Yar Khan & \\
\hline 6 & Sandy Desert & Sindh & Khairpur, Sanghar, Tharparkar & $\begin{array}{l}\text { The soils are sandy and loamy fine sand. } \\
\text { The land is used for grazing. }\end{array}$ \\
\hline 7 & $\begin{array}{l}\text { Dry Western } \\
\text { Plateau }\end{array}$ & Balochistan & $\begin{array}{l}\text { Awaran, Chagai, Gwadar, Kech, } \\
\text { Kharan, Lasbela, Nushki, Panjgur, } \\
\text { Washuk }\end{array}$ & $\begin{array}{l}\text { Dry Western Plateau - mountainous areas. } \\
\text { The coastal belt receives a sea breeze. The } \\
\text { land is used mainly for grazing. Melons, fruit } \\
\text { crops, vegetables, and wheat are grown } \\
\text { where water is available. }\end{array}$ \\
\hline 8 & Karachi & Sindh & All districts of Karachi & $\begin{array}{l}\text { Located on the coastline of Sindh province, } \\
\text { along a natural harbor on the Arabian Sea. } \\
\text { Built on coastal plains with scattered rocky } \\
\text { outcroppings, hills, and coastal marshland. }\end{array}$ \\
\hline
\end{tabular}




\section{MEASURING THE INFLUENCES OF CLIMATE CHANGE}

We mapped the trend in monthly historical rainfall and temperature in each of the eight agroecological zones by analyzing data for 1901 to 2016 from weather stations in the districts that make up each zone. To compare earlier and more recent temporal trends, we also conducted separate analyses for the periods 1901-90 and 1991-2016.

We see notable differences in rises in temperature across the zones (Table 3.2). In the earlier decades, the temperatures vary from averages of $27\left({ }^{\circ} \mathrm{C}\right)$ in Southern Irrigated/Sandy Desert and Karachi to $16^{\circ} \mathrm{C}$ in the Northern Dry Mountains. However, they have risen considerably in the last 25 years. The overall rise in temperature between 1901 and 2016 is $1.1^{\circ} \mathrm{C}$, of which about $0.5^{\circ} \mathrm{C}$ has occurred after 1990.

Table 3.2 Temperature changes across agroecological zones, 1901-2016

\begin{tabular}{|l|c|c|c|}
\hline \multirow{2}{*}{ Zone } & \multicolumn{2}{|c|}{ Temperature average } & $\begin{array}{c}\text { Change in averages between } \\
\text { 1901-90 and 1991-2016 }\left({ }^{\circ} \mathbf{C}\right)\end{array}$ \\
\hline 3. Northern Dry Mountains & $1901-1990$ & $1991-2016$ & 0.14 \\
\hline 1. Barani Lands and Northern Irrigated Plains & 16.3 & 16.5 & $0.22^{*}$ \\
\hline 2. Wet Mountains and KP Irrigated Plains & 24.2 & 24.4 & $0.22^{*}$ \\
\hline 4. Western Dry Mountains & 17.7 & 17.9 & $0.67^{* *}$ \\
\hline 6. Sandy Desert & 18.9 & 19.5 & $0.70^{* *}$ \\
\hline 5. Southern Irrigated Plains & 26.3 & 27.0 & $0.73^{* *}$ \\
\hline 8. Karachi & 26.6 & 27.3 & $0.84^{* *}$ \\
\hline 7. Dry Western Plateau & 25.9 & 26.7 & $1.02^{* *}$ \\
\hline PAKISTAN & 22.6 & 23.6 & $0.5^{* *}$ \\
\hline
\end{tabular}

*Significant at $p<0.05 ; *$ * $p<0.01$.

Source: The World Bank Climate Change Knowledge Portal.

Figure 3.2 shows the spatial distribution of changes in temperature across the zones. The temperature increase is unevenly distributed across the northern, southern, and western parts of Pakistan. Somewhat an anomaly, GB (in the north) has seen a considerable rise in temperature of $0.6^{\circ} \mathrm{C}$ in the recent past, caused possibly by greater impact of global warming at higher altitudes, leading to much of the glacier mel ting (data not shown). There is a minimal rise in the Northern Dry Mountains, Barani/Northern Irrigated Plains and KP Irrigated Plains and Wet Mountains. In contrast, there is a substantial rise in temperatures in the Dry Western Plateau, the Western Dry Mountains, and Sandy Desert. Karachi has experienced a 0.8 degree rise in temperature in just 25 years (1991-2016) over the 1901-90 period. The differences in temperature noted are statistically significant across all the regions.

Figure 3.2 Average changes in temperature, 1901-2016

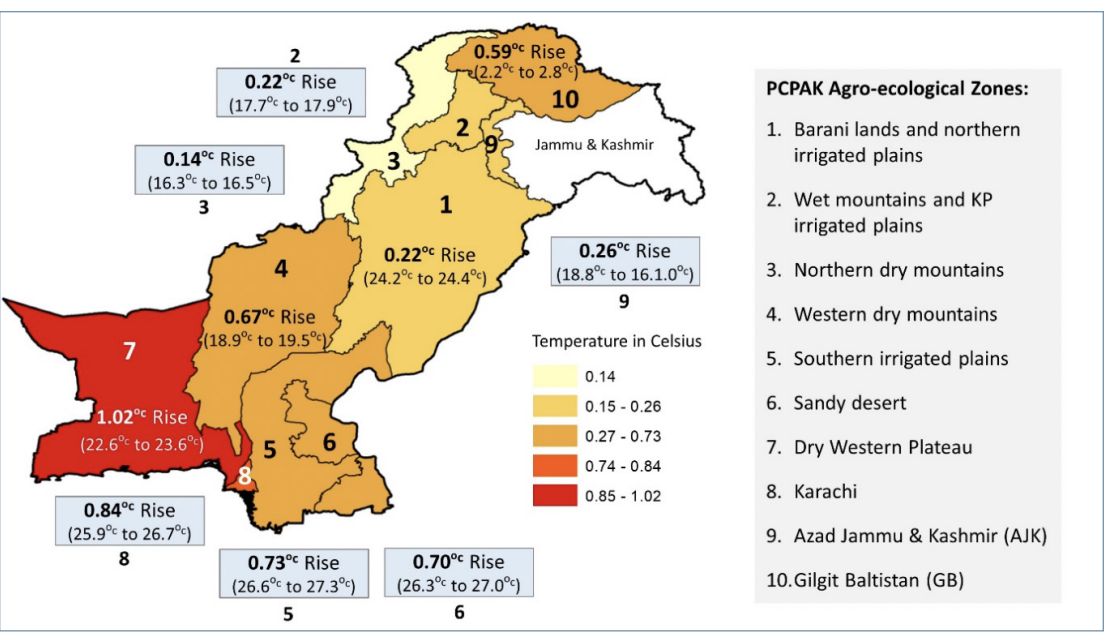


The results of the rainfall analysis are presented in Table 3.3. We find, first, that the relatively dry regions of Pakistan have become drier, and the rainier parts much wetter, with an average increase of around 10 millimeters (mm) in the last 25 years alone (1991-2016). It is important to note that the departure from previous trends, i.e., the difference in rainfall between 1901-90 and 1991-2016, is lower for the southern and western parts of Pakistan (Figure 3.3). However, the Dry Western Plateau has experienced the most statistically significant decline. There has also been a substantial decline in rainfall levels in Karachi, the Western Dry Mountains, the Southern Irrigated Plains, and Sandy Desert area.

In contrast, the northern part of the country has become wetter. A statistically significant rise in rainfall is seen in the Barani/Northern Irrigated, Wet and Dry Mountains/KP Irrigated and Northern Dry Mountain areas.

Table 3.3 Rainfall changes across agroecological zones, 1901-2016

\begin{tabular}{|l|c|c|c|}
\multicolumn{1}{|c|}{ Zone } & \multicolumn{2}{c|}{ Rainfall in millimeters (average) } & $\begin{array}{c}\text { Change in average } \\
\text { between the two major } \\
\text { time periods (mm) }\end{array}$ \\
\hline 7. Dry Western Plateau & $1901-1990$ & $1991-2016$ & $-3.6^{* *}$ \\
\hline 8. Karachi & 12.1 & 8.5 & -3.4 \\
\hline 4. Western Dry Mountains & 16.7 & 13.3 & -2.2 \\
\hline 5. Southern Irrigated Plains & 22.1 & 20.0 & -1.3 \\
\hline 6. Sandy Desert & 12.5 & 11.3 & -0.9 \\
\hline 1. Barani Lands and Northern Irrigated Plains & 14.1 & 13.2 & $6.2^{* *}$ \\
\hline 3. Northern Dry Mountains & 37.9 & 44.1 & $8.9^{* *}$ \\
\hline 2. Wet Mountains and KP Irrigated Plains & 53.8 & 62.6 & $10.3^{* *}$ \\
\hline PAKISTAN & 66.3 & 76.6 & $3.2^{*}$ \\
\hline
\end{tabular}

*Significant at $\mathrm{p}<0.05 ;{ }^{* *} \mathrm{p}<0.01$.

Source: The World Bank Climate Change Knowledge Portal.

Figure 3.3 Average changes in rainfall, 1901-2016

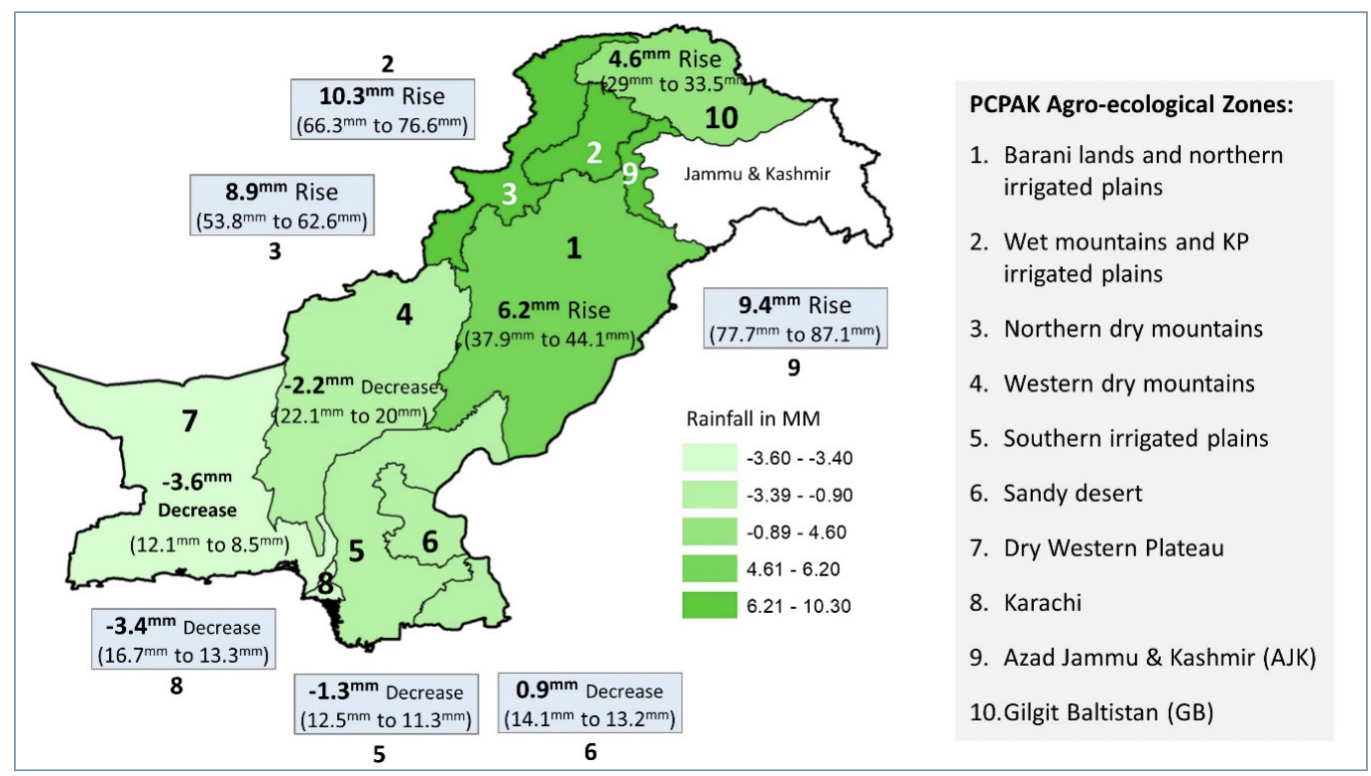

Source: World Bank. 
The above analysis indicates that the populations of the eight agroecological zones are exposed to varying degrees of change in climate in terms of temperature rise and rainfall reduction. For further analysis, we divide the zones into three categories, i.e., less affected, including 1) Barani lands and northern irrigated plains; 2) wet mountains and KP irrigated plains; and 3) northern dry mountains; severely affected (i.e., experiencing the sharpest temperature increases and rainfall reductions), including 4) western dry mountains; 5) southern irrigated plains; 6) sandy desert, 7) dry western plateau; and Karachi, which is also a severely affected zone but is treated as a separate category because it is entirely urbanized, has a unique importance because of its large size and great significance as the economic hub of the country.

\section{COUNTING THE MOST AFFECTED}

The data for this section are extracted from the six censuses conducted by the Government of Pakistan in 1951, 1961, 1972, 1981, 1998, and 2017. District-level demographic data from the censuses have been combined across the agroecological zones to see changes over time and across the zones. Unfortunately, detailed data of the 2017 census have still not been released, thus we were unable to conduct a more complete analysis of aspects such as age structures, employment, and sex ratios. In some cases, we utilize the most recent survey data instead.

The first important finding from our results is that the majority of Pakistanis are not yet too affected by changes in climate patterns (Table 3.4). Nevertheless, a substantial part of the population is severely affected, including the 49 million people-a little less than a quarter of the country's population-residing in severely affected zones, as well as the 16 million residents of Karachi, who face additional risks of seawater rise and cyclones. In total, 65 million persons in Pakistan are exposed to rapid changes in the climate, and the associated risks to their livelihoods, well-being, and survival.

The largest proportion of Pakistanis have always lived in the Barani and Northern Irrigated areas of Punjab and continue to reside there. This is possibly the most stable area in terms of agriculture, and is often called the country's "bread basket." It has also experienced minimal change in temperature and probably best benefitted from rises in rainfall. Closely comparable to this zone, with lower temperatures and increased rainfall, are the Wet Mountains and Irrigated regions of KP.

Karachi with its almost urban population is exposed to fast-rising temperatures and reduced rainfall. Alongside these environmental stresses, its population has increased 15-fold from 1.1 million to an estimated 16 million.

Table 3.4 Total population size and changes across time, by zone category, 1951-2017

\begin{tabular}{|l|c|c|c|}
\multirow{2}{*}{ Zone category } & \multicolumn{3}{|c|}{$\begin{array}{c}\text { Population and Housing Census } \\
\text { (Population in Million) }\end{array}$} \\
\cline { 2 - 4 } & 1951 & 1981 & 2017 \\
\hline Less affected zones (1 to 3) & 25.9 & 59.1 & 142.7 \\
\hline Severely affected zones (4 to 7) & 6.5 & 19.8 & 49.0 \\
\hline Karachi & 1.1 & 5.4 & 16.1 \\
\hline PAKISTAN & 33.5 & 84.3 & 207.8 \\
\hline
\end{tabular}

Source: Pakistan Population and Housing Census 1951, 1981 and 2017. 
Between 1951 and 2017, the population has grown more in the more affected zones-from 6.5 million to 49 million, a 7.5 times increase-than in the less affected regions, which have grown at a slower pace by 5.5 times. Table 3.5 and Figure 3.4, which present intercensal population growth rates, show that a spurt in growth took place from 1951 to 1981 in the severely affected regions, which was far stronger than the growth seen in the other regions. In 1981-2017, population growth rates in some of the severely affected zones started slowing down, especially in the Southern Irrigated Plains and Sandy Desert. But the Dry Western Plateau and Western Dry Mountains still have high population growth rates. Interestingly, even in the less affected zones, those affected by floods, i.e., the KP Irrigated Plains and Northern Dry Mountains, have experienced higher growth rates. Population growth is driven by both fertility and in-migration, and the rates presented may reflect higher fertility, or, more possibly, an increase in migration, both internal and international, from regions of the former Federally Administered Tribal Areas (FATA) ${ }^{3}$ and Afghanistan.

Populations have grown faster in the severely affected zones, especially in 1961-98. It is interesting to note that growth rates in the less affected zones peaked in 1961-72, and started waning much earlier. In contrast, the severely affected areas continued to grow rapidly until the 1972-81 period and then began to decline. Even in Karachi, largely as a result of its high rates of in-migration, population growth rates only began to wane after 1981.

Table 3.5 Annual estimated growth in population across the zone categories, 1951-2017

\begin{tabular}{|l|r|r|r|r|r|}
\hline Zone category & 1951-1961 & 1961-1972 & 1972-1981 & 1981-1998 & 1998-2017 \\
\hline Less affected zones (1 to 3) & 2.17 & 3.52 & 2.46 & 3.62 & 2.30 \\
\hline Severely affected zones (4 to 7) & 2.88 & 4.57 & 3.54 & 3.51 & 2.53 \\
\hline Karachi & 5.89 & 5.16 & 4.56 & 3.50 & 2.57 \\
\hline PAKISTAN & 2.46 & 3.82 & 2.83 & 2.66 & 2.37 \\
\hline
\end{tabular}

Source: Pakistan Population and Housing Censuses.

Figure 3.4 Comparison of annual average population growth rate (PGR) in 1951-81 and 1998-2017, by agroecological zone

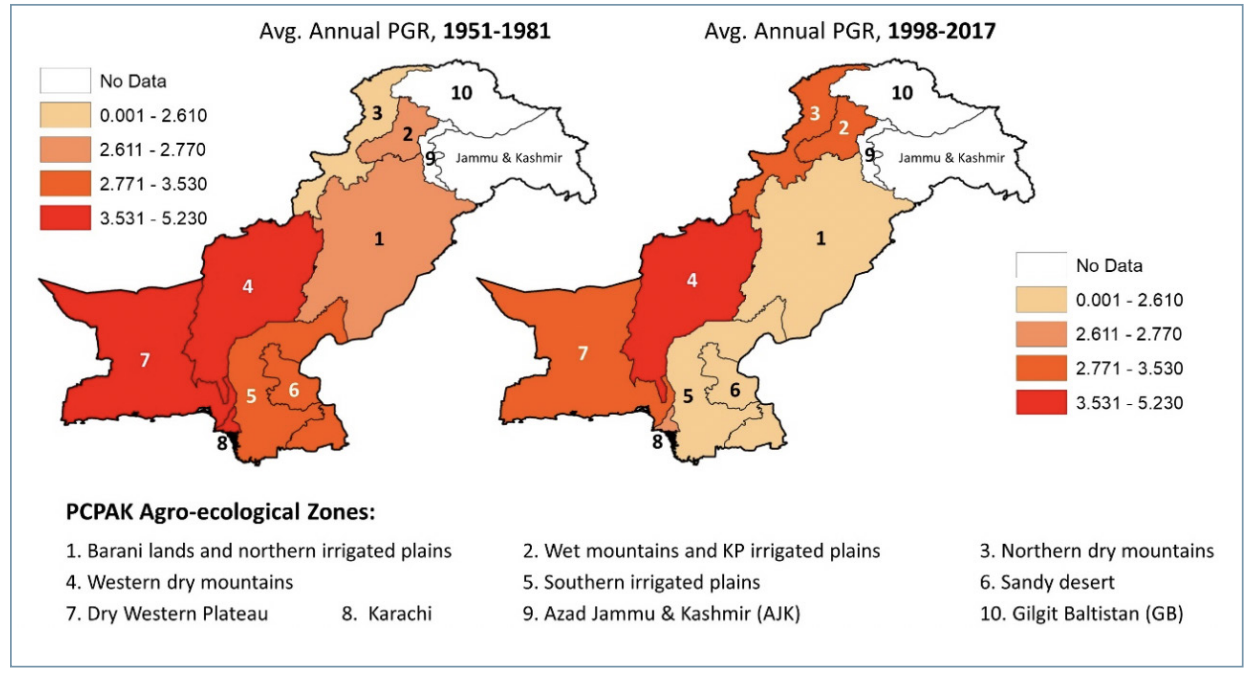

Source: Pakistan Population and Housing Censuses.

\footnotetext{
${ }^{3}$ This region has recently been merged with the Khyber Pakhtunkhwa province.
} 
Pakistan is certainly urbanizing at a fast rate, and the less affected zones have managed to urbanize faster. Table 3.6 below confirms that population growth has indeed been high throughout the country but definitely higher in urban areas, mainly because of in-migration. In fact, in proportional terms, the urban population has increased and the proportions of rural dwellers to urban dwellers has declined in Pakistan. There were barely 6 million Pakistanis living in urban areas in 1951, out of whom 1 million lived in Karachi. There are now 75 million Pakistanis living in urban areas, representing more than a 12-fold increase.

Pakistan has become a much more urbanized country particularly after 1981. It is important to point out that it is the most urbanized country of South Asia. As Table 3.6 shows, urban growth rates exceed rural growth rates in all zones by about $1.5 \%$, but the difference in growth rates is smaller in the zones we have categorized as severely affected. As can be seen in Figure 3.5, in 1951, barely two regions (namely Karachi and the Barani Lands and Northern Irrigated Plains) were urbanized as opposed to a large part of the country by 2017.

The most dramatic urbanization in Pakistan took place before 1972 in the less affected zones, probably reflecting an earlier diversification of incomes and employment away from agriculture to nonagricultural alternatives. The more severely affected regions did not urbanize until later. This may represent an inability to adapt earlier and a later and more acute reaction to climate patterns and limitations to agricultural growth. In contrast the urban areas of the less affected zones had higher pull factors drawing urban inmigration earlier on.

Table 3.6 Annual estimated growth in urban and rural population across the zone categories, 1951-2017

\begin{tabular}{|c|c|c|c|c|c|}
\hline Zone category & 1951-1961 & 1961-1972 & 1972-1981 & 1981-1998 & 1998-2017 \\
\hline \multicolumn{6}{|l|}{ URBAN } \\
\hline Less affected zones ( 1 to 3 ) & 4.24 & 4.66 & 3.93 & 3.39 & 3.03 \\
\hline Severely affected zones ( 4 to 7 ) & 5.80 & 5.15 & 3.94 & 3.82 & 3.32 \\
\hline Karachi & 5.82 & 5.53 & 4.37 & 3.44 & 2.46 \\
\hline PAKISTAN & 4.78 & 4.92 & 4.03 & 3.47 & 2.96 \\
\hline \multicolumn{6}{|l|}{ RURAL } \\
\hline Less affected zones ( 1 to 3 ) & 1.74 & 3.22 & 2.01 & 2.35 & 1.98 \\
\hline Severely affected zones ( 4 to 7 ) & 2.32 & 4.44 & 3.44 & 2.12 & 2.23 \\
\hline Karachi & 6.97 & -3.31 & 10.25 & 4.77 & 4.16 \\
\hline PAKISTAN & 1.88 & 3.48 & 2.39 & 2.30 & 2.06 \\
\hline
\end{tabular}

Source: Pakistan Population and Housing Censuses.

Growth rates in rural parts of the severely affected zones continued to be high until 1981 but have been slowing down, while urban growth rates in these zones remain above the national average.

Pakistan remains primarily agricultural, but climate vagaries are more likely to influence rural populations of the more severely affected zones. The rural population is mostly dependent on agriculture, the backbone of Pakistan's economy. This population was 27.5 million in 1951 but has risen to 100 million. Because of the direct implications of environmental changes for agricultural productivity, rural populations face high risks to their livelihoods and well-being. ${ }^{2}$

\footnotetext{
${ }^{2}$ In a recent study by the World Bank, Punjab is definitely classified as best off in terms of water availability for agriculture through both canal irrigation and rainfall. Khyber Pakhtunkhwa, while better off in terms of rain, does not have the same advantage as Punjab in terms of irrigation or groundwater retention. Sindh was considered a close second to Punjab in terms of water availability and river water recharge, but rainwater is likely to have diminished as a source of groundwater available for agriculture (Young et al. 2019).
} 
The rural population in the less affected zones is shrinking. Rural growth rates have certainly slowed down in the last few decades and are now $1.98 \%$ in the less affected zones, lower than the national average of $2.4 \%$. Rural growth rates in severely affected areas are also lower than national growth averages at just above $2.2 \%$. This finding has to be investigated in much more detail and broken down into its components of fertility changes and outmigration. Both factors, a decline in fertility and possible outmigration, have implications for agricultural production and may be a manifestation that agricultural growth may be slowing down. This is based on the assumption that the movement of population from agriculture to nonagriculture, from rural areas to cities, and from cities to work abroad are all part of the processes of economic migration-directly or indirectly linked with whether the agricultural base and agricultural incomes provide sufficient attractions to stay back. A deeper investigation will look at these factors more carefully. The next study in this volume provides sufficient evidence of outmigration and its differential patterns across the zones.

Urban growth still presents alternative employment opportunities. There is a slowdown in urban growth especially in the less affected regions, except for the Northern Dry Mountains. The Barani and Northern Irrigated and KP Irrigated and Wet Mountains are seeing a major slowdown in urban growth. Karachi, the major urban center has also seen a major decline in population growth in the recent decade. Urban growth rates in the more severely affected areas have not slowed down as much. Destinations for economic migrants may be changing to district capitals and newer towns rather than big cities, such as Gwadar, Faisalabad, Lasbella, and Mardan, rather than Quetta, Lahore, Karachi, and Peshawar. The largest cities may have peaked in terms of the returns they offer. This is also a topic for further investigation; as changes in climate patterns become more accentuated, it will be increasingly important to ascertain outmigration flows and destinations.

Figure 3.5 Urban proportion (\%) across agro-ecological zones, 1951 and 2017

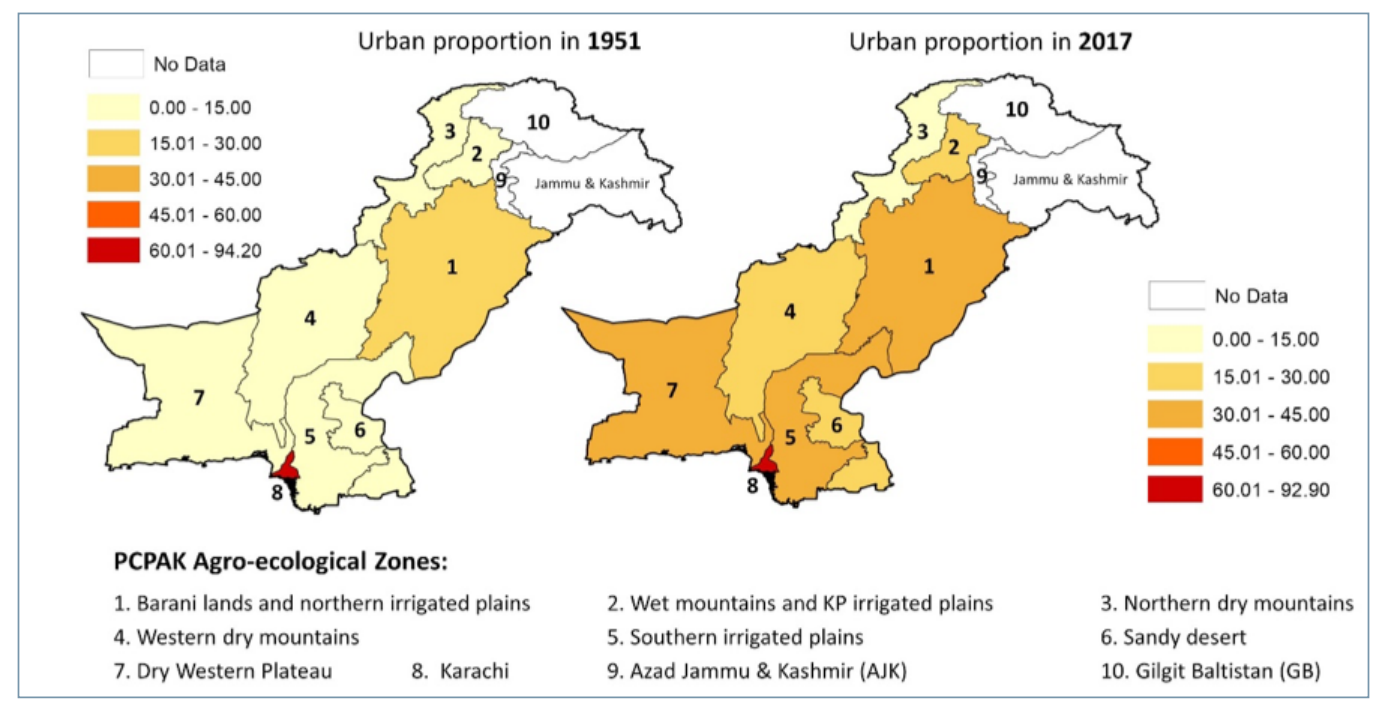

Source: Pakistan Population and Housing Censuses.

While urbanization is an inevitable part of development, it does translate into a visible squeeze of resources because of more finite urban limits. Population pressure is being felt most acutely in the form of high population densities. We can observe in Figure 3.6 that the densest area, of course, was Karachi, followed by Northern Irrigated Plains and Barani Lands in 1951. These zones continue to have the highest densities in 2017 but are joined by Southern Irrigated Plains and the Western Plateau.

The main jump in population densities occurred after 1981 when the average numbers of persons living per square kilometer in Pakistan went from 106 to 261. Even more interesting is the observation of which regions have the greatest population densities. The high-density populations are concentrated in three zones, including only one less affected zone-the Barani Lands and Northern Irrigated Plains-while all the rest are situated in zones severely affected by changes in climate patterns, including the Southern Irrigated Plains, Dry Western Plateau, and Karachi (Table 3.7). 
Table 3.7 Population density changes across the zone categories, 1951-2017

\begin{tabular}{|l|r|r|r|r|r|r|r|}
\hline \multirow{2}{*}{ Zone category } & \multicolumn{6}{|c|}{ Population density, per sq. km } & $\begin{array}{c}\text { Increase in population } \\
\text { density from 1951 to } \\
2017 \text { (Times) }\end{array}$ \\
\cline { 2 - 8 } & 1951 & 1961 & 1972 & 1981 & 1998 & 2017 & 5.5 \\
\hline Less affected zones (1 to 3) & 87 & 109 & 160 & 199 & 311 & 482 & 7.6 \\
\hline Severely affected zones (4 to 7) & 13 & 18 & 29 & 40 & 61 & 99 & 14.2 \\
\hline Karachi & 321 & 580 & 1,023 & 1,542 & 2,795 & 4,551 & 6.2 \\
\hline PAKISTAN & 42 & 54 & 82 & 106 & 166 & 261 & \\
\hline
\end{tabular}

Source: Pakistan Population and Housing Censuses.

Figure 3.6 Comparison of population density in agro-ecological zones, 1951 and 2017

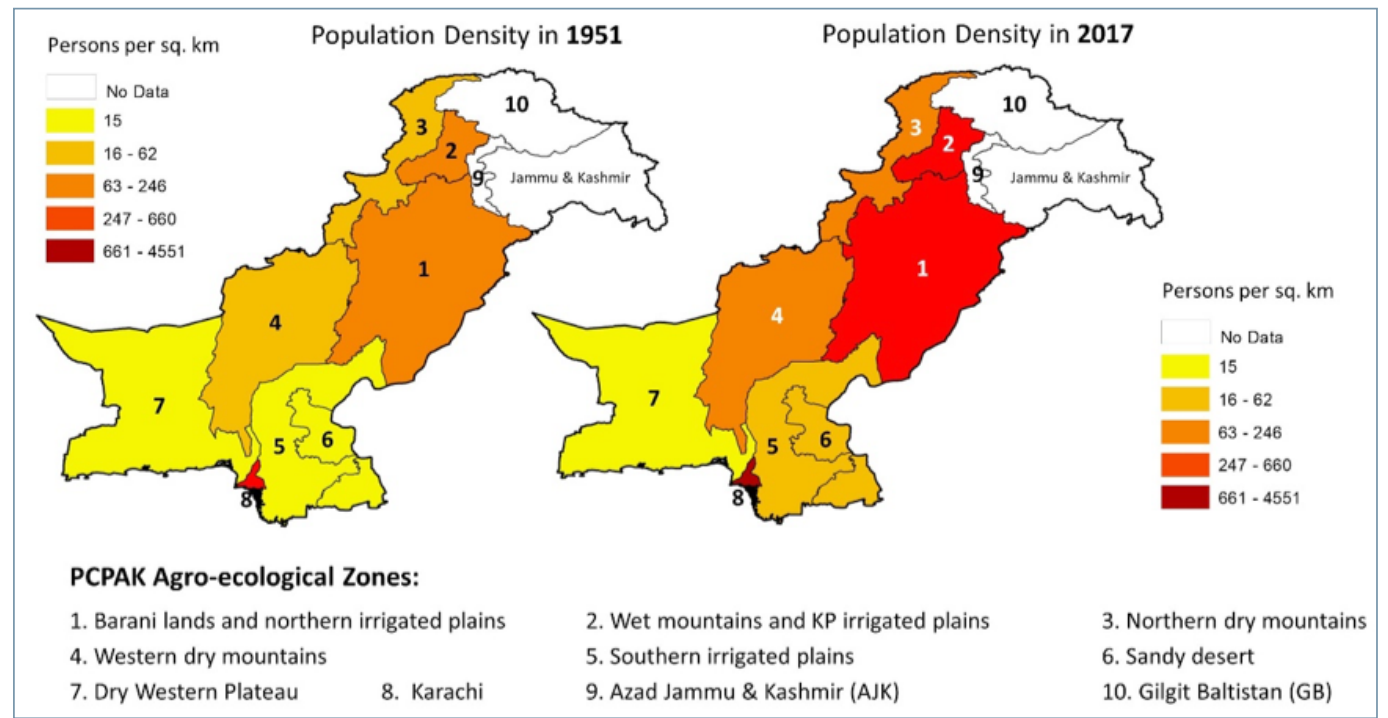

Source: Pakistan Population and Housing Censuses.

As an indicator of carrying capacity or concentration of population growth in relation to a limited geography, population density tells an interesting story. The severely affected regions once again emerge as the ones whose densities have risen disproportionately more rapidly, suggesting that demographic and environmental stresses may be combining to compound challenges in adaptation. In Karachi, for example, the density has reached 4,550 persons per square kilometer, and even higher levels in the growing katchi abadis (slums).

Stressors on the rapidly expanding urban areas of Pakistan are an important subject for the climate change discourse. This is another area deserving further disaggregation and deeper study. A big question to answer, going forward, is the carrying capacity of Karachi and other big cities and whether we have reached the limits, especially in providing services.

\section{ASSESSING HOUSEHOLD VULNERABILITY AND ADAPTIVE POTENTIAL}

The earlier section has provided us an idea of who and how many are being affected more by changes in climate patterns, and also how major demographic changes, such as population growth, urbanization, and migration, are affecting the zones differentially. We now look deeper at differences in household-level behaviors that provide indications of vulnerability to changing climate patterns, as well as capacities to cope and adapt. The specific topics in this part of our investigation include household conditions, engagement in agriculture, investments in children, fertility and health outcomes, and poverty levels.

We utilize the most recent (2014-15) district-level rounds of the Pakistan Social and Living Standards Measurement Survey (PSLMS) to assess most behaviors, including the measurement of poverty. Fertility rates, immunization, and nutritional status are computed using the data of the last two rounds (2012-13 and 2017-18) of the Pakistan Demographic and Health Survey (PDHS). 


\section{HOUSING CONDITIONS}

It is not surprising that the more severely affected areas have the highest number of household members compared to the less affected zones, and especially Karachi, where the average is less than five persons (Table 3.8). Differences across urban and rural areas are minimal except in the case of Karachi. But a keener measure of quality of life may lie in the average numbers of people living in one room, which is again highest in the severely affected areas at almost four persons per room. Karachi on the other hand has a significantly lower number of 2.5 persons living in a room. Although there are slightly better urban living conditions in each of the zones, these do not differentiate the zones.

Household sizes measure a combination of three factors-fertility levels, migration, and nuclear-extended family living. There has been a substantial decline of 0.4 in household size in Pakistan between the 1998 and 2017 censuses. This change is greater in urban than in rural areas, also reflecting lower fertility levels in the urban areas but possibly the lowering of the surge of rural-to-urban migration mentioned earlier. Interestingly,

Table 3.8 Household size and number of persons per room, by zone category, 2014-15

\begin{tabular}{|l|c|c|c|c|c|c|}
\multirow{2}{*}{ Zone category } & \multicolumn{2}{|c|}{ Number of persons per Household } & \multicolumn{3}{|c|}{ Number of members per room } \\
\cline { 2 - 7 } & Overall & Rural & Urban & Overall & Rural & Urban \\
\hline Less affected zones (1 to 3) & 6.3 & 6.3 & 6.1 & 3.1 & 3.2 & 3.0 \\
\hline Severely affected zones (4 to 7) & 6.7 & 6.7 & 6.7 & 3.9 & 4.1 & 3.6 \\
\hline Karachi & 4.9 & 5.2 & 4.9 & 2.5 & 3.5 & 2.4 \\
\hline PAKISTAN & 6.2 & 6.4 & 5.9 & 3.3 & 3.4 & 3.0 \\
\hline
\end{tabular}

Source: Pakistan Social and Living Standards Measurement Survey (PSLMS) 2014-15.

the larger proportionate changes in household size across 1998-2017 are noted in the urban parts of the Barani Lands and Northern Irrigated Plains, Southern Irrigated, Sandy Desert, Western Dry Mountains, and Karachi zones. There is an increase in household size in the Dry Western Plateau, the most vulnerable region, and also a slight increase in household size in the rural parts of the Western Dry Mountains.

The more severely affected are living in vulnerable living conditions. An important measure of living standard is the structure and amenities in the household. As can be seen in Table 3.9, those living in Karachi live in more stable conditions in terms of pakka (concrete) walls, having a toilet in the household, and safe sanitation, followed quite closely by those living in less affected zones (especially their urban areas). If we focus on the urban areas alone, then pakka walls and even a toilet in the household seem to be the norm. However, safe sanitation is not available to $79 \%$ of those living in the urban areas of severely affected zones. This really reaffirms their much more adverse living conditions.

Table 3.9 Household conditions, by zone category, 2014-15

\begin{tabular}{|c|c|c|c|c|c|c|c|c|c|c|c|c|}
\hline \multirow{2}{*}{$\begin{array}{c}\text { Zone } \\
\text { category }\end{array}$} & \multicolumn{3}{|c|}{ Pacca walls } & \multicolumn{3}{|c|}{ No toilet in the household } & \multicolumn{3}{|c|}{ Safe sanitation* } & \multicolumn{3}{|c|}{ Improved water** } \\
\hline & Overall & Rural & Urban & Overall & Rural & Urban & Overall & Rural & Urban & Overall & Rural & Urban \\
\hline $\begin{array}{l}\text { Less } \\
\text { affected } \\
\text { zones } \\
\text { (1 to } 3 \text { ) }\end{array}$ & 89.3 & 85.4 & 98.0 & 14.1 & 20.0 & 0.8 & 66.5 & 58.8 & 84.0 & 91.6 & 90.2 & 94.8 \\
\hline $\begin{array}{l}\text { Severely } \\
\text { affected } \\
\text { zones } \\
(4 \text { to } 7)\end{array}$ & 55.9 & 43.9 & 86.3 & 13.9 & 18.9 & 1.5 & 16.7 & 14.7 & 21.8 & 84.5 & 81.9 & 91.0 \\
\hline Karachi & 99.0 & 86.7 & 99.8 & 0.4 & 5.1 & 0.1 & 96.7 & 58.1 & 99.3 & 87.8 & 79.0 & 88.4 \\
\hline PAKISTAN & 81.6 & 73.8 & 95.9 & 13.0 & 19.6 & 0.8 & 56.2 & 46.4 & 74.4 & 89.5 & 87.8 & 92.7 \\
\hline
\end{tabular}

Source: Pakistan Social and Living Standards Measurement Survey (PSLMS) 2014-15.

*Flush to sewerage and flush to septic tank.

**Piped water, hand pump, motorized pumping, close well, mineral water and filtration plant are classified as sources of improved water. 


\section{RELIANCE OF HOUSEHOLD ECONOMY ON AGRICULTURE}

There is continuing reliance of the household economy on agriculture across rural Pakistan. Overall about a quarter of adult household members in rural areas are engaged in agriculture. While unchanging, this proportion is about 10 percent higher in the more severely affected zones compared to the less affected. Expectedly, in Karachi, the proportion is as low as $8.4 \%$ and down from ten years earlier (Table 3.10).

Of possible greater significance, are changes in ownership of agricultural land. Dramatically the ownership of agricultural land in rural Pakistan, has come down from 46.7 to $37.3 \%$ in just ten years. Agricultural land ownership is slightly higher in the severely affected areas. However, change in ownership of agricultural land are more dramatic in the less affected areas have been wiped out in Karachi.

These changes may reflect quite different patterns of utilization of agricultural land, most probably because of its greater demand and therefore changing price structures. One possible pathway is the rising demand on the numbers of housing units due to population pressure. Another is increased commercial activity in rural areas. Certainly this requires an investigation into rising costs of agricultural land.

Another piece of supporting evidence is that land ownership by those households involved in agriculture has also declined drastically, most probably reflecting changes in household economic choices. In the less affected zones it has come down from $68 \%$ to $45 \%$, and more slightly from $42.3 \%$ to $31.3 \%$ in the more severely affected zones. We intend to investigate these trends further in our subsequent research, as they provides clues of the possible pathways between agriculture and population dynamics.

Table 3.10 Indicators of household involvement in agriculture, by zone category, 2014-15

\begin{tabular}{|l|r|r|r|r|r|r|}
\hline \multirow{2}{*}{ Zone category } & \multicolumn{2}{|c|}{$\begin{array}{c}\text { Proportion engaged in agri- } \\
\text { culture culture (aged 10+) }\end{array}$} & $\begin{array}{l}\text { Percentage of rural house- } \\
\text { holds owning agricultural } \\
\text { land }\end{array}$ & $\begin{array}{c}\text { Percentage of households } \\
\text { involved in agriculture and } \\
\text { owning land }\end{array}$ \\
\cline { 2 - 8 } & $2004-05$ & $2014-15$ & $2004-05$ & $2014-15$ & $2004-05$ & $2014-15$ \\
\hline Less affected zones (1 to 3) & 20.7 & 21.2 & 48.3 & 40.0 & 67.7 & 44.6 \\
\hline Severely affected zones (4 to 7) & 30.1 & 30.8 & 42.3 & 31.3 & 52.0 & 42.4 \\
\hline Karachi & 11.1 & 8.5 & 22.3 & 0 & 33.1 & 0 \\
\hline PAKISTAN & 22.9 & 23.7 & 46.7 & 37.3 & 62.9 & 142.7 \\
\hline
\end{tabular}

Source: Pakistan Social and Living Standards Measurement Survey (PSLMS) 2014-15.

\section{INVESTMENTS IN THE NEXT GENERATION}

The fertility transition has been slow in happening in Pakistan. In general, the argument states that it is when parents start to make greater investments in children and focus on their quality of life that fertility begins to fall.

Earlier, even the urban areas of Pakistan did not show much change, but now urban living is increasingly associated with lower fertility. Karachi is at the lead in the fertility transition (Table 3.11). One of the factors behind its resilience, in the face of both climatic risks and rapid in-migration, is probably its lower rate of natural increase. This is not reflected in its higher population growth rates, which include in-migration. In fact, the slight increase seen in fertility in Table 3.11 may be attributable to a new influx of migrants, possibly internally displaced persons with much higher levels of fertility.

Fertility levels have dropped in all zones (except Karachi) in the last five years by about 0.2 children per woman, but they are still high, especially in the severely affected zones (Table 3.11, Figure 3.7).

Families in the less affected zones are having much fewer children. Moreover, the differences between urban and rural fertility in these zones are quite narrow, indicating diffusion of the idea of lower family sizes in these areas.

While the fertility transition does seem to have finally permeated across the country, not surprisingly, the most fragile areas are the slowest to change. Karachi's fertility levels have not permeated to contiguous zones, i.e., the Western Plateau and Southern Irrigated Plains, as reflected in Figure 3.7. Indeed, there is almost a divide of higher fertility in the more affected zones, and lower fertility in the less affected ones. 
Table 3.11 Total fertility rates in 2012-13 and 2017, by zone category

\begin{tabular}{|l|c|c|}
\multirow{2}{*}{ Zone category } & \multicolumn{2}{|c|}{ Total Fertility Rate (TFR) } \\
\cline { 2 - 3 } & $\mathbf{2 0 1 2 - 1 3}$ & $\mathbf{2 0 1 7 - 1 8}$ \\
\hline Less affected zones (1 to 3) & $\mathbf{3 . 7 7}$ & $\mathbf{3 . 5 3}$ \\
\hline Severely affected zones (4 to 7) & 4.59 & 4.32 \\
\hline Karachi & $\mathbf{2 . 5 2}$ & $\mathbf{2 . 7 1}$ \\
\hline PAKISTAN & 3.8 & 3.6 \\
\hline
\end{tabular}

Source: Pakistan Demographic and Health Survey (PDHS) 2012-13 and 2017-18.

Figure 3.7 Total fertility rates in 2012-13 and 2017 across agroecological zones

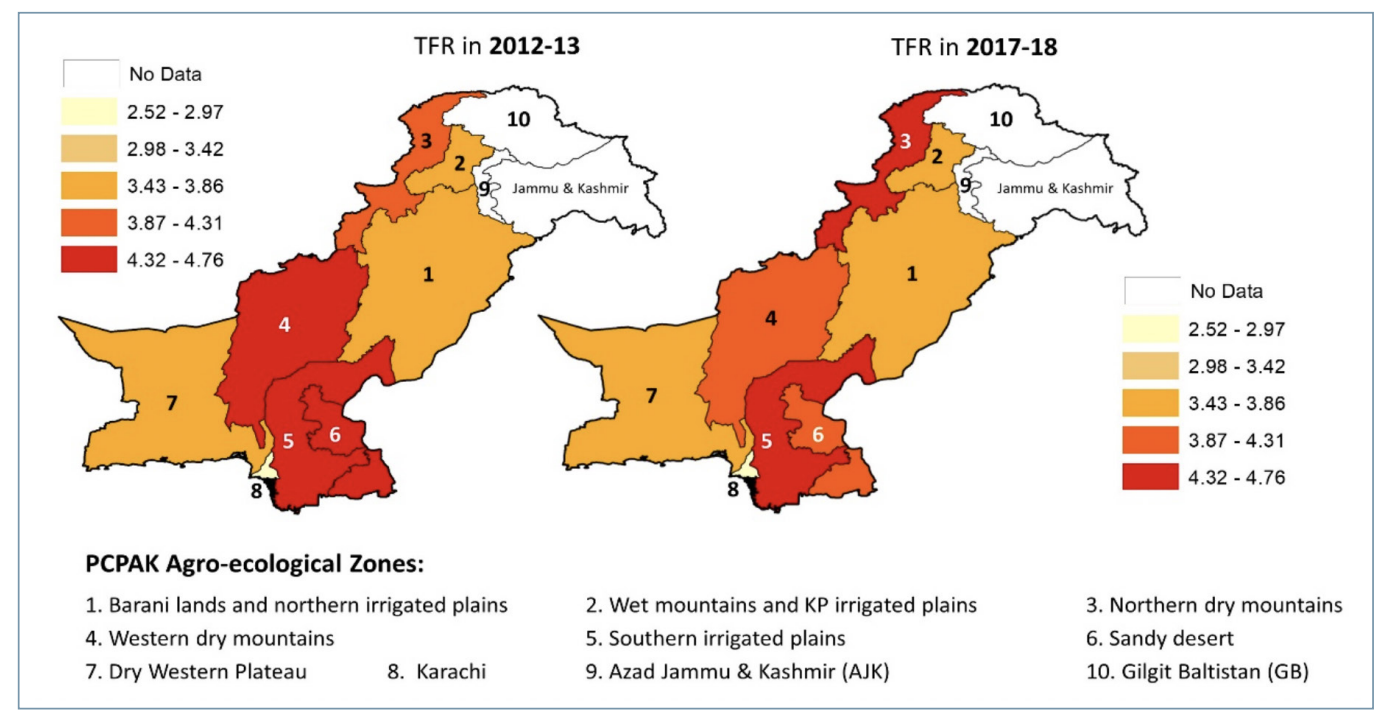

Source: Pakistan Demographic and Health Survey (PDHS) 2012-13 and 2017-18.

A strong reason why fertility is related to adaptation capacity is associated directly with the feeding, educating, and upkeep of young children in the household. Table 3.12 shows that there is a dramatic difference in the number of children in the household across our three zone categories: Karachi has half the number of children in the household compared to the more severely affected zones. Even the less affected zones also have a substantial number of children under 15 , raising their vulnerability compared to Karachi.

As a result, Karachi is quite advanced in terms of a lower dependency ratio compared to both the less and more severely affected zones. Lower dependency ratios are directly related to lower consumption, higher savings, and greater prosperity. This may be one of the strongest adaptation features that still presents Karachi as an attractive and viable city despite the high density and the elevated climate risk.

Table 3.12 Mean number of children under 15 and age dependency ratios, by zone category, 2014-15

\begin{tabular}{|l|c|c|c|c|c|c|}
\hline \multirow{2}{*}{ Zone category } & \multicolumn{3}{|c|}{ Mean number of children under 15 } & \multicolumn{3}{c|}{ Age dependency ratio } \\
\cline { 2 - 7 } & Overall & Rural & Urban & Overall & Rural & Urban \\
\hline Less affected zones (1 to 3) & 2.5 & 2.6 & 2.2 & 0.761 & 0.820 & 0.642 \\
\hline Severely affected zones (4 to 7) & 3.0 & 3.1 & 2.7 & 0.884 & 0.938 & 0.759 \\
\hline Karachi & 1.5 & 1.8 & 1.5 & 0.496 & 0.529 & 0.493 \\
\hline PAKISTAN & 2.5 & 2.7 & 2.1 & 0.766 & 0.849 & 0.630 \\
\hline
\end{tabular}

Source: Pakistan Demographic and Health Survey (PDHS) 2012-13 and 2017-18. 
Families living in the less affected zones are also investing more in the education of their children (including daughters). Investments in education, especially secondary education, are a strong indicator of future adaptive capacities, particularly in relation to nonagricultural livelihood options. A certain amount of education is a necessity, but a secondary education and beyond is required for nonagricultural work. While primary enrollment rates have risen for both boys and girls in the last decade (Table 3.13) they are much lower in the more affected zones.

Furthermore, the primary and secondary rates of enrollment are closer to parity in the less affected areas and actually even better for girls in Karachi! For secondary education, the differences are quite narrow for males and females in less affected zones and for Karachi, but quite substantial for the more severely affected areas. The gender parity index augurs well for Karachi and also for the less affected zones: although secondary schooling is still much below desirable levels, families are at least investing in both boys and girls equally. However, girls in the more severely affected zones are definitely left far behind, increasing gender disparities and lowering their level of empowerment and options for life beyond unpaid work.

The differences in primary and secondary enrollment, and in gender parity, all point to higher vulnerability and lower capacity to adapt to climate-related stresses, with greater dependence on agricultural livelihoods; in the zones most affected by climatic changes, the next generation is least equipped to cope and to diversify income sources in the future.

Last, in terms of investments in children's health, immunization levels have improved tremendously in Pakistan, but they still differ across regions (Table 3.14). Once again, children of the less affected zones are much more likely (72\%) to have the full set of basic vaccinations while less than half (43\%) of children living in the severely affected zones receive this essential service. Karachi does not fare well in the comparison, at $66 \%$.

Even more importantly, children are much more acutely malnourished in the severely affected zones: $53 \%$ are stunted, $13 \%$ wasted, and $44 \%$ are underweight. The rates are much lower for the less affected zones, in fact faring better than Karachi, where the relatively poor indicators of child health raise serious questions about the adequacy of services.

Table 3.13 Net enrollment rates in primary and secondary for boys and girls and gender parity index, by zone category, 2014-15

\begin{tabular}{|l|c|c|c|c|c|c|}
\multirow{2}{*}{ Zone category } & \multicolumn{3}{|c|}{ Primary level } & \multicolumn{3}{c|}{ Secondary level } \\
\cline { 2 - 7 } & Boys & Girls & GPI & Boys & Girls & GPI \\
\hline Less affected zones (1 to 3) & 63.4 & 58.3 & 0.92 & 38.9 & 35.4 & 0.91 \\
\hline Severely affected zones (4 to 7) & 53.6 & 39.9 & 0.74 & 28.7 & 18.5 & 0.64 \\
\hline Karachi & 59.0 & 63.2 & 1.07 & 43.5 & 47.3 & 1.09 \\
\hline PAKISTAN & 60.1 & 53.0 & 0.88 & 36.4 & 31.8 & 0.87 \\
\hline
\end{tabular}

Source: Pakistan Social and Living Standards Measurement Survey (PSLMS) 2014-15.

Table 3.14 Immunization levels (percentage of children of ages 12-23 months who received all basic vaccinations) and nutritional levels of children, by zone category, 2017-18

\begin{tabular}{|l|c|c|c|c|}
\multirow{2}{*}{ Zone category } & \multirow{2}{*}{$\begin{array}{c}\text { All basic } \\
\text { vaccinations }\end{array}$} & Stunted & Wasted & Underweight \\
\cline { 3 - 5 } & 72.4 & 33.0 & 4.8 & 15.7 \\
\hline Less affected zones (1 to 3) & 43.3 & 53.2 & 13.0 & 43.8 \\
\hline Severely affected zones (4 to 7) & 66.4 & 29.6 & 8.9 & 21.3 \\
\hline Karachi & 65.6 & 37.6 & 7.1 & 23.1 \\
\hline PAKISTAN & & (Percentage below -2 Standard (deviation ) \\
\hline
\end{tabular}

Source: Pakistan Demographic and Health Survey (PDHS) 2017-18.

*BCG, three doses of DPT-HEPB-HIB, three doses of oral polio vaccine (excluding polio vaccine given at birth), and one dose of measles vaccine. 


\section{IMPACT ON MULTIDIMENSIONAL POVERTY}

The less affected zones and Karachi are more economically viable and improving their status. Meanwhile, in the more severely affected zones, people live in much poorer housing conditions, have larger households with more children under age 15, and are dependent on agriculture with lower proportions owning agricultural land. They invest less in their children's welfare, with low immunization rates and high rates of stunting and wasting. Above all, educational attainment of children, especially girls, is lower in comparison to less affected zones. Karachi has demonstrated that urbanization is a source of adaptation as despite its vulnerability to climate, it has still flourished in other respects. These trends suggest a poor outlook for the economic viability, health, and general wellbeing of people living in the more severely affected zones.

Poverty levels measured on a multidimensional scale are expected to demonstrate the overall impact of these major underlying differences. We find substantial variation (Table 3.15) in levels of multidimensional poverty across the major zones ranging from just $4.4 \%$ in Karachi to $72 \%$ in the western dry plateau and western dry mountains. Populations living in the most severely affected zones are more likely to live in poverty despite improvements in the last ten years. Poverty has declined most in the urban areas throughout Pakistan.

Rural poverty changes are more directly linked to agriculture and thereby climate effects. We find that the

Table 3.15 Poverty levels (Multidimensional Poverty Headcount) and improvements in the last decade, by zone category

\begin{tabular}{|c|c|c|c|c|c|c|}
\hline \multirow{2}{*}{ Zone category } & \multicolumn{3}{|c|}{ 2004-05 } & \multicolumn{3}{|c|}{ 2014-15 } \\
\hline & Overall & Rural & Urban & Overall & Rural & Urban \\
\hline Less affected zones ( 1 to 3 ) & 50.8 & 62.8 & 19.9 & 34.6 & 46.8 & 6.9 \\
\hline Severely affected zones (4 to 7 ) & 72.4 & 86.2 & 41.5 & 62.6 & 77.3 & 25.3 \\
\hline Karachi & 14.9 & 79.6 & 12.3 & 4.4 & 36.7 & 2.3 \\
\hline PAKISTAN & 53.3 & 68.5 & 23.0 & 39.4 & 55.3 & 9.8 \\
\hline
\end{tabular}

Source: Pakistan Social and Living Standards Measurement Survey (PSLMS) 2004-05 and 2014-15.

less affected zones have experienced the largest decline in rural poverty from $63 \%$ to $47 \%$ whereas the corresponding decline in poverty in the more severely affected areas is from $86 \%$ to $77 \%$. The Barani Lands, Northern Irrigated Plains, Wet and Northern Dry Mountains, and KP Irrigated Plains have experienced substantial reductions in poverty. That is not the case in the Western Plateau, Sandy Desert, or Western Mountains (Figure 3.8). Karachi has a very low rate of poverty and has seen a dramatic reduction in rural poverty to just $37 \%$. In the last decade, the rural areas of the less affected zones have benefitted much more in poverty reduction.

Figure 3.8 Changes in poverty levels in urban and rural regions of the zones, 2005-15

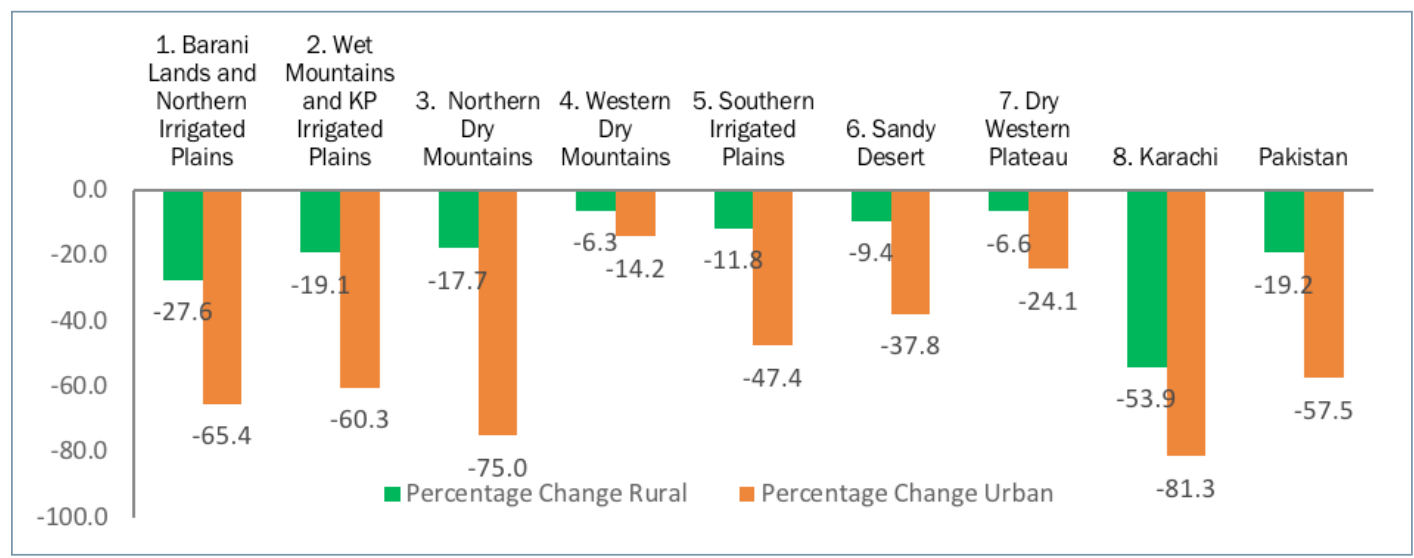

Source: Pakistan Social and Living Standards Measurement Survey (PSLMS) 2004-05 and 2014-15. 


\section{CONCLUSIONS}

Our analysis of meteorological data ranging from 1901-2016 finds clear differences in the exposure of the agroecolo gical zones of Pakistan to changes in the climate. When we overlay our picture of climate exposure with an analysis of demographic and socioeconomic data, a consistent picture emerges of higher vulnerability and lower adaptive capacity in the regions most affected by climate change.

What is clear is that the challenges arising from changes in climate patterns are likely to be compounded by the needs of an increasing population in both urban and rural areas, making it more important than ever to support human adaptation to ensure that a balance between natural resources and the environment is maintained. Moreover, it is of concern that the severely affected and more vulnerable population is growing at a faster rate than the better-off populations of less affected zones. The increase in severely affected population will be $130 \%$ by 2050 (at current levels of population growth), compared to $110 \%$ for the less affected areas.

This study is preliminary and requires much further investigation to support some of the major factors that emerge as strategies of adaptation-education, lower population growth, urbanization, and diversified sources of income away from agriculture, particularly through migration. Geography and climate patterns do matter, but in enabling adaptation, the potential of human investments in education and lower fertility should not be underestimated. 


\title{
constreas \\ Climate Change and Migration- as-Adaptation in Pakistan: Preliminary Findings
}

\author{
G.M. ARIF AND MAQSOOD SADIQ
}

\section{INTRODUCTION}

The key past observed trends of climate change in Pakistan include a rise in average annual temperature, an increase in heat wave days, sea level rise, and decrease in winter and summer rainfall in the arid plains and coastal areas and a rise in the summer rainfall over the core monsoon regions (Chaudhry 2017). The mountain regions of the country have also experienced warming during the last century and extreme precipitation has increased overall as well (Krishnan et al. 2019). Future projections show an increase in the temperature in Pakistan higher than the global average, high frequency of hot days and nights, and a decrease in per capita water availability (Chaudhry 2017, Krishna et al. 2019). More frequent occurrence of extreme events, such as floods, is also expected. The agricultural sector of Pakistan is highly vulnerable to climate change (see chapter 1 ). Although results from an estimation of historical data reveal that there has been no significant negative impact of climate change on agriculture production, notably wheat, as yet, in the future (and after 2020 particularly), agricultural output will significantly depend on climate change variables (Ahmed, Siftain, and lqbal 2014). Because of changes in precipitation patterns, farmers have already delayed wheat sowing across the country at least for 14 days (Ahmed, Siftain, and lqbal 2014); this may have an adverse effect on wheat production in the long run.

"Food security is the fundamental percept of the right to adequate food" (Rasul et al. 2019). The performance of the agriculture sector is critical for food security in two ways: it produces the food people eat; and, more importantly, it provides the primary source of livelihood for more than one-third of the world's total workforce (FAO 2018). In Pakistan, this sector also provides employment to more than $40 \%$ of the total labor force and is the major source of livelihood for the rural population. Despite a continuous decline in rural poverty during the last two decades, approximately one-third (31\%) of the rural population still live below the poverty line (GoP 2018); multidimensional poverty is even higher (see chapter 3). Thus, a major challenge is to reduce the vulnerability of the rural population to both environmental and nonenvironmental risks. Assistance given during extreme events, such as the 2010 floods under the Watan Program, "not only restores livelihood and replaces damaged assets, but also has an enduring effect by easing mental burdens, and thus raising aspirations for the future" (Kosec and Mo 2017). 
Considering the changes in climate currently underway and the poverty situation, rural populations of Pakistan, particularly small farmers and landless households, need to diversify their sources of income to reduce their vulnerability. Such diversification in rural areas has been the subject of some earlier studies, which showed the importance of both nonfarm and transfer incomes for rural households (Adams and $\mathrm{He}$ 1995, Malik 2005). Transfer income includes internal and international remittances, government pensions, and zakat payments. Internal and international remittances are generally transferred by a household member working somewhere within the country or overseas. The inflow of remittances is considered a potential source for improving local food security and well-being (Rasul et al. 2019).

The total stock of overseas migrants from South Asia is estimated to have increased from 10.08 million in 1990 to 27.22 million in 2015, i.e., by about 2.7 times. The sharp increase in low-skilled labor migration, initially fueled by the oil boom in Gulf countries in the 1970s, has been sustained by subsequent growth in the oil-rich economies, which created a huge demand for low-skilled workers (Srivastava and Pandey 2017). All South Asian countries experienced a sudden increase in the total volume of emigration after 2000 because of high demand, with Bangladesh, India, and Pakistan showing the highest shares and resulting inflows of remittances.

However, internal migration, which consists of permanent, semi-permanent, and temporary/seasonal migration flows, is on the whole more important in South Asia than international migration in terms of both volume as well as flow of remittances (Deshingkar 2012). Employment is one of the most important reasons given for internal migration. Urban migration for economic reasons is increasing in most South Asian countries, and Pakistan is no exception; in addition to active participation in overseas labor migration, movement of the population within the country is a common and significant phenomenon.

This study considers migratory flows of population, both within Pakistan and overseas, as an adaptation strategy of households to diversify their sources of income in order to reduce both environmental and nonenvironmental risks. However, the scope of this study is limited; and it aims to examine the magnitude of mobility or outmigration (within Pakistan or abroad), particularly from rural areas, direction of the move, selectivity of migrants, factors affecting the decision to migrate, and percent of households receiving remittances (domestic and international), across agroclimatic zones. The variations in patterns of migration across the agroclimatic zones can, at least partially, be attributed to environmental factors. For our analysis, we have used microdata from the 2017-18 Pakistan Demographic and Health Survey, which includes a module on outmigration.

\section{MIGRATION-AS-ADAPTATION: THE CONCEPTUAL FRAMEWORK}

There are three views regarding the relationship of migration with vulnerability and resilience in the face of environmental and socioeconomic change. The first view sees migration as a forced undertaking, reflecting failure to adapt to changes, with people moving to random destinations as an emergency response. The number of people who will be forced to move globally because of climate change by 2050 is estimated to be between 200 million and 1 billion. In this approach, "adaptation aims to avoid forced migration as a distressed response to livelihood destruction caused by climate change" (Scheffran, Marmer, and Sow 2012).

The second view is that the relationship between migration and climate change is complex. The decision to migrate to a chosen destination is mediated by pull and push as well as intervening factors that either facilitate or constrain migration, including access to social networks in destination areas and government policies that restrict or encourage migration. Whereas mobility of the entire family is often associated with coping with extreme events, and often occurs as a last resort, migration, internal or international, of part of the available labor in a household is generally undertaken for the purpose of reducing dependency and enhancing livelihood security and opportunities. Migration is also a coping strategy that reduces population pressure, lessens the strain on scarce resources, facilitates risk reduction, and offers better chances for survival. Scheffran, Marmer, and Sow (2012) have termed this view "migration-as-adaptation." 
The third view looks at the relationship between migration and climate change as "migration-for-adaptation." Scheffran, Marmer, and Sow (2012) argue that new opportunities, resources, and networks of migrants in the host regions can diversify household livelihood, support climate adaptation, and build social resilience in the regions of origin, partly compensating for initial resource losses. Capabilities and transfer of resources in migrant networks, including knowledge, remittances, and return migration can contribute to technical and institutional innovations in the home communities for climate adaptation, sustainable development, and peace-building.

This paper builds on the second view, "migration-as-adaptation" (while we acknowledge that there is a thin line between the second and third classifications), which sees human migration as an adaptive response not only to poverty and social deprivation but also to environmental and climate change (Scheffran, Marmer, and Sow 2012). Migration is thus an important household strategy to reduce vulnerability to environmental and non-environmental risks, including economic shocks and social marginalization.

\section{DATA SOURCE AND METHODOLOGY}

The impact of climate change on population redistribution and mobility has generally been examined through specially designed surveys. For example, Bhatta et al. (2015) selected more than 2,660 farm households from 133 villages located in Bihar, India; Terai, Nepal; and Coastal Bangladesh representing hotspots in South Asia and a high degree of socioeconomic vulnerability to climate changes. However, the use of large nationally representative datasets to assess the climate change-migration nexus is not uncommon. Kumar and Viswanathan (2012), for example, used the census and National Sample Survey (NSS) data for this purpose, but they also pooled the district-level data on weather variability in India with the NSS micro-data while modeling for the determinants of migration. This data pooling strategy helped explain the relationship between weather variability and the migration decision.

In this study, we use the 2017-18 Pakistan Demographic and Health Survey (PDHS) to explore the magnitude of internal and international migration from different rural settings of the country (agroclimatic zones). It offers the most suitable microdata for this purpose for two reasons. First, with a large sample of more than 16,000 households, it is representative for 13 domains, including the four provinces and their rural and urban subdomains; Azad Jammu and Kashmir (AJK), with rural and urban areas; Islamabad Capital Territory (ICT); the Federally Administered Tribal Area (FATA); and Gilgit-Baltistan (GB). Second, and most importantly, it includes two migration modules-in-migration and outmigration, with the latter covering international migration as well.

This study is based on the outmigration module of the 2017-18 PDHS. The module asks respondents whether there are any members of their household who lived there in the past 10 years but who have since moved away. Where the response is affirmative, information has been obtained about the migrant's current place of residence (country, if abroad), age at the time of migration, educational attainment, reasons for migration, and the period elapsed since he/she moved out.

About $14 \%$ of the PDHS 2017-18 sampled households reported a previous member living or working in other districts of the country, while about $7 \%$ reported that a member had moved overseas during the last 10 years. About half of the outmigrants had moved away for better economic opportunities. Members of this subsample are termed "economic outmigrants" and are used in this study to examine the phenomenon of migration-as-adaptation. The 2017-18 PDHS also provides information about whether the sampled household has received remittances from within Pakistan or/and from overseas during the last 12 months. However, the amount of remittances received is not documented in the outmigration module of the PDHS. In cases of outmigration of a previous household member, this study considers remittances to be a source of diversification of household income which can reduce economic, social and environmental vulnerabilities.

The decision to migrate is usually closely linked to the socioeconomic status of a household as well as to the age and educational attainment of the migrating person. Poor rural households may decide to send their 
members to another rural area while the better-off households may choose a city or a foreign country as a migration destination. The outmigration module of the 2017-18 PDHS provides the information required to examine the direction of the move, and the strategy of rural households for income diversification. ${ }^{4}$ For internal migration, the interest of this study is focused on four types of moves: "rural-rural," "rural-urban," "urban-urban," and "urban-rural." For international migration, the destination countries are divided into two broad categories: Middle East and "other countries."

In view of the possible impact of climate change on agriculture, internal and international migration are also examined across nine agroecological zones. ${ }^{5}$ Table 4.1 shows the districts/agencies included in each zone. The Barani Lands zone consists of nine districts, including four located administratively in Rawalpindi Division; Mianwali; Islamabad; and three districts of Khyber Pakhtunkhwa (KP), i.e., Bannu, Lakki Marwat, and Tank. The Northern Irrigated Plains zone includes 31 of the 36 districts of Punjab and D.I. Khan from KP. The Southern Irrigated Plains zone includes most of the districts from Sindh except Khairpur, Sanghar, and Tharparkar, which are part of the Sandy Desert zone. However, Karachi is included in the Dry Western Plateau zone along with Awaran, Chagai, Gwadar, Kech, Kharan, Lasbela, Nushki, Panjgur, and Washuk districts of Balochistan. The remaining districts of Balochistan are included in the Western Dry Mountains zone.

Khyber Pakhtunkhwa is divided into three agroecological zones: the Northern Irrigated Plains (Charsadda, Haripur, Mardan, Nowshera, Peshawar, Swabi); Wet Mountains (Abbottabad, Kohistan, Mansehra, Torghar, Batagram, Buner, Shangla); and Northern Dry Mountains (Bajaur Agency, Chitral, Khyber Agency, Kurram Agency, Lower Dir, Malakand Protected Area, Mohmand Agency, North Waziristan, Orakzai Agency, South

Table 4.1: Districts comprising the agroecological zones

\begin{tabular}{|c|c|c|c|}
\hline Sr. & Agro-ecological zone & Province & Districts included \\
\hline \multirow{2}{*}{1} & \multirow{2}{*}{ Barani Lands } & Punjab & Attock, Chakwal, Islamabad, Jhelum, Mianwali, Rawalpindi \\
\hline & & KP & Tank, Bannu, Lakki Marwat \\
\hline \multirow[t]{2}{*}{2} & \multirow[t]{2}{*}{$\begin{array}{l}\text { Northern } \\
\text { Irrigated Plains }\end{array}$} & Punjab & $\begin{array}{l}\text { Bahawalnagar, Bahawalpur, Chiniot, Dera Ghazi Khan, Faisalabad, Gujranwa- } \\
\text { la, Gujrat, Hafizabad, Jhang, Kasur, Khanewal, Lahore City, Layyah, Lodhran, } \\
\text { Mandi Bahauddin, Multan, Muzaffargarh, Nankana Sahib, Narowal, Okara, } \\
\text { Pakpattan, Rajanpur, Sahiwal, Sargodha, Sheikhupura, Sialkot, Toba Tek } \\
\text { Singh, Vehari, Bhakkar, Khushab }\end{array}$ \\
\hline & & KP & Dera Ismail Khan \\
\hline 3 & $\begin{array}{l}\text { KP Northern Irrigated } \\
\text { Plains }\end{array}$ & KP & Charsadda, Haripur, Mardan, Nowshera, Peshawar, Swabi \\
\hline \multirow[t]{2}{*}{4} & \multirow[t]{2}{*}{$\begin{array}{l}\text { Southern } \\
\text { Irrigated Plains }\end{array}$} & Sindh & $\begin{array}{l}\text { Mirpur Khas, Badin, Dadu, Ghotki, Hyderabad, Jacobabad, Kambar Shahdad } \\
\text { Kot, Kashmor, Larkana, Matiari, Naushahro Feroze, Nawab Shah, Shikarpur, } \\
\text { Sujawal, Sukkur, Tando Allah Yar, Tando Muhammad Khan, Thatta, Umer Kot }\end{array}$ \\
\hline & & Punjab & Rahim Yar Khan \\
\hline 5 & Wet Mountains & KP & Abbottabad, Kohistan, Mansehra, Torghar, Batagram, Buner, Shangla \\
\hline 6 & $\begin{array}{l}\text { Northern Dry Moun- } \\
\text { tains }\end{array}$ & KP & $\begin{array}{l}\text { Bajaur Agency, Chitral, Khyber Agency, Kurram Agency, Lower Dir, Malakand } \\
\text { Protected Area, Mohmand Agency, North Waziristan, Orakzai Agency, South } \\
\text { Waziristan, Swat, Upper Dir, Hangu, Karak, Kohat }\end{array}$ \\
\hline 7 & Western Dry Mountains & Balochistan & $\begin{array}{l}\text { Jafarabad, Jhal Magsi, Lehri, Nasirabad, Sohbatpur, Barkhan, Bolan, Dera } \\
\text { Bugti, Kalat, Khuzdar, Killa Abdullah, Killa Saifullah, Kohlu, Loralai, Mastung, } \\
\text { Musakhel, Pishin, Quetta, Sherani, Sibi, Zhob, Ziarat }\end{array}$ \\
\hline \multirow[b]{2}{*}{8} & \multirow[b]{2}{*}{ Dry Western Plateau } & Balochistan & Awaran, Chagai, Gwadar, Kech, Kharan, Lasbela, Nushki, Panjgur, Washuk \\
\hline & & Sindh & $\begin{array}{l}\text { Karachi Central, Karachi City, Karachi East, Karachi South, Karachi West, } \\
\text { Korangi, Malir }\end{array}$ \\
\hline 9 & Sandy Desert & Sindh & Khairpur, Sanghar, Tharparkar \\
\hline
\end{tabular}

${ }^{4}$ The other data sources with a migration module, such asthe Pakistan Labour Force Survey, do not collect information on outmigrants. ${ }^{5}$ The Pakistan Agriculture Research Council (PARC) developed these zones. PARC divided Pakistan into 10 agroecological zones based on physiography, climate, land use and water availability. The Population Council (Pakistan Office) made some adjustments based on demographic changes in these zones. Some other studies carried out over the last three decades have developed other cropping zones (see for example, Pickney 1989; Iqbal et al. 2015, Chaudhry 2017). 
Waziristan, Swat, Upper Dir, Hangu, Karak, and Kohat). Notably, two regions, AJK and GB, are not included in this zonal scheme but are included in our analysis based on regionally representative data in the 2017-18 PDHS. The analysis carried out in chapter 3 shows the western dry mountains, southern irrigated plains, sandy desert, and dry western plateau zones as the severely affected areas from climate change.

\section{ECONOMIC MIGRATION: INCIDENCE, DIRECTION OF MOVE, AND SELECTIVITY}

This section first assesses the magnitude or incidence of economic migration indicated by analysis of the outmigration module of the 2017-18 PDHS. It then reviews the direction in which people are moving internally for work, including rural-urban, rural-rural, urban-urban, and urban-rural migration. Selectivity has always been part of the migration process; economic migrants are rarely a random cross-section of the origin population, and typically have a number of characteristics that set them apart from their nonmigrant peers. We examine this aspect in the final part of this section, with a closer look at the age and educational attainment of migrants at the time of migration.

\section{INCIDENCE OF ECONOMIC MIGRATION}

In the outmigration module of the 2017-18 PDHS, where movement of a previous household member is reported for the purpose of employment, business, or study, this study considers it to be "economic migration"-a strategy of the concerned households to diversify their sources of income and enhance livelihood security. A seasonal migrant born in a district different from the district of enumeration is also part of "economic migration." However, a circular migrant enumerated at the place of birth (district) is not a migrant under the definition used in the PDHS. Overall, $14 \%$ of the sampled households reported movement within Pakistan of a (previous) member (column 2, Table 4.2); economic migration within Pakistan, however, took place from $9 \%$ of the sampled households, suggesting that approximately one-tenth of the households adopted migration as a strategy to reduce vulnerabilities. The incidence of economic migration from rural areas is double $(11.1 \%)$ the magnitude of migration from urban areas $(5.7 \%)$. This urban-rural difference in the incidence of economic migration prevails in all provinces of the country. At the provincial/regional level, the highest incidence of economic migration within Pakistan is found in Gilgit-Baltistan, followed by AJK and FATA. This points toward the contribution of stresses such as lack of economic opportunities as well as climate change and conflicts in migration decisionmaking. In the recent past, a vast area of $\mathrm{GB}$ has been affected by the melting of glaciers, while FATA has seen an extended period of conflict. Moreover, economic opportunities in all three regions-GB, AJK, and FATA-seem to be relatively limited compared to other regions/provinces of the country, which could be a strong push factor generating different migratory streams from these regions.

Table 4.2 also shows statistics on the incidence of emigration; $7 \%$ of the households reported emigration of a household member during the last 10 years. As expected, the Middle East is the choice of the majority of households because of the availability of more job opportunities for Pakistanis in this region than in other parts of the world. But emigration to other parts of the world is not uncommon. Like internal migration, rural-urban differences in emigration prevails in all provinces in favor of rural areas. However, in the choice of a destination other than the Middle East, more urban households are engaged than their rural counterparts, probably due to the former's better socioeconomic status and ability to finance emigration to Europe, North America, or Australia.

Almost three-quarters of internal as well as international migrants moved to their place of destination during the five years preceding the 2017-18 PDHS (Figure 4.1). Only $10 \%$ of them moved before 2010. Considering that a great majority of the economic migrants moved during the recent past, it is safe to argue that a considerable proportion of households, particularly in rural areas, attach great importance to migration to diversify their sources of income to reduce vulnerabilities (see chapter 3 about the climate change in recent past). 
Table 4.2 Magnitude of outmigration within Pakistan and abroad, by province

\begin{tabular}{|c|c|c|c|c|c|}
\hline \multirow{2}{*}{ Province/Region } & \multirow{2}{*}{$\begin{array}{l}\text { \% households } \\
\text { reporting an } \\
\text { outmigrant within } \\
\text { Pakistan during } \\
\text { last } 10 \text { years }\end{array}$} & \multirow{2}{*}{$\begin{array}{l}\text { \% households re- } \\
\text { porting an economic } \\
\text { outmigrant within } \\
\text { Pakistan during } \\
\text { last } 10 \text { years }\end{array}$} & \multicolumn{3}{|c|}{$\begin{array}{l}\% \text { households reporting at least } \\
\text { one emigrant during last } 10 \text { years }\end{array}$} \\
\hline & & & Middle East & Other countries & All countries \\
\hline Pakistan & 14.3 & 9.0 & 5.7 & 1.3 & 7.0 \\
\hline Urban & 11.0 & 5.7 & 4.6 & 1.5 & 6.1 \\
\hline Rural & 16.4 & 11.1 & 6.5 & 1.1 & 7.6 \\
\hline Punjab & 18.2 & 11.4 & 6.1 & 1.8 & 7.9 \\
\hline Urban & 14.2 & 7.8 & 5.8 & 2.1 & 7.9 \\
\hline Rural & 20.6 & 13.6 & 6.3 & 1.7 & 8.0 \\
\hline Sindh & 5.7 & 3.1 & 2.0 & 0.3 & 2.3 \\
\hline Urban & 5.9 & 2.5 & 2.3 & 0.6 & 2.9 \\
\hline Rural & 5.5 & 3.7 & 1.7 & 0 & 1.7 \\
\hline KP & 15.7 & 10.6 & 12.2 & 0.9 & 13.1 \\
\hline Urban & 12.0 & 5.6 & 7.7 & 1.4 & 9.1 \\
\hline Rural & 16.7 & 11.9 & 13.3 & 0.7 & 14.0 \\
\hline Balochistan & 5.2 & 3.6 & 0.7 & 0.1 & 0.8 \\
\hline Urban & 6.1 & 2.6 & 1.2 & 0 & 1.2 \\
\hline Rural & 4.9 & 3.9 & 0.6 & 0.1 & 0.7 \\
\hline Islamabad & 12.2 & 4.8 & 4.4 & 2.3 & 6.7 \\
\hline FATA & 21.2 & 19.4 & 8.7 & 0.5 & 9.2 \\
\hline AJK & 25.4 & 19.9 & 14.7 & 3.8 & 18.5 \\
\hline Gilgit-Baltistan & 28.0 & 25.9 & 2.7 & 0.6 & 3.3 \\
\hline
\end{tabular}

Source: Computed by the authors from PDHS 2017-18 microdata.

Figure 4.1 Percent distribution of internal outmigrants and emigrants by year of migration

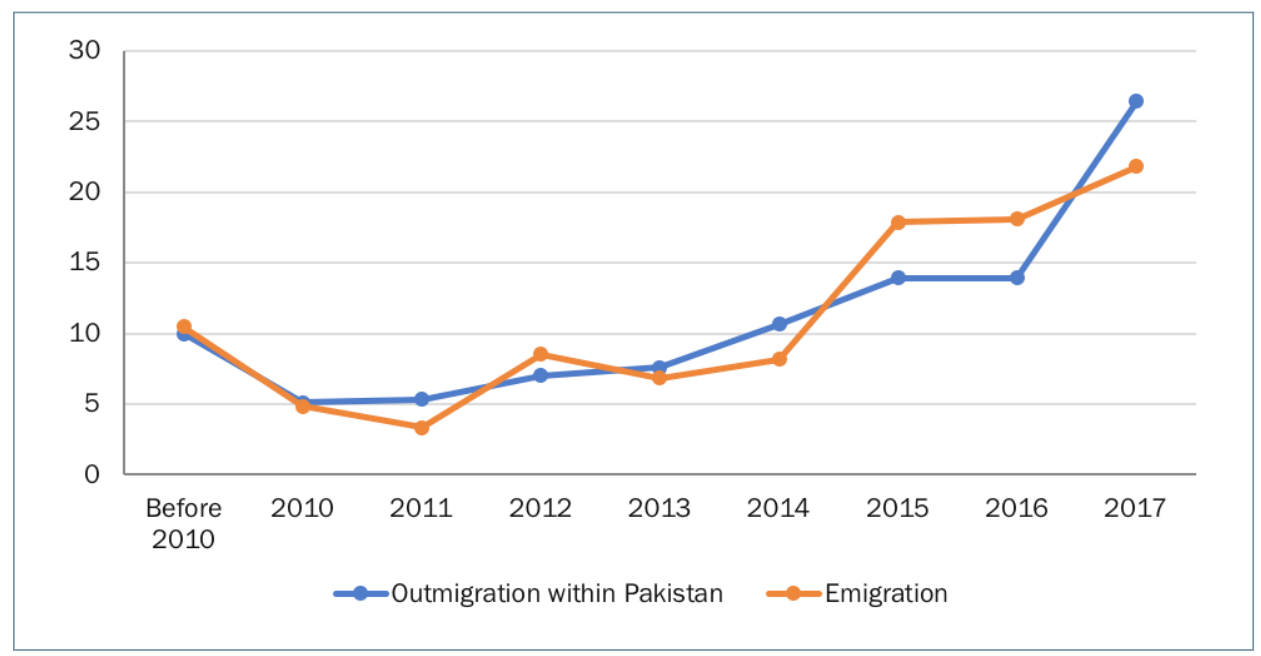

Source: PDHS 2017-18. 
Table 4.3 sets out the data on the incidence of migration by nine agroecological zones. There is a great variation across these zones; compared to only $4 \%$ of households in the Dry Western Plateau zone, almost one-fifth of households in Wet Mountain and Northern Dry Mountain zones reported the movement of a household member within the country. In fact, migration, internal as well as international, is more pronounced from all agroecological zones of Punjab and KP compared to Sindh and Balochistan (Table 4.2). The Bureau of Emigration and Overseas Employment (BEOE) registration data also show that highemigration districts are located largely in Central and Northern Punjab, KP, and AJK.

Although it is difficult to link this pattern of migration with climate change or natural disasters, high internal migration zones include some districts that were severely affected by the $2010 \mathrm{flood}$. Overseas migration is relatively higher from Northern Dry Mountains, Barani Lands, and Wet Mountain zones. Rural areas of the Barani Lands zone and a large other part of KP, where Northern Dry Mountains and Wet Mountain zones are situated, depend on rain for farming. These areas have a long history of overseas migration to support their families. Data from the last 10 years, as shown by the PDHS 2017-18, also reveal relatively high migration from these areas. The incidence of migration is relatively low in zones severely affected by climate change (see chapter 3). It appears that a mix of environmental and non-environmental factors generate migratory streams of working -age populations in order to reduce households' vulnerabilities and improve the well-being

Table 4.3 Magnitude of outmigration within Pakistan and abroad by agroecological zones

\begin{tabular}{|c|c|c|c|c|c|}
\hline \multirow[b]{2}{*}{ Agroecological zones } & \multirow{2}{*}{$\begin{array}{l}\text { \% households } \\
\text { reported an } \\
\text { outmigrant within } \\
\text { Pakistan during last } \\
10 \text { years }\end{array}$} & \multirow{2}{*}{$\begin{array}{l}\text { \% households } \\
\text { reported an } \\
\text { economic } \\
\text { outmigrant within } \\
\text { Pakistan during last } \\
10 \text { years }\end{array}$} & \multicolumn{3}{|c|}{$\begin{array}{l}\% \text { households reported at least one emi- } \\
\text { grant during last } 10 \text { years }\end{array}$} \\
\hline & & & Middle East & $\begin{array}{l}\text { Other } \\
\text { countries }\end{array}$ & $\begin{array}{l}\text { All } \\
\text { countries }\end{array}$ \\
\hline Total & 14.7 & 10.5 & 5.3 & 2.0 & 7.3 \\
\hline Barani Lands & 14.9 & 12.3 & 10.3 & 1.5 & 11.8 \\
\hline Northern Irrigated Plains & 18.7 & 12.9 & 4.9 & 2.9 & 7.7 \\
\hline KP North. Irrigated Plains & 14.1 & 9.9 & 9.3 & 3.2 & 12.5 \\
\hline Southern Irrigated Plains & 9.5 & 6.7 & 2.3 & 0.1 & 2.3 \\
\hline Wet Mountains & 21.3 & 17.8 & 10.7 & 3.5 & 14.2 \\
\hline Northern Dry Mountains & 20.3 & 17.7 & 15.0 & 1.2 & 16.2 \\
\hline Western Dry Mountains & 5.9 & 4.1 & 0.3 & 0.2 & 0.6 \\
\hline Dry Western Plateau & 4 & 1.6 & 2.5 & 1.3 & 3.7 \\
\hline Sandy Desert & 7.4 & 5.9 & 2.1 & 0.0 & 2.1 \\
\hline Rural areas & 16.9 & 12.9 & 6.0 & 1.9 & 7.8 \\
\hline Barani Lands & 14.8 & 12.5 & 10.9 & 1.2 & 12.2 \\
\hline Northern Irrigated Plains & 21.2 & 15.6 & 5.1 & 2.7 & 7.9 \\
\hline Kp North. Irrigated Plains & 15.2 & 11.5 & 10.4 & 3.6 & 14.0 \\
\hline Southern Irrigated Plains & 9.1 & 7.3 & 1.9 & 0.0 & 1.9 \\
\hline Wet Mountains & 22.4 & 18.8 & 11.4 & 3.4 & 14.9 \\
\hline Northern Dry Mountains & 21.2 & 18.6 & 15.7 & 1.1 & 16.7 \\
\hline Western Dry Mountains & 5.9 & 4.7 & 0.3 & 0.2 & 0.5 \\
\hline Dry Western Plateau & 0.5 & 0.5 & 1.0 & 0.0 & 1.0 \\
\hline Sandy Desert & 7.6 & 5.4 & 3.0 & 0.0 & 3.0 \\
\hline
\end{tabular}

Source: Computed by the authors from PDHS 2017-18 microdata. 
Figure 4.2 Percentage of households reported an outmigrant within Pakistan during last 10 years

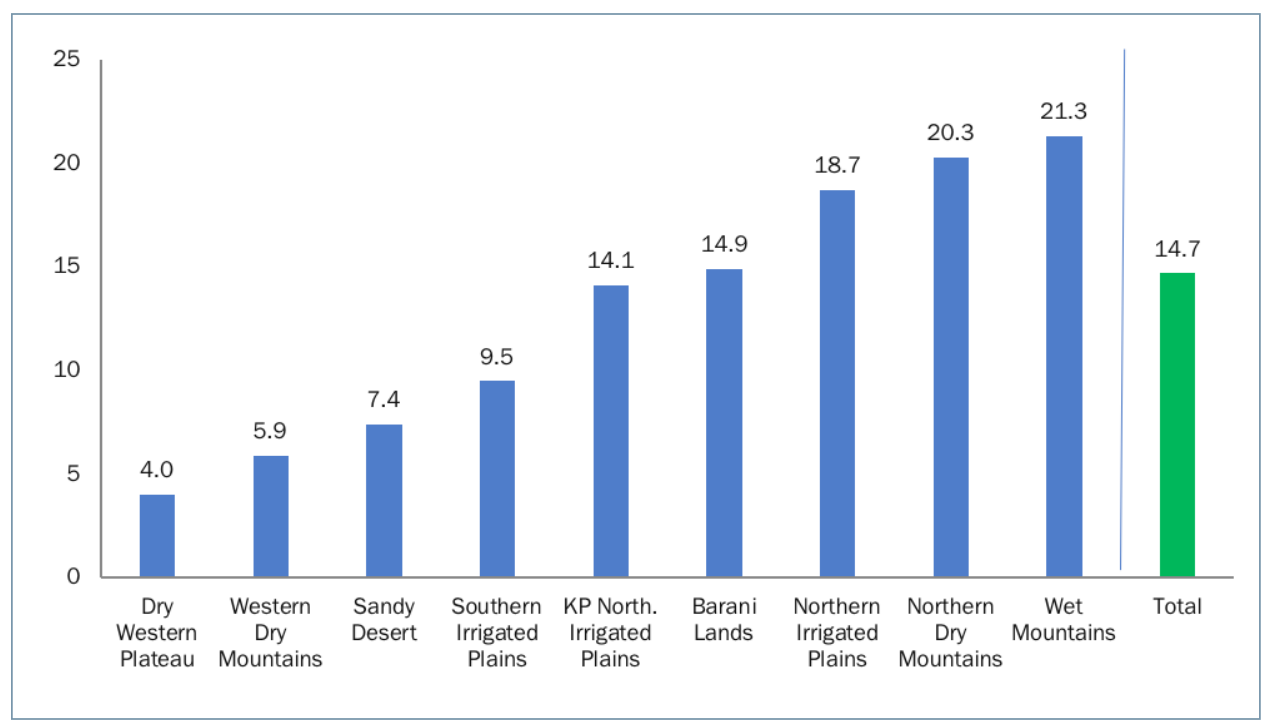

Source: Computed by the authors from PDHS 2017-18 microdata.

of their members. This is what a recent study on migration in the Hindu Kush Himalaya region has concluded (Siddiqui et al. 2019).

\section{DIRECTION OF MOVE}

Table 4.4 presents data on the direction of move by province and agroecological zone. Overall about twothirds (61\%) of internal economic migrants moved from rural areas to urban centers. The movement in this direction is higher than the national average in KP, Balochistan, FATA, AJK, and GB. About one-fifth of the internal economic outmigrants moved within urban areas while $16 \%$ of them migrated from one rural area to other rural area. The movement of economic migrants from urban to rural areas is not common (only 3.7\%). We may infer that, among rural economic migrants, the popular direction is toward urban centers, although the movement between rural areas is not uncommon, particularly in KP. The movement of economic outmigrants within urban centers is substantial in Sindh (33\%) and Punjab (22\%).

Rural-to-urban migration is also a major move across agroecological zones. It is, however, more pronounced in Wet Mountains, Western Dry Mountains, and the Southern and KP Northern Irrigated Plains than in other zones. The largest movement within rural areas is found in the Northern Dry Mountain zone consisting of FATA and some districts of KP including Bajaur Agency, Chitral, Lower Dir, Malakand Protected Area, Swat, Upper Dir, Hangu, Karak, and Kohat.

Again, the relationship between the direction of move and climate change appears to be highly complex. The decision to migrate to a chosen destination, particularly to an urban center, is likely to be undertaken to diversify household sources of income, enhance livelihood security, and reduce risks at the place of origin, including the risks related to climate change. The occurrence of floods or drought could be possible reasons 
Table 4.4 Direction of move of the internal economic outmigrant population, by province/region and agroecological zone

\begin{tabular}{|c|c|c|c|c|c|}
\hline Province/Region & Rural to rural & Rural to urban & Urban to urban & Urban to rural & Total \\
\hline All & 15.9 & 60.7 & 19.7 & 3.7 & 100 \\
\hline Punjab & 16.2 & 58.4 & 22.0 & 3.4 & 100 \\
\hline Sindh & 4.8 & 53.6 & 33.3 & 8.4 & 100 \\
\hline Khyber Pakhtunkhwa & 20.2 & 69.6 & 8.2 & 2.0 & 100 \\
\hline Balochistan & 7.1 & 70.3 & 16.3 & 6.3 & 100 \\
\hline Islamabad & 9.4 & 48.3 & 32.3 & 10.1 & 100 \\
\hline FATA & 16.4 & 77.1 & 2.5 & 4.1 & 100 \\
\hline Azad Jammu and Kashmir & 21.8 & 68.2 & 7.7 & 2.4 & 100 \\
\hline Gilgit-Baltistan & 14.4 & 74.4 & 9.8 & 1.3 & 100 \\
\hline \multicolumn{6}{|l|}{ Agro-Ecological Zone } \\
\hline Barani Lands & 7.6 & 53.9 & 35.8 & 2.7 & 100 \\
\hline Northern Irrigated Plains & 18.7 & 56.9 & 20.4 & 4.0 & 100 \\
\hline KP Northern Irrigated Plains & 9.0 & 72.4 & 16.3 & 2.3 & 100 \\
\hline Southern Irrigated Plains & 6.0 & 72.6 & 18.5 & 3.0 & 100 \\
\hline Wet Mountains & 13.8 & 83.7 & 2.5 & 0.0 & 100 \\
\hline Northern Dry Mountains & 35.5 & 59.1 & 4.1 & 1.4 & 100 \\
\hline Western Dry Mountains & 6.8 & 76.5 & 9.9 & 6.8 & 100 \\
\hline Dry Western Plateau & 1.4 & 1.3 & 70.0 & 27.3 & 100 \\
\hline Sandy Desert & 4.9 & 65.1 & 30.0 & 0.0 & 100 \\
\hline
\end{tabular}

Source: Computed by the authors from PDHS 2017-18 microdata.

for migration, while relatively few farming opportunities and dependence on rain for farming in AJK and GB (and more lately Sindh) are likely to have contributed in generating different migratory streams.

\section{SELECTIVITY OF ECONOMIC MIGRANTS}

It is well established that migrants are a select group of individuals with respect to a number of characteristics, such as age and education. Migration is generally highly age-selective, with adults in the working age groups displaying a greater propensity to migrate. Table 4.5 shows that, overall, $88 \%$ of the economic migrants within Pakistan are in working age groups (15-59) and this pattern is almost universal in the case of international migration. Within the working age groups, a great majority of both internal and international migrants were less than 40 years old at the time of migration. Almost half of the internal migrants (45\%) were youths (15-24 years). Internal outmigrants and emigrants are predominantly male (Table 4.5).

This age selectivity persists in all four directions of move (Table 4.5). Almost $80 \%$ of rural-urban migrants were 15-39 years old at the time of migration; it is worth repeating that three-quarters of migrants, internal as well as international, moved during the last five years. It is likely that this recent movement of young people is in response to some environmental or non-environmental risks at their place of origin. Another notable observation on age selectivity is that, in the case of internal migration, the youth age group (15-24) dominates, while for international migration the dominant category is 25-39 years.

Education can facilitate migration through knowledge of destinations and employment opportunities. More educated persons may also find it easier to finance the costs of migration. As a result, migrants tend to exhibit a high level of educational attainment compared with the general population in their communities of 
Table 4.5 Percent distribution of economic migrants in and from Pakistan, by age at the time of migration and direction of move

\begin{tabular}{|c|c|c|c|c|c|c|}
\hline Age & $<15$ years & 15-24 years & $25-39$ years & 40-59 years & $\geq 60$ Years & All ages \\
\hline Outmigrants within Pakistan & $\begin{array}{r}10.7 \\
(77 \%)\end{array}$ & $\begin{array}{r}45.4 \\
(92 \%)\end{array}$ & $\begin{array}{r}33.1 \\
(94 \%)\end{array}$ & $\begin{array}{r}9.1 \\
(92 \%)\end{array}$ & $\begin{array}{r}1.7 \\
(90 \%)\end{array}$ & $\begin{array}{r}100 \\
(91 \%)\end{array}$ \\
\hline Emigrants & $\begin{array}{r}1.4 \\
(100 \%)\end{array}$ & $\begin{array}{r}36.3 \\
(99 \%)\end{array}$ & $\begin{array}{r}49.6 \\
(98 \%)\end{array}$ & $\begin{array}{r}11.9 \\
(99 \%)\end{array}$ & $\begin{array}{r}0.9 \\
(100 \%)\end{array}$ & $\begin{array}{r}100 \\
(98 \%)\end{array}$ \\
\hline \multicolumn{7}{|c|}{ Direction of move (within Pakistan) } \\
\hline Rural-rural & 13.9 & 39.0 & 38.3 & 6.5 & 2.3 & 100 \\
\hline Rural-urban & 11.2 & 47.8 & 31.8 & 7.7 & 1.6 & 100 \\
\hline Urban-urban & 7.1 & 42.0 & 34.5 & 14.8 & 1.6 & 100 \\
\hline Urban-rural & 9.0 & 50.4 & 25.6 & 12.7 & 2.3 & 100 \\
\hline
\end{tabular}

Source: Computed by authors from PDHS 2017-18 microdata. Note: Statistics in parenthesis show the percent of male.

origin. There is a broad consensus that education increases employment opportunities and returns to wages and helps to mitigate the risk and cost of moving. However, selectivity of the Pakistani outmigrant population by educational attainment is more pronounced for international migration than for internal migrationPakistani emigrants are more educated than internal migrants. As mentioned above, economic outmigrants were mainly in the 15-39 age groups at the time of migration. PDHS 2017-18 data show that about a quarter of this group had no education while $35-46 \%$ had secondary or higher levels of education.

In the case of internal migrants, Table 4.6 shows that $22 \%$ were illiterate, and $45 \%$ had completed secondary education at the time of migration. The proportion who were illiterate was even higher for rural-ᄀ-rural (28\%) and rural-urban (26\%) migrants. For international migration, the share of the illiterate adult population is less than $10 \%$ while more than half ( $56 \%$ ) had attained secondary or higher level of education. It appears from these very simple education selectivity statistics that educated migrants from rural as well as urban areas prefer to find a job in the overseas market and moving to another location within Pakistan is probably Table 4.6 Percent distribution of economic outmigrants in and from Pakistan, by educational attainment and direction of move

\begin{tabular}{|l|r|r|r|r|r|r|}
\hline \multicolumn{1}{|c|}{ Characteristics } & No education & Primary & Middle & Secondary & Higher & All \\
\hline $\begin{array}{l}\text { Outmigrants within } \\
\text { Pakistan }\end{array}$ & 21.8 & 19.3 & 13.5 & 22.7 & 22.2 & 100 \\
\hline Emigrants & 9.3 & 13.5 & 21.1 & 32.3 & 23.8 & 100 \\
\hline Direction of move (within Pakistan) & \multicolumn{5}{|l|}{} \\
\hline Rural-rural & 28.0 & 22.8 & 13.7 & 21.0 & 13.9 & 100 \\
\hline Rural-urban & 25.6 & 19.5 & 14.9 & 22.9 & 16.7 & 100 \\
\hline Urban-urban & 8.2 & 16.0 & 10.4 & 23.6 & 41.2 & 100 \\
\hline Urban-rural & 6.6 & 20.1 & 7.7 & 21.7 & 43.9 & 100 \\
\hline
\end{tabular}

Source: Computed by the authors from PDHS 2017-18 microdata. 
their second choice.

\section{FACTORS AFFECTING THE DECISION TO MIGRATE}

An interplay of demographic, economic, environmental, political, and social factors is likely to have contributed to the decision of sampled households to place a member in the domestic or overseas labor market to reduce their vulnerabilities. According to Siddiqui and colleagues (2019), "due to complex interactions between these drivers, it is rarely possible to identify individuals whose migration decision was solely influenced by one particular driver." This section examines the factors associated with the decision to migrate through multivariate analyses, based on three regression models Model 1 includes all international migrants and internal economic migrants; a value of one is given to households that report the movement of a member within the country or abroad during the last 10 years; otherwise, zero is assigned. In Model 2, only households that report an economic migrant within Pakistan are included. Model 3 includes households that report an international migrant. A common set of social, economic, and demographic factors is used in the three models as independent variables including educational attainment of the head of the household, ownership of land and livestock, number of persons per room, whether any member of the household maintains a bank account, roof material, language spoken in the household, household size, and number of adult (working age) males. Dummies for rural and urban residence and agroecological zones are also entered in the models. The household is the unit of analysis.

Results of the analysis are presented in Table 4.7. Economic factors such as land ownership, housing quality, and having a bank account have a positive and significant effect on the decision to migrate both within Pakistan and abroad. This indicates that migration, particularly international migration, is a costly undertaking and a household's better economic position serves to enable individual members to migrate. On the other hand, educational attainment of the head of the household is negatively associated with the decision to migrate (Table 4.7).

If education is considered an indicator of the economic position of a household, it should have been positively associated with the decision to migrate. If it is taken as a social status indicator, its association with the decision to migrate is likely to be negative. The negative association between the decision to migrate and educational attainment of the heads of households shows that families whose heads are better educated are well placed in their current position, and thus not vulnerable or less vulnerable to environmental and nonenvironmental risks. Their strategy for coping with risks is probably the utilization of resources available to them.

Two demographic variables, household size and number of adult males (of working age) in the household, are significantly associated with the decision to migrate, but association is positive in the case of the former and negative for the latter. The positive association of household size with the decision to migrate indicates the population pressure on household resources, and the mobility of a member is primarily to ease this pressure. The expectation is that more adult male members would also enable the concerned households to afford the movement of a member; the likely reason for the negative association is that more adult members are a source of diversification of household resources even without engaging in migration. It is worth nothing here that male participation in the labor force is nearly universal in Pakistan.

The language spoken in the household is statistically significant in models 2 (internal migration) and 3 (international migration), with Sindhi-speaking households less likely to engage in overseas migration than Punjabi-speaking households. Saraiki-speaking households are more likely than their Punjabi counterparts to participate in internal migration, but less likely to participate in overseas migration, which reflects their lower capacity to finance emigration.

As expected, rural households are more likely than their urban counterparts to engage in economic migration because of both relatively high demographic pressure and limited employment opportunities in rural areas. 
Table 4.7 Socio-demographic factors affecting the decision to migrate (three models)

\begin{tabular}{|l|l|l|}
\hline Model 1 (all migrants) & Model 2 (internal migrants) & Model 3 (international migrants)
\end{tabular}

EDUCATION OF THE HEAD

No education, preschool

\begin{tabular}{|r|c|}
\hline No education, preschool & \\
\hline Primary & $0.720^{* *}$ \\
\hline Secondary & $0.619^{* *}$ \\
\hline Higher & $0.523^{* *}$ \\
\hline Adult male 15-64 (Continuous) & $0.684^{* *}$ \\
\hline Household Size (Continuous) & $1.145^{* *}$ \\
\hline \multicolumn{2}{|l}{ OWNS LAND USABLE FOR AGRICULTURE } \\
\hline
\end{tabular}

\begin{tabular}{|c|c|c|}
\hline & & \\
\hline $0.685^{* *}$ & 0.84 \\
\hline $0.577^{* *}$ & $0.699^{*}$ \\
\hline $0.498^{* *}$ & $0.566^{* *}$ \\
\hline $0.732^{* *}$ & $0.692^{* *}$ \\
\hline $1.099^{* *}$ & $1.180^{* *}$ \\
\hline
\end{tabular}

\begin{tabular}{|r|l|l|l|}
\hline No & & & \\
\hline Yes & $1.178^{*}$ & 1.141 & 1.188 \\
\hline MAIN ROOF MATERIAL
\end{tabular}

\begin{tabular}{|c|c|c|c|}
\hline \multicolumn{4}{|l|}{ Natural roofing } \\
\hline Rudimentary roofing & $2.431^{*}$ & $2.061^{*}$ & $96.5^{* *}$ \\
\hline Finished roofing & $3.051^{* *}$ & $2.319 *$ & $135.5^{* *}$ \\
\hline \multicolumn{4}{|c|}{ NATIVE LANGUAGE OF RESPONDENT } \\
\hline \multicolumn{4}{|l|}{ Punjabi } \\
\hline Urdu & 0.813 & 0.868 & 0.682 \\
\hline Sindhi & $0.422^{* *}$ & $0.472 * *$ & $0.298^{* *}$ \\
\hline Saraiki & 1.114 & $1.360^{*}$ & $0.551^{* *}$ \\
\hline Baluchi & 0.837 & 1.06 & $0.419^{*}$ \\
\hline Pushto & 0.900 & 0.918 & 0.814 \\
\hline Other & 0.878 & 0.891 & 0.820 \\
\hline \multicolumn{4}{|l|}{ PERSONS PER ROOM } \\
\hline \multicolumn{4}{|l|}{$<=2$} \\
\hline$>2 \&<=3$ & $0.677^{* *}$ & $0.682^{* *}$ & $0.757^{*}$ \\
\hline$>3 \&<=4$ & $0.538^{* *}$ & $0.589 * *$ & $0.556^{* *}$ \\
\hline$>4 \&<=5$ & $0.489 * *$ & $0.554^{* *}$ & $0.416 * *$ \\
\hline$>5$ & $0.304^{* *}$ & $0.388^{* *}$ & $0.247^{* *}$ \\
\hline
\end{tabular}

\begin{tabular}{rr|c|c|c|}
\hline & No & & & \\
\hline & Yes & 1.023 & 1.131 & 0.845 \\
\hline HAS BANK ACCOUNT & & & & \\
\hline No & & $1.453^{* *}$ & \\
\hline Yes & $1.894^{* *}$ & & \\
\hline PLACE OF RESIDENCE & & & & $1.505^{* *}$ \\
\hline Urban & & $1.391^{* *}$ & $1.294^{*}$ \\
\hline Rural & $1.352^{* *}$ & &
\end{tabular}

\section{AGRO-ECOLOGICAL ZONES BY PARC}

\begin{tabular}{|r|r|r|r|}
\hline Barani Lands & & & \\
\hline Northern Irrigated Plains & 0.906 & 1.088 & $0.737^{*}$ \\
\hline KP Northern Irrigated Plains & 1.141 & 0.924 & $1.444^{*}$ \\
\hline Southern Irrigated Plains & $0.633^{*}$ & $0.746^{* *}$ & $1.302^{*}$ \\
\hline Wet Mountains & $1.498^{*}$ & 1.382 & $1.852^{* *}$ \\
\hline Northern Dry Mountains & $1.761^{* *}$ & $1.536^{*}$ & $0.061^{* *}$ \\
\hline Western Dry Mountains & $0.208^{* *}$ & $0.343^{* *}$ & $0.513^{*}$ \\
\hline Dry Western Plateau & $0.304^{* *}$ & $0.209^{* *}$ & 0.702 \\
\hline Sandy Desert & 0.762 & $0.993^{* *}$ & 0.001 \\
\hline
\end{tabular}

Source: Computed by the authors from PDHS 2017-18 microdata. 
But the findings of agroecological dummies provide more insights on the decision to migrate. In Model 1 which includes both internal and international migration, households in three zones-Southern Irrigated Plains, Western Dry Mountains, and Dry Western Plateau-are less likely to migrate than the households located in Barani Lands. It is worth noting that the three low-migration zones are located in Sindh and Balochistan province and are among the severely affected areas (see chapter 3 ). On the other hand, members of households of the Wet Mountain and Northern Dry Mountain zones are more likely than those in the Barani Lands zone to engage in migration. These zones are part of KP province.

The internal migration model (2) shows that households in Northern Dry Mountain zones are more likely than those in Barani Lands to send a worker to other place within the country. But participation in internal migration of a zone from Sindh (Southern Irrigated Plains) and two from Balochistan-Western Dry Mountains and Dry Western Plateau-remains significantly lower than Barani Lands. In the case of international migration (Model 3), the results show that households in the Barani Lands zone are more likely to send a member abroad than the households of other zones expect KP Northern Irrigated Plains and Northern Dry Mountains.

The results for different agroecological zones indicate an interplay of environmental and non-environmental factors in the decision to migrate. They show that because of both environmental and non-environmental factors, migration is considered a coping strategy in KP, large parts of Punjab, AJK, FATA, and GB. In contrast, participation of households in Sindh and Balochistan in internal as well as international migration remains low, despite poverty, floods, and drought in some districts. This low incidence of migration from these regions, particularly from Sindh, raises questions that should be examined in future research.

\section{DIVERSIFICATION OF HOUSEHOLD INCOME THROUGH REMITTANCES}

Migration-as-adaptation refers to the moving of a household member to another location within the country or abroad to earn money and send home savings. The role of migration, internal as well as international, in reducing vulnerabilities is examined through exploring the question: How many households participating in economic migration received remittances during the year preceding the PDHS 2017-18? It is hypothesized that migration of an adult household member enables the concerned households to diversify their sources of income through domestic or overseas remittances.

Table 4.8 presents data on the proportion of households that have received remittances from internal or overseas migrants. Overall, more than one-third of the households with an economic migrant within Pakistan reported the receipt of some remittances, and this percentage is higher in rural households (36\%) than in urban households. There is variation across regions and provinces; the proportion of households receiving remittances is highest in AJK (62\%), followed by KP (40\%), Punjab (34\%), Balochistan (26\%), and Sindh (25\%). Table 4.9 shows that, among the agroecological zones, $47 \%$ of households received remittances in Barani Lands, followed by KP Northern Irrigated Plains (41\%), Northern Dry Mountains (36\%), Northern Irrigated Plains (34\%), and Wet Mountains (30\%).

A similar pattern is observed for international remittances. Overall, $44 \%$ of the households with an emigrant received remittances from abroad during the year preceding the survey. More rural households (47\%) received remittances from abroad than their urban counterparts (37\%). As for internal remittances, the proportion of households receiving international remittances is highest in AJK and FATA (72\%), followed by KP, Punjab, Balochistan, and Sindh. Among the agroecological zones, almost two-thirds of migrant households in Barani Lands and KP Northern Irrigated Plains received foreign remittances, followed by other Northern Dry Mountains (57\%) and Northern Irrigated Plains (41\%). 
Table 4.8 Percentage of households who received remittances, reporting economic outmigrants, by administrative region and urban/rural location

\begin{tabular}{|c|c|c|c|c|}
\hline \multirow{2}{*}{ Province/Region } & \multirow{2}{*}{$\begin{array}{l}\text { Households with an economic } \\
\text { outmigrant within Pakistan }\end{array}$} & \multicolumn{3}{|c|}{ Households with at least one emigrant during last 10 years } \\
\hline & & Middle East & Other countries & All countries \\
\hline Pakistan & 33.6 & 43.0 & 47.0 & 44.4 \\
\hline Urban & 26.7 & 34.9 & 47.0 & 39.6 \\
\hline Rural & 35.8 & 46.7 & 47.0 & 46.8 \\
\hline Punjab & 33.5 & 42.5 & 47.0 & 44.3 \\
\hline Urban & 26.2 & 36.4 & 48.8 & 41.3 \\
\hline Rural & 36.0 & 36.4 & 46.0 & 46.0 \\
\hline Sindh & 25.0 & 13.7 & $(38.3)$ & 22.1 \\
\hline Urban & 18.6 & 14.6 & - & 22.6 \\
\hline Rural & 30.1 & 12.0 & - & 21.2 \\
\hline $\mathrm{KP}$ & 39.6 & 49.7 & 50.6 & 49.9 \\
\hline Urban & 48.0 & 54.0 & 57.1 & 55.0 \\
\hline Rural & 38.4 & 49.0 & - & 49.1 \\
\hline Balochistan & 25.9 & $(37.3)$ & - & 34.8 \\
\hline Urban & 14.2 & $(26.5)$ & - & 29.2 \\
\hline Rural & 29.2 & $(44.7)$ & - & 38.9 \\
\hline Islamabad & 34.7 & 55.3 & 39.8 & 50.2 \\
\hline FATA & 30.7 & 74.0 & - & 71.1 \\
\hline AJK & 62.3 & 79.9 & 60.0 & 72.9 \\
\hline Gilgit-Baltistan & 38.7 & (59.6) & (78.9) & 71.3 \\
\hline
\end{tabular}

Source: Computed by the authors from PDHS 2017-18 microdata.

Note: Figures in parentheses are based on 25-49 unweighted cases. An asterisk indicates that a figure is based on fewer than 25 unweighted cases and has been suppressed.

Table 4.9 Percentage of households reporting economic outmigrants who received remittances, by agro-ecological zone

\begin{tabular}{|c|c|c|c|c|}
\hline \multirow[t]{2}{*}{ Agroecological zones } & \multirow{2}{*}{$\begin{array}{l}\text { Households with an } \\
\text { economic outmigrant } \\
\text { within Pakistan }\end{array}$} & \multicolumn{3}{|c|}{$\begin{array}{l}\text { Households with at least one emigrant } \\
\text { during last } 10 \text { years }\end{array}$} \\
\hline & & Middle East & Other countries & All countries \\
\hline Barani Lands & 47.3 & 63.1 & 52.0 & 60.2 \\
\hline Northern Irrigated Plains & 33.6 & 37.7 & 46.5 & 41.4 \\
\hline KP Northern Irrigated Plains & 40.6 & 63.6 & 54.2 & 60.3 \\
\hline Southern Irrigated Plains & 15.2 & 25.4 & - & 25.5 \\
\hline Wet Mountains & 30.4 & $(19.5)$ & $(24.6)$ & 21.0 \\
\hline Northern Dry Mountains & 36.3 & 55.1 & 63.1 & 56.9 \\
\hline Western Dry Mountains & 27.4 & (79.5) & - & $(47.5)$ \\
\hline Dry Western Plateau & 33.4 & 8.3 & $(37.6)$ & 20.7 \\
\hline Sandy Desert & $(44.9)$ & - & - & $(20.0)$ \\
\hline
\end{tabular}

Source: Computed by the authors from PDHS 2017-18 microdata.

Note: Figures in parentheses are based on 25-49 unweighted cases. An asterisk indicates that a figure is based on fewer than 25 unweighted cases and has been suppressed. 
From these very simple statistics, it is hard to draw any conclusion about variations in the proportion of remittance-receiving households across provinces, regions, and agroecological zones. However, two observations can be extended. First, relatively more households from the rainfed regions and zones, e.g., AJK and Barani Lands, received remittances from within Pakistan or abroad for their livelihood. These are relatively better-off regions/zones because their inhabitants have been able to diversify their income sources through nonagriculture employment in Pakistan and overseas jobs. Second, inflows of remittances are also relatively higher in the Northern Dry Mountains and KP Northern Irrigated Plains. The Northern Irrigated Plains zone is among the flood-prone districts of the country. Thus, there appears to be a combination of economic, social, demographic, and environmental factors that not only generate migratory streams within Pakistan or abroad but also attract inflows of remittances.

\section{CONCLUSIONS}

This study has utilized PDHS 2017-18 microdata to assess the contribution of migration to diversification of household income to reduce vulnerabilities. Although the PDHS 2017-18 is not designed for this type of assessment, its outmigration module does enable preliminary analysis. Some broad conclusions can be drawn from the findings of this analysis.

First, migration in Pakistan is characterized by diverse flows, such as internal movement of population in different directions, e.g., rural to urban, rural to rural, and overseas migration to the Middle East as well as some other parts of the world. It appears that securing a job in overseas markets is the first priority of many prospective migrants, particularly with better education, but it is a costly phenomenon, so people who cannot finance it move internally to localities with relatively better job opportunities.

Second, as in other parts of the world, migration is selective in Pakistan-young and educated people are more likely to engage in migration, particularly in overseas jobs, than older persons. This may reflect a decrease in the interest of the younger generation in farming, which may lead to low productivity in agricultural activities. But the inflow of remittances is "undoubtedly a potential source for improving food security and livelihood through enhanced income" (Rasul et al. 2019). It also has the potential to lead to more investments in the agriculture sector in the form of better-quality inputs, such as seeds and fertilizer, which rural households can afford when they receive remittances.

Third, it is not possible from the analysis to identify migratory streams solely influenced by one environmental or non-environmental factor. Rather, the analysis supports the view that an interplay of several socio-demographic factors, probably influenced by both environmental and non-environmental risks, affects the decision to migrate.

Fourth, it appears that households participating in migration have in general been successful in diversifying their sources of income through inflows of remittances. Migration thus appears to have the potential to improve the ability to adapt to changes associated with environmental and non-environmental stresses.

Finally, migration of population in working age need not be discouraged. It is beneficial for households, communities, and the country since it is generally associated with inflows of remittances, conducive for reducing all types of risks. 


\section{Epilogue}

The discourse on climate change in Pakistan is alive in the highest policy platforms, and activism to protect the environment is escalating, especially among young people. However, at both levels, there is a lack of solid discussion of how important a role Pakistan's alarming rate of population growth is playing in exacerbating the risks and increasing vulnerabilities of large parts of the population.

The contributions to this monograph are an attempt to explore the empirical evidence on linkages between climate changes, population, and vulnerability in Pakistan in order to substantiate the importance of taking a more human-centered approach. Such an approach focuses on the location of those most affected and likely to be affected, their numbers and housing, and the social and economic characteristics that are highly associated with vulnerability and with adaptation capacities, especially fertility, investments in children, employment opportunities, access to food, poverty, and opportunities to migrate -in other words, the very essential features of quality of life.

The findings provide a strong base for studying vulnerabilities to climate patterns across different agroecological zones. We clearly establish that different regions are at varying stages of dependence on agriculture and, to some extent, adaptation, differing in rates of outmigration, and demographic characteristics, particularly fertility levels and dependency ratios. This already reflects stark economic inequalities. Even more importantly, the findings point toward a future sharpening of these inequalities as climate patterns continue to change and related events escalate. Thus, there is both a need to look at current levels of vulnerabilities and to project future scenarios for the respective zones.

The centrality of the agriculture sector is crucial, especially for the rural areas of Pakistan, as this is likely to be most directly affected by climate through changes in temperature, water scarcity, and factors such as flooding. However, it is important to investigate further the pathways of influence and particularly potential adaptation features.

The findings also underscore how urbanization throughout the country, though waning in some areas, continues to be rapid in some of the more climatically and economically fragile zones. Although on the surface urban areas appear to be better off and are still attracting migration from rural areas, they too are affected by climate patterns and additional risks because of their locations; for example, Karachi, on the coast of the Arabian Sea, faces an increasing risk of sea level rise and cyclones, while Gilgit is located in a region at risk of flooding from the melting of glaciers. These risks add to existing challenges associated with the greater inequalities in urban living, ranging from the high-end to the squatter settlements and slums in many of the large cities across the world, including Pakistan.

We strongly recommend a disaggregated approach both by agroclimatic zones and urban and rural divisions for the Disaster Management authorities and for inclusion in the National Climate Change Policy 2012. As underscored earlier, planning infrastructural changes and warning systems is essential, but it is even more important to adopt differentiated and tailored approaches for the populations that the policies and programs seek to protect. Better and informed communication, that can prepare the most affected populations based on their own behaviors, concerns, and abilities to absorb shocks, is largely missing and critical to include.

Finally, the authors clearly identify the shortcomings of their findings, mainly related to data constraints. But there are some strong themes that need to be looked at with the interdisciplinary approach adopted in the monograph. Certainly, we recommend a deeper dive into many of the regional patterns highlighted, by mining more data and rigorous analysis of some of the major associations between climate, population, and economic challenges. 


\section{REFERENCES}

Adams, R.H. and J.J. He. 1995. Sources of Income Inequality and Poverty in Rural Pakistan (Vol. 102). Washington, DC: International Food Policy Research Institute (IFPRI).

Ahmad, M. and U. Farooq. 2010. "The state of food security in Pakistan: Future challenges and coping strategies," The Pakistan Development Review 49(4), 903-923.

Ahmad, M., M. Iqbal, and M.A. Khan. 2013. "Climate Change Brief: Climate Change, Agriculture and Food Security in Pakistan: Adaptation Options and Strategies." Islamabad: Pakistan Institute of Development Economics.

Ahmad, M., H. Siftain, and M. Iqbal. 2014. "Impact of Climate Change on Wheat Productivity in Pakistan: A District Level Analysis." Climate Change Working Paper Series No. 1. Islamabad: Pakistan Institute of Development Economics.

Alam, M., A. Rahman, M. Rashid, G. Rabbani, P. Bhandary, S. Bhadwal, M. Lal, and M. Soejachmoen. 2007. “Impacts, Vulnerability and Adaptation to Climate change in Asia; Background Paper." Produced for the UNFCCC Asia Regional Workshop on Climate Change Adaptation, Beijing, 11-13 April.

Ali, G. 2011. "Climate Change Concerns and Emerging Challenges for Water and Food Security of Pakistan." Presentation made at the Regional Workshop on Climate Change, Food and Water Security, Colombo, Sri Lanka , 24-25 February, Available at: http://www.slideshare.net/globalwaterpartnership/8-g-ali-gwp-iwmi-ws.

Ali, S., Y. Liu, M. Ishaq, T. Shah, A. Ilyas, and I. udDin. 2017. "Climate change and its impact on the yield of major food crops: Evidence from Pakistan," Foods 6(6): 1-19.

Baig, M.H.A. and G. Rasul. 2008. "Diagnosis of the impact of deep depressional activity in Northern Arabian Sea over Karachi during monsoon," Pakistan Journal of Meteorology 5(9): 77-96.

Balk, Deborah, José Miguel Guzmán, and Daniel Schensul. 2013. "Harnessing census data for environment and climate change analysis." In Martine, George and Daniel Schensul (eds.). The Demography of Adaptation to Climate Change. New York, London, and Mexico City: UNFPA, IIED and El Colegio de México.

Bhatta, G.D., P.K. Aggarwal, S. Poudel, and D.A. Belgrave. 2015. "Climate-induced migration in South Asia: Migration decisions and the gender dimensions of adverse climatic events," The Journal of Rural and Community Development 10(4): 1-23.

Bongaarts, J. and B.C. O'Neill. 2018. “Global warming policy: Is population left out in the cold?” Science 361(6403): 650-652.

Boserup, E. 1965. The Conditions of Agricultural Growth. The Economics of Agrarian Change Under Population Pressure. New York: Routledge.

Brown, L.. 2013. "The real threat to our future is peak water," The Guardian, 6 July. Available at: https://www.theguardian.com/global-development/2013/jul/06/water-supplies-shrinking-threat-to-food.

Chaudhry Q. Z.. 2017. Climate Change Profile of Pakistan. Manila: Asian Development Bank.

Cline, W.R. 2007. Global Warming and Agriculture: Impact Estimates by Country. Washington, DC: Peterson Institute for International Economics.

Dawn. 2018. "Over 500 children died in drought-hit Thar this year, Murad told." 20 October. Available at: https://www.dawn.com/news/1440059/over-500-children-died-in-drought-hit-thar-this-year-murad-told.

Dehlavi, A., A. Gorst, B. Groom, and F. Zaman. 2015. "Climate Change Adaptation in the Indus Ecoregion: A Microeconometric Study of the Determinants, Impacts and Cost Effectiveness of Adaptation Strategies." Islamabad: World Wide Fund for Nature (WWF) Pakistan.

Deshingkar, P. 2012. Environmental Risk, Resilience and Migration: Implications for Natural Resource Management and Agriculture. Bristol, UK: IOP Publishing Ltd.

Di Falco, S. and J.P. Chavas. 2009. "On crop biodiversity, risk exposure, and food security in the highlands of Ethiopia," American Journal of Agricultural Economics 91(3): 599-611. 
Eckstein, D., M.L. Hutfils, and M. Winges. 2019. Global Climate Risk Index 2019: Who Suffers Most From Extreme Weather Events? Weather-related Loss Events in 2017 and 1998 to 2017. Bonn: Germanwatch.

Ehrlich, P.R. 1968. The Population Bomb. New York: Ballantine Books.

Engelman, R., Y.G. Terefe, G. Gourmelon, J. Yang, J. Bish, J. Fanta, L.M. Hunter, V. Markham, G. Kalema-Zikusoka, S. Sellers, and K.R. Weiss. 2016. Family Planning and Environmental Sustainability: Assessing the Science. Washington, DC: Wordwatch Institute.

Eswaran, H., F. Beinroth, and P. Reich. 1999. "Global land resources and population-supporting capacity," American Journal of Alternative Agriculture 14(3): 129-136.

Falkenmark, M., J. Rockström, L. and Karlberg. 2009. "Present and future water requirements for feeding humanity," Food Security 1(1): 59-69.

FAO, 1996. "Rome Declaration on World Food Security and World Food Summit Plan of Action." World Food Summit 13-17 November. Rome: Food and Agriculture Organization (FAO) of the United Nations.

2018. Asia and Pacific Regional Overview of Food security and Nutrition: Accelerated Progress Towards the SDGs.

Bangkok: Food and Agriculture Organization (FAO) of the United Nations.

_. 2019. The FAOSTAT: Land Use. Food and Agriculture Organization (FAO) of the United Nations.

FAO and ITPS. 2015. Status of the World's Soil Resources (SWSR) - Main Report. Rome: Food and Agriculture Organization (FAO) of the United Nations and Intergovernmental Technical Panel on Soils (FAO).

Fischer, G., M.M. Shah, and H.T. van Velthuizen. 2002. Climate Change and Agricultural Variability. A Special Report on Climate Change and Agricultural Vulnerability, Contribution to the World Summit on Sustainable Development. Vienna: International Institute for Applied Systems Analysis.

Food Security Cluster. 2016. Sindh Drought Needs Assessment: The State of Agriculture, Livelihood, Food Security, Nutrition, Water and Sanitation in Drought Affected Communities in Sindh. Islamabad: Food Security Cluster, Pakistan.

Fullbrook, D. 2010. "Food as security," Food Security 2(1): 5-20.

Gioli, G., T. Khan, S. Bisht, and J. Scheffran. 2014. "Migration as an adaptation strategy and its gendered implications: A case study from the Upper Indus Basin," Mountain Research and Development 34(2): 255-265.

Government of Pakistan. 2013. Framework for Implementation of Climate Change Policy. Islamabad: Climate Change Division Islamabad: Government of Pakistan.

_. 2016. Pakistan Economic Survey 2015-2016. Islamabad: Economic Adviser's Wing, Finance Division, Government of Pakistan.

_. 2018. Pakistan Economic Survey 2017-18. Islamabad: Economic Adviser's Wing, Finance Division, Government of Pakistan.

Guzman, J.M, G. McGranahan, and S Giorguli, 2013. “Foreword.” In Martine, George and Daniel Schensul (eds.), pp. x-xi. The Demography of Adaptation to Climate Change. New York, London and Mexico City: UNFPA, IIED and EI Colegio de México.

Guzmán, José Miguel, Daniel Schensul, and Sainan Zhang. 2013. “Understanding vulnerability and adaptation using census data." In Martine, George and Daniel Schensul (eds.), pp. 55-73. The Demography of Adaptation to Climate Change. New York, London and Mexico City: UNFPA, IIED and EI Colegio de México.

Hanif, M. 2015. "Climate Change Impact, Challenges - Threats - Way Forward.” Climate Change Center. Collaborative project on Farmer Perception on Climate Change in FATA. Peshawar: The University of Agriculture. Funded by InterCooperation (IC-SDC).

Hartemink, A.E. 2007. “Soil science, population growth and food production: Some historical developments.” In Bationo, A. et al. (eds.), pp. 85-98. Advances in Integrated Soil Fertility Management in sub-Saharan Africa: Challenges and Opportunities. Dordrecht: Springer.

Imran, M. 2019. “Pakistan's ground water level falling a meter every year,: The News. 22 March. Available at: https://www. thenews.com.pk/print/447130-pakistan-s-ground-water-level-falling-a-meter-every-year. 
IPCC, 2018. “Summary for policymakers.” In Masson-Delmotte, V. et al. (eds.), pp. 3-24. Global Warming of $1.5^{\circ} \mathrm{C}$. An IPCC Special Report on the impacts of global warming of $1.5^{\circ} \mathrm{C}$ above pre-industrial levels and related global greenhouse gas emission pathways, in the context of strengthening the global response to the threat of climate change, sustainable development, and efforts to eradicate poverty. Geneva: World Meteorological Organization, Switzerland, 32 pp.

IPCC, 2007. Climate Change 2007: Impacts, Adaptation and Vulnerability. Contribution of Working Group II to the Fourth Assessment Report of the Intergovernmental Panel on Climate Change, M.L. Parry, O.F. Canziani, J.P. Palutikof, P.J. van der Linden and C.E. Hanson, Eds., Cambridge University Press, Cambridge, UK, 976 pp.

Iqbal, M., Ahmad, M. and Mustafa, G., 2015. Climate Change, Vulnerability, Food Security and Human Health in Rural Pakistan: A Gender Perspective. MPRA Paper No. 72866. Munich Personal RePEc Archive (MPRA).

Iqbal, M.M., M.A. Goheer, and A.M. Khan. 2009. "Climate-change aspersions on food security of Pakistan," A Journal of Science for Development 15(1): 15-23.

Janjua, P.Z., G. Samad, N.U. Khan, and M. Nasir. 2010. “Impact of climate change on wheat production: A case study of Pakistan," The Pakistan Development Review 49(4): 799-822.

JTWC. 2019. “Naval Oceanography Portal: Joint Typhoon Warning Center (JTWC).” Available at: https://www.metoc.navy. mil/jtwc/jtwc.html.

Khan, M.J. and I. Khan. 2018. “Impact of Climate Change on Key cCrops of Khyber Pakhtunkhwa." ADP Project financed by the Government of Khyber Pakhtunkhwa. Peshawar: Climate Change Center, The University of Agriculture.

Khan, M.A., M. Ahmad, and H.S. Hashmi. 2012. “Review of available knowledge on land degradation in Pakistan,” OASIS Country Report 3. Kabul: International Center for Agricultural Research in the Dry Areas (ICARDA).

Kosec, K. and C.H. Mo. 2017. "Aspirations and the role of social protection: Evidence from a natural disaster in rural Pakistan," World Development 97: 49-66.

Kreft, S., D. Eckstein, and I. Melchior. 2016. Global Climate Risk Index 2017: Who Suffers Most from Extreme Weather Events? Weather-related Loss Events in 2015 and 1996 to 2015. Bonn: Germanwatch.

Krishnan, R., Shrestha, A.B., Ren, G., Rajbhandari, R., Saeed, S., Sanjay, J., Syed, M.A., Vellore, R., Xu, Y., You, Q. and Ren, Y., 2019. Unravelling climate change in the Hindu Kush Himalaya: rapid warming in the mountains and increasing extremes. In The Hindu Kush Himalaya Assessment (pp. 57-97). Springer.

Kumar, K. and J. Parekh. 1998. "Climate Change Impacts on Indian Agriculture: The Ricardian Approach in Measuring the Impact of Climate Change on Indian Agriculture." World Bank Technical Paper No. WTP 402. Washington, DC: The World Bank.

Kumar, K.K.S. and B. Viswanathan 2012. “Weather Variability and Agriculture: Implications for Long and Short-term Migration in India." Working Paper No. 220. Delhi: Centre for Development Economics Department of Economics, Delhi School of Economics.

Kunbher, A.D., Ullah, S. and Alam, M., 2017. “Multi-sector, nutrition-sensitive response to drought emergency in Pakistan.” Field Exchange 55: 98.

Lal, R. 1989. “Land degradation and its impact on food and other resources." In D. Pimentel (ed.), pp. 85-140. Food and Natural Resources. San Diego: Academic Press.

_. 2018. "Managing agricultural soils of Pakistan for food and climate," Soil \& Environment 37(1): 1-10.

Mahmood, N., B. Ahmad, S. Hassan, and K. Bakhsh. 2012. “Impact of temperature and precipitation on rice productivity in rice-wheat cropping system of Punjab province," The Journal of Animal and Plant Sciences 22(4): 993-997.

Malik, S. 2005. "Agriculture Growth and Rural Poverty: A Review of the Evidence." Working Paper 2, Pakistan Resident Mission Working Paper Series. Islamabad: Asian Development Bank, Pakistan Resident Mission.

Martine, G. and D. Schensul. 2013. “Introduction.” In Martine, George and Daniel Schensul (eds.) pp. xv-xxi. The Demography of Adaptation to Climate Change. New York, London and Mexico City: UNFPA, IIED and El Colegio de México.

Martine, G., D. Schensul, and J.M. Guzmán (eds.). 2013. The Demography of Adaptation to Climate Change. UNFPA, IIED, and El Colegio de México. 
Mendelsohn, R., A. Dinar, and A. Sanghi. 2001. "The effect of development on the climate sensitivity of agriculture," Environment and Development Economics 6(1): 85-101.

Mitra, R. and C.R. Bhatia. 2008. “Bioenergetic cost of heat tolerance in wheat crop,” Current Science 94(8): 1049-1053.

MoE. 2009. Climate Change Vulnerabilities in Agriculture in Pakistan. Annual Report. Islamabad: Ministry of Environment (MoE), Government of Pakistan, pp. 1-6.

Mueller, V., C. Gray, and K. Kosec. 2014. "Heat stress increases long-term human migration in rural Pakistan," Nature Climate Change 4(3): 182-185.

National Institute of Population Studies (NIPS) and ICF International. 2013. Pakistan Demographic and Health Survey, 2012-13. Islamabad, Pakistan and Rockville, MD: NIPS and ICF International.

_. 2018. Pakistan Demographic and Health Survey, 2017-18. Islamabad, Pakistan and Rockville, MD: NIPS and ICF International.

Nizami, A. and J. Ali. 2017. "Climate change and women's place-based vulnerabilities-a case study from Pakistani highlands," Climate and Development 9(7): 662-670.

NOAA. 2019. "Is sea level rising?" Washington, DC: National Oceanic and Atmospheric Administration (NOAA), US Department of Commerce. Available at: https://oceanservice.noaa.gov/facts/sealevel.html.

Pakistan Engineering Congress. 2018. “World Water Day, March 2018: Nature for water." Lahore: Pakistan Engineering Congress. Available at: https://pecongress.org.pk/images/upload/books/WWD-2018.pdf.

Pimentel, D., Houser, J., Preiss, E., White, O., Fang, H., Mesnick, L., Barsky, T., Tariche, S., Schreck, J. and Alpert, S., 1997. Water resources: agriculture, the environment, and society. BioScience, 47(2), pp. 97-106.

Peña, Landy Sanchez and Regina Fuchs. 2013. "Using households surveys in climate vulnerability and adaptation analysis." In Martine, George and Daniel Schensul (eds.) pp. 96-114. The Demography of Adaptation to Climate Change. New York, London and Mexico City: UNFPA, IIED and El Colegio de México.

Pinckney, T.C., 1989. The demand for public storage of wheat in Pakistan (Vol. 77). Washington DC: International Food Policy Research Institute.

Qasim, M., K. Hubacek, M. Termansen, and A. Khan. 2011. "Spatial and temporal dynamics of land use pattern in District Swat, Hindu Kush Himalayan region of Pakistan," Applied Geography 31(2): 820-828.

Rasul, G. 2012. Climate Data Modelling and Analysis of the Indus Ecoregion. Lahore: World Wide Fund for Nature.

Rasul, G., A. Saboor, P.C. Tiwari, A. Hussain, N. Ghosh, and G.B. Chettri. 2019. “Food and nutrition security," In Phillipus, Wester et al (eds.), pp. 301-338. The Hindu Kush Himalaya Assessment: Mountains, Climate Change, Sustainability and People. Cham, Swizterland: Springer.

Ritchie, H. and M. Roser. 2018. “CO and other Greenhouse Gas Emissions.” Published online. Oxford: OurWorldInData. Available at: https://ourworldindata.org/ $/ \mathrm{CO}_{2}$-and-other-greenhouse-gas-emissions.

Saeed, M., R.U. Sheikh, and M. Shoaib. 2018. "A Review On: Water Saving Techniques for Domestic, Agricultural and Industrial Water Usage.” World Water Day 2018, 75th Session. Lahore: Pakistan Engineering Congress.

Saif Ullah., 2017. Climate change impact on agriculture of Pakistan-A leading agent to food security. Int. J. Environmental Science and Natural Resources, 6(3), pp. 1-4.

Sathar, Z.A., M. Khalil, S. Hussain, M. Sadiq, and K. Khan. 2018. Climate Change, Resilience, and Population Dynamics in Pakistan: A Case Study of the 2010 Floods in Mianwali District. Islamabad: Population Council.

Scheffran, J., E. Marmer, and P. Sow. 2012. "Migration as a contribution to resilience and innovation in climate adaptation: Social networks and co-development in Northwest Africa," Applied Geography 33(1): 119-127.

Schensul, D. and D. Dodman. 2013. “Populating adaptation: Incorporating population dynamics in climate change adaptation policy and [ractice." In In Martine, George and Daniel Schensul (eds.) pp. 1-23. The Demography of Adaptation to Climate Change. New York, London and Mexico City: UNFPA, IIED and El Colegio de México.

Semenov, M.A.. 2009. "Impacts of climate change on wheat in England and Wales," Journal of the Royal Society Interface 6(33): 343-350. 
Siddiqui, T., R.B. Bhagat, S. Banerjee, C. Liu, B. Sijapati, R. Memon, P. Thinley, M. Ito, O. Nemat, and G.M. Arif. 2019. "Migration in the Hindu Kush Himalaya: Drivers, consequences, and governance. In Phillipus, Wester et al (eds.), pp. 517-544. The Hindu Kush Himalaya Assessment. Cham, Switzerland: Springer.

Sivakumar, M.V.K. and R. Stefanski. 2011. "Climate change in South Asia." In Lal, R. et al (eds.), pp. 13-30. Climate Change and Food Security in South Asia. Springer Science \& Business Media.

Smil, V. 1987. Energy, Food, Environment: Realities, Myths, Options. Oxford: Oxford University Press.

Srivastava, R. and A.K. Pandey. 2017. "Internal and international migration” in South Asia: Drivers, Interlinkage and Policy Issues, pp. 1-65. New Delihi: United Nations Educational, Scientific, and Cultural Organization.

State Bank of Pakistan, 2019. The State of Pakistan's Economy: Third Quarterly Report for the year 2018-19. Islamabad: State Bank of Pakistan (SBP).

Sustainable Development Policy Institute, 2009. Food Insecurity in Pakistan. Sustainable Development Policy Institute (SDPI), Swiss Development Corporation, and World Food Programme, Islamabad, Pakistan.

TDAP. 2016. Statistics for 2015-2016. Islamabad: Trade Development Authority of Pakistan (TDAP).

Available at: http://www.tdap.gov.pk/tdap-statistics.php.

UN DESA. 2018. World Urbanization Prospects: The 2018 Revision. United Nations Department of Economic and Social Affairs (UN DESA). New York: Population Division, United Nations.

UN News. 2011. “A year after Pakistan's devastating floods, UN continues effort to rebuild lives.” 28 July. Available at: https://news.un.org/en/story/2011/07/382952-year-after-pakistans-devastating-floods-un-continueseffort-rebuild-lives.

UNDP. 2016. Before the Flood. Islamabad: United Nations Development Programme (UNDP).

USAID. 2018. Pakistan: Food Assistance Fact Sheet - May 29, 2018. Washington, DC: USAID. Available at: https://reliefweb.int/sites/reliefweb.int/files/resources/FFP\%20Fact\%20Sheet_Pakistan_05.29.2018.pdf.

UNISDR, UNDP and IUCN. 2009. Making disaster risk reduction gender-sensitive: policy and practical guidelines. Geneva, Switzerland: UNISDR, UNDP and IUCN.

Watto, M.A. 2018. "Groundwater - one of the most neglected resources," Dawn, 15 January. Available at: https://www.dawn.com/news/1382878.

WHO. 2019. "Pakistan: Floods in Balochistan." 6 March. Factsheet. Geneva: World Health Organization (WHO). Available at: https://reliefweb.int/sites/reliefweb.int/files/resources/who_situation_report_flood_balochistan_pakistan_ mar_2019.pdf.

WMO. 2013. The Global Climate 2001-2010: A Decade of Climate Extremes. Summary Report. WMO- No. 1103. Geneva: World Commission on Dams, 2000. Tarbela Dam and Related Aspects of the Indus River Basin in Pakistan. World Meteorological Organization (WMO),

_. 2017. WMO Guidelines on the Calculation of Climate Normals. Geneva: World Meteorological Organization (WMO) .

_. 2019. WMO Statement on the State of the Global Climate in 2018. Geneva: World Meteorological Organization (WMO).

World Bank. 2017. World Development Indicators. Washington, DC: World Band. Available at: https//data.worldbank.org.

_..2019. Pakistan@100 Environmental Sustainability. Washington, DC: World Bank Group.

Yonetani, M. and T. Morris. 2013. Global Estimates 2012: People Displaced by Disasters. Geneva: Internal Displacement Monitoring Centre (IDMC).

Young, G.J. and K. Hewitt. 1990. “Hydrology Research in the Upper Indus Basin, Karakoram Himalaya, Pakistan.” Proceedings of the Strbské Pleso Workshop, Czechoslovakia, June 1988. IAHS Publ. No. 190. Wallingford, UK: (International Association of Hydrological Sciences (IAHS).

Young, W.J., A. Anwar, T. Bhatti, E. Borgomeo, S. Davies, W.R. Garthwaite III, E.M. Gilmont, C. Leb, L. Lytton, I. Makin, and B. Saeed. 2019. "Pakistan: Getting More from Water." Water Security Diagnostic. Washington, DC: World Bank. 
